DoD Corrosion Prevention and Control Program

\title{
Innovative Coating System for Corrosion Prevention and Temperature Reduction in Heat Distribution Manholes
}

Final Report on Project FAR-11 for FY06

Alfred D. Beitelman, Thomas A. Carlson, Barclay G. Jones,

August 2009

Charles P. Marsh, David Kessler, Jennifer J. Ong, and Ling Zou 



\section{Innovative Coating System for Corrosion Prevention and Temperature Reduction in Heat Distribution Manholes}

Final Report on Project FAR-11 for FY06

Alfred D. Beitelman, Thomas A. Carlson, Charles P. Marsh, David Kessler, and Jennifer J. Ong

Construction Engineering Research Laboratory

U.S. Army Engineer Research and Development Center

2902 Newmark Drive

Champaign, IL 61822

Barclay G. Jones and Ling Zou

Department of Nuclear, Plasma, and Radiological Engineering

University of Illinois at Urbana-Champaign

103 S. Goodwin Ave.

Urbana, IL 61801

Final report

Approved for public release; distribution is unlimited.

Prepared for Office of the Secretary of Defense (OUSD(AT\&L))

3090 Defense Pentagon

Washington, DC 20301-3090

Under Military Interdepartmental Purchase Request MIPR6FCERB1020, 20 Mar 06;

MIPR6H6AG3CPC1, 15 May 06; and MIPR6HMBHDE097, 31 May 06 


\begin{abstract}
Heat distribution system (HDS) pipes and appurtenances are subject to significantly reduced service life when they are located inside manholes with severely corrosive environments. This report documents the demonstration of an innovative coating system for HDS components intended to protect pipes directly, by preventing the corrosion of steel, and indirectly, by reducing heat-related corrosive conditions within manholes. The demonstration was performed at Redstone Arsenal, AL.
\end{abstract}

Field performance of the coating system components was mixed. The primer was straightforward to apply and showed no signs of degradation during the performance period. The topcoat essentially failed shortly after application by turning to powder. The topcoat failure mechanism appears to have been destruction of its acrylic binder by excessive heat, and the result was replicated in the laboratory through an extension of the initial oven tests. At this time it appears that topcoat material did not perform in accordance with the manufacturer's published product data. Because the primer material remains intact and is expected to offer corrosion protection in line with the product data, it represents a significant technology application for corrosion prevention and control. The report includes a return-on-investment calculation based on extension of HDS component service life. Lessons learned are documented.

DISCLAIMER: The contents of this report are not to be used for advertising, publication, or promotional purposes. Citation of trade names does not constitute an official endorsement or approval of the use of such commercial products. All product names and trademarks cited are the property of their respective owners. The findings of this report are not to be construed as an official Department of the Army position unless so designated by other authorized documents. 


\section{Contents}

List of Figures and Tables ..................................................................................................

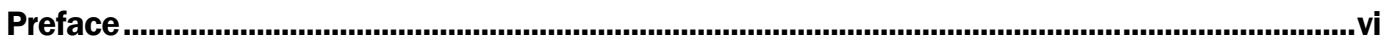

Executive Summary ....................................................................................................................................vii

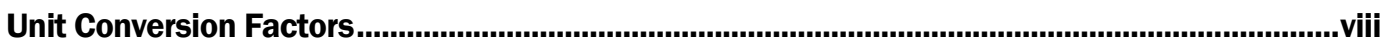

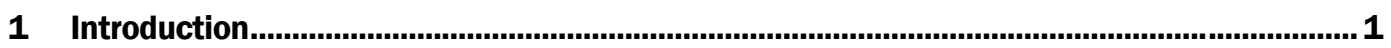

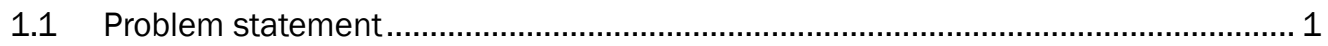

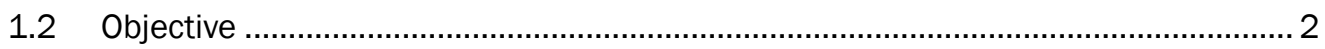

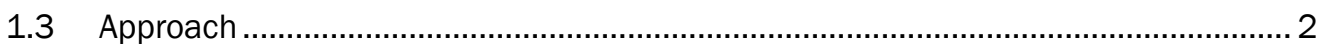

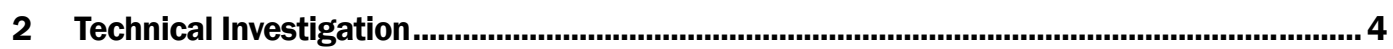

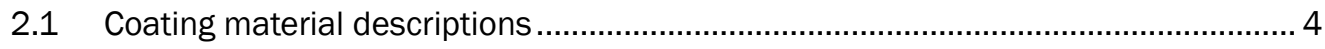

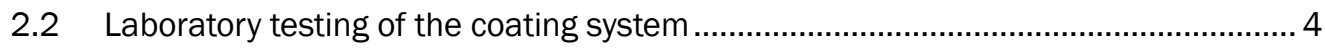

2.2.1 Thermal conductivity tests................................................................................ 4

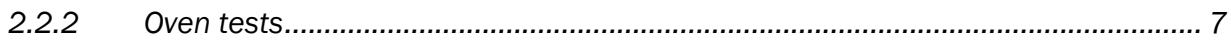

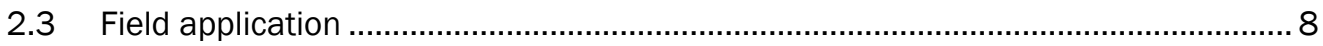

2.4 Performance monitoring and data collection ....................................................... 11

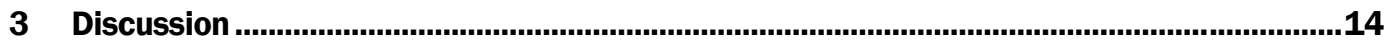

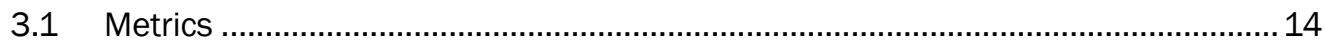

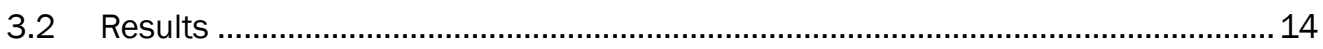

3.2.1 Initial observed field performance .................................................................... 14

3.2.2 Follow-up observations of metrics panels ........................................................... 14

3.2.3 Laboratory verification of coating failure................................................................ 16

3.3 Lessons learned .......................................................................................... 16

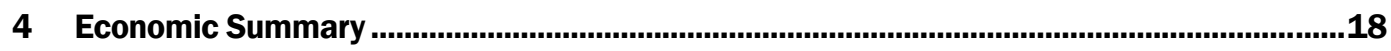

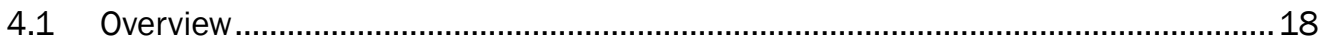

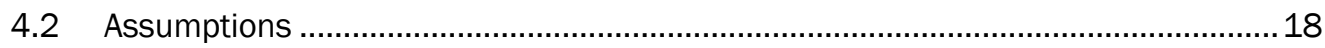

4.3 Projected return on investment ................................................................. 19

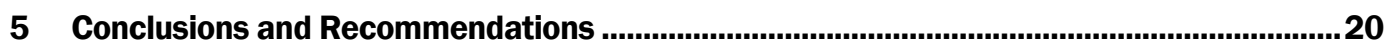

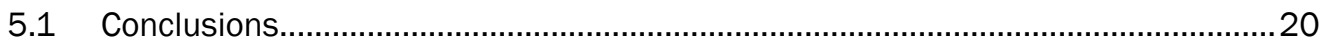

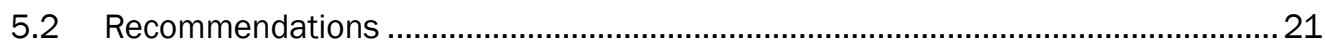

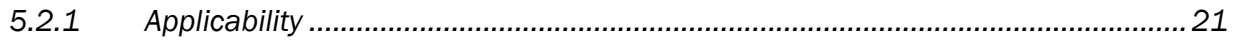

5.2.2 Implementation ........................................................................................ 21

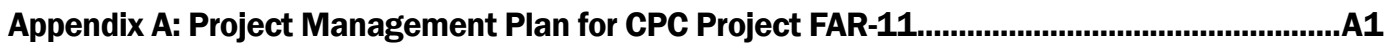

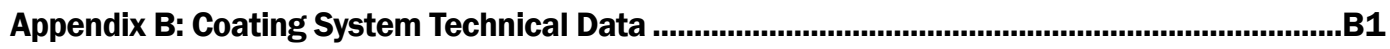


Appendix C: Thermal Conductivity Testing of Ceramic-Filled Coating ..........................................

Appendix D: Independent Return on Investment (ROI) Analysis ..............................................D1

Appendix E: Recommended Implementation Guidance .................................................................... E1

Report Documentation Page 


\section{List of Figures and Tables}

\section{Figures}

Figure 2.1. Test apparatus set up in lab...

6

Figure 2.2. Metrics setup in control pit, showing panels hung near manhole wall, data logger, probe lead, and control coupon mounted in insulation cutout. ..

\section{Tables}

Table 2.1. Test apparatus specifications. 6

Table 2.2. Oven test data for TC Ceramic topcoat (primed metrics panels)....................................... 8

Table 2.3. Individual pit data................................................................................................. 9

Table 3.1. Summary of metrics panel observations at 19 weeks. .................................................... 15

Table 3.2. Final comparative oven test data for TC Ceramic topcoat (primed metrics panels) 


\section{Preface}

This demonstration was performed for the U.S. Army Installation Management Command (IMCOM) under U.S. Army Corrosion Prevention and Control (CPC) Program Project IMA-2; Military Interdepartmental Purchase Requests MIPR6FCERB1020, 20 Mar 06; MIPR6H6AG3CPC1, 15 May 06; and MIPR6HMBHDE097, 31 May 06. The proponent was the U.S. Army Office of the Assistant Chief of Staff for Installation Management (ACSIM). The technical monitors were Paul M. Volkman (IMPW-E) and David N. Purcell (DAIM-FDF). The stakeholders are Mr. Steve J ackson (IMA SERO), Mr. Tom Tehada (USN), and Ms. Nancy Coleal (USAF). The customer was Mr. Timothy Smith, Department of Logistics and Engineering, Redstone Arsenal.

The work was performed by the Materials and Structures Branch (CF-M) of the Facilities Division (CF), Construction Engineering Research Laboratory - Engineer Research and Development Center (ERDC-CERL). The Program Manager for the ERDC-CERL CPC Program was Dr. Ashok Kumar, and the Project Officer was Vincent F. Hock (CEERD-CF-M). The Project Managers were Dr. Charles P. Marsh and Alfred D. Beitelman (CEERD-CF-M). Implementation was done under contract with Don Martin Heavy Equipment Refurbishing, Swansea, SC, and Thermal Insulation Inc., Decatur, AL. At the time of coating application quality assurance was performed on site by Mr. Beitelman. Independent economic analysis was performed by The PERTAN Group, Champaign, IL. The project was facilitated by the assistance and cooperation of Tim Smith, Redstone Arsenal installation engineering.

At the time this report was prepared, the Chief of the ERDC-CERL Materials and Structures Branch was Vicki L. Van Blaricum (CEERD-CF-M), the Chief of the Facilities Division was L. Michael Golish, (CEERD-CF), and the Technical Director for Installations was Martin J . Savoie (CEERD-CVZT). The Deputy Director of ERDC-CERL was Dr. Kirankumar Topudurti and the Director was Dr. Ilker Adiguzel.

The Commander and Executive Director of the U.S. Army Engineer Research and Development Center was COL Richard B. J enkins and the Director was Dr. James R. Houston. 


\section{Executive Summary}

Heat distribution system (HDS) pipes and appurtenances are subject to significantly reduced service life when they are located inside manholes with severely corrosive environments. This report documents the demonstration of an innovative coating system for HDS components intended to protect pipes directly, by preventing the corrosion of steel, and indirectly, by reducing heat-related corrosive conditions within manholes. The demonstration was performed at Fort J ackson, SC.

The selected coating system component materials were commercially available products not currently used in standard practice by Army. The primer coat was Hi-Temp 1027 CUI, a single-component primer formulated to prevent corrosion of high-temperature steel under thermal insulation. The topcoat was TC Ceramic High Build (HB), a ceramic-filled acrylic-based coating with thermal insulation properties. The primary purpose of the coating system was to prevent corrosion of the pipes and appurtenances housed in HDS manholes. Another purpose was to investigate whether the thermal barrier topcoat would significantly reduce the temperature inside manholes and thereby mitigate the corrosivity of the interior environment. Before application at the demonstration site, the coating system components were subjected to laboratory oven tests, and the ceramic-filled topcoat was subjected to heat conductivity testing.

Field performance of the coating system components was mixed. The primer was straightforward to apply and showed no signs of degradation during the performance period. The topcoat essentially failed shortly after application by turning to powder. The topcoat failure mechanism appears to have been destruction of its acrylic binder by excessive heat, and the result was replicated in the laboratory through an extension of the initial oven tests. At this time it appears that topcoat material did not perform in accordance with the manufacturer's published product data.

Because the primer material remains intact and is expected to offer corrosion protection in line with the product data, it represents a significant technology application for corrosion prevention and control. The report includes a return-on-investment calculation based on extension of HDS component service life. Lessons learned are documented. 


\section{Unit Conversion Factors}

\begin{tabular}{|l|c|l|}
\hline Multiply & By & To Obtain \\
\hline degrees Fahrenheit & $($ F-32)/1.8 & degrees Celsius \\
\hline feet & 0.3048 & meters \\
\hline gallons (U.S. liquid) & $3.785412 \mathrm{E}-03$ & cubic meters \\
\hline inches & 0.0254 & meters \\
\hline mils & 0.0254 & millimeters \\
\hline square feet & 0.09290304 & square meters \\
\hline
\end{tabular}




\section{Introduction}

\subsection{Problem statement}

The U.S. Army Installation Management Command (IMCOM) and the Office of the Assistant Chief of Staff for Installation Management (ACSIM) have identified heat distribution systems as a critical infrastructure component needed to support the installation mission. Manholes are an essential design feature of heat distribution systems (HDS). Also called valve pits*, manholes provide maintenance workers access to valves that control service to the branches of the HDS network. The pipes and appurtenances housed in manholes are wrapped with insulation, which tends to deteriorate over time. Regardless of the insulation condition, however, the interior of a given manhole is typically hotter than the ambient environment. Furthermore, water ingress from precipitation or the ground is inevitable, contributing to a humid and warm environment that promotes rapid corrosion of steel HDS components. The corrosivity of the manhole interior environment can become severe virtually overnight if a manhole floods and the pipe insulation becomes saturated. Damaged or missing pipe insulation greatly elevates the temperature inside a manhole, and longer-term manhole flooding can result in a boiling manhole, which accelerates degradation and energy loss much further.

Corrosion-related degradation of HDS components inside manholes can lead to unscheduled service interruptions due to leakage or catastrophic loss of system pressure. ${ }^{\dagger}$ Even before such failures occur, HDS operators often pay excessive energy costs because of heat losses related to degraded manhole pipes and appurtenances. Furthermore, corrosion can dramatically shorten the service life of components housed in manholes. Such a loss of service life in critical infrastructure translates directly into expensive new unprogrammed repair or replacement requirements. Therefore, innovative corrosion prevention and control technologies are continually sought to address the many problems related to excessive corrosion inside HDS manholes.

\footnotetext{
* The terms manhole and pit are used interchangeably in this report.

† Myers, James R., Ellen G. Segan, Charles P. Marsh, and Vincent F. Hock. July 1991. Causes and Control of Corrosion in Buried-Conduit Heat Distribution Systems, USACERL Technical Report M-91/08. Champaign, IL: U.S. Army Construction Engineering Research Laboratory.
} 
This report documents a technology demonstration project at Redstone Arsenal, AL, in which an innovative coating system is being tested on HDS components housed in manholes. The coating system consists of a hightemperature primer coat and a high-solids ceramic-filled acrylic topcoat. A novel property of the topcoat is that it provides significant thermal insulation owing to its high content of porous ceramic particles. In combination with a suitable primer, this innovative coating system is expected both to effectively prevent corrosion of steel HDS components in manholes and to provide a layer of thermal insulation that will be much more resistant to water-related degradation than conventional insulation wrapping materials. This combination of effective corrosion protection and thermal insulation offers the potential to ensure that steel HDS components in manholes reach their designed service life with lower probability of failure.

\subsection{Objective}

The objective of this project was to demonstrate an innovative coating system that may directly protect steel pipes and appurtenances in HDS system manholes from corrosion while mitigating the corrosivity of the interior manhole environment by reducing its heat.

\subsection{Approach}

The coating system demonstrated in this work consisted of two commercially available products:

- a primer coat of Hi-Temp 1027 CUI, a product of Hi-Temp Coatings, Acton, MA

- a topcoat of TC Ceramic High Build (HB), a product of Capstone Manufacturing Co., Seattle, WA.

Technical descriptions of both coating materials are provided in the body of this report. Neither product is currently covered by a military specification (MIL-SPEC). The topcoat material has been used in industrial applications for more than 10 years but is not currently used for Army HDS manhole piping.

In the preliminary phase of this project, a simple test apparatus was constructed to assess the thermal conductivity and other characteristics of the ceramic-filled topcoat in a controlled laboratory experiment. In the main portion of the demonstration, the two-part coating was applied to steel 
pipes and appurtenances inside nine manholes located at Redstone Arsenal. In addition, pipe insulation and jacketing were applied according to prevailing industry standards. All demonstration work performed onsite complied with installation requirements for health and safety. Performance observations and data collection were conducted as documented in the main text of this report.

Appendix A reprints the complete project management plan (PMP) for this work, as amended. Additional appendices provide details on coating material technical specifications, laboratory testing results, a numerical return on investment (ROI) projected for Army-wide adoption of the technology, and recommendations for implementation in Army engineering guidance. 


\section{Technical Investigation}

\subsection{Coating material descriptions}

The primer used in this program, Hi-Temp $1027 \mathrm{CUI}$ (Hi-Temp Coatings, Acton, MA), is a high-temperature primer formulated for steel. It is specifically designed to prevent corrosion under thermal insulation in hightemperature HDSs. The product is a single-component material, which makes it easy to apply whether the steel is hot or at ambient temperature. The manufacturer's product data sheet indicates that Hi-Temp 1027 is capable of withstanding sustained temperatures of $649^{\circ} \mathrm{C}\left(1,200^{\circ} \mathrm{F}\right)$, and can withstand cycling between high-temperature steam and boiling water temperatures. The primer is typically applied in two coats to achieve a total film thickness of 10 - 12 mils, but it will perform satisfactorily at high temperatures if applied to greater thicknesses. Technical data on the product are reproduced in Appendix B.

Capstone TC Ceramic High Build (HB), the ceramic-filled topcoat used in this program, is the thermal barrier component of the demonstrated coating system. It provides an insulating property that can reduce excessive heat inside HDS manholes. This heat reduction, in addition to improving worker safety inside the manhole, reduces corrosivity in the manhole interior. Technical data on the product are also provided in Appendix B.

\subsection{Laboratory testing of the coating system}

Two laboratory tests were performed before the coating system was applied in the field. One was a thermal conductivity test of the ceramic-filled topcoat to collect data necessary for calculating portions of the return on investment (ROI) projection. The investigation examined the topcoat material's thermal conductivity both in a dry and a saturated state. The other test was a controlled temperature exposure investigation in which panels were hung in a standard laboratory oven and exposed to temperatures replicating those expected in service at the surface of HDS pipes and appurtenances.

\subsubsection{Thermal conductivity tests}

The test apparatus consisted of a thermally insulated container of water into which a capped, coated test pipe section was immersed to a specified 
depth. Water decanted into the test pipe section was heated with an immersion heater. The water in the insulated bath was stirred using a standard laboratory power stirring device with a magnetic agitator to ensure acceptable uniformity of temperature, and the temperature was monitored using a mercury immersion thermometer (Figure 2.1 and Table 2.1).

Test specimens consisted of common 2 in. diameter steel pipe sections. Each specimen was $12 \mathrm{in}$. long with one end welded closed. All specimens were abrasive blasted with aluminum oxide grit for a surface profile of 2.5 mils, as measured by ASTM D 4417 Method C. All specimens were primed with an epoxy zinc primer meeting MIL-DTL-24441 Formula 159. Primer thickness was measured to be 2.5 mils, using a Positector 6000 gage in accordance with ASTM D 1186. Experimental specimens were topcoated with Capstone TC Ceramic at thicknesses of 50 and 85 mils (ASTM D 1186). The topcoat dried a minimum of 2 weeks at laboratory conditions before initiating the tests.

Water in the pipe was heated with an immersion heater and maintained at a boil throughout the test. Small increments of water were added to the specimen pipe during the test to replace water that had evaporated. Water in the insulated container was agitated using the magnetic stirrer. Its initial temperature was approximately $24^{\circ} \mathrm{C}$ (indoor ambient) and was monitored at 1 minute intervals by reading from the immersion thermometer. During the test, the thermometer was moved to different places in the insulated test bath, and was found to vary less than $2{ }^{\circ} \mathrm{C}$ between locations. Temperatures were recorded starting when the water in the pipe first reached a rolling boil, and observations were concluded when the temperature in the insulated container stopped rising and reached a constant level. 


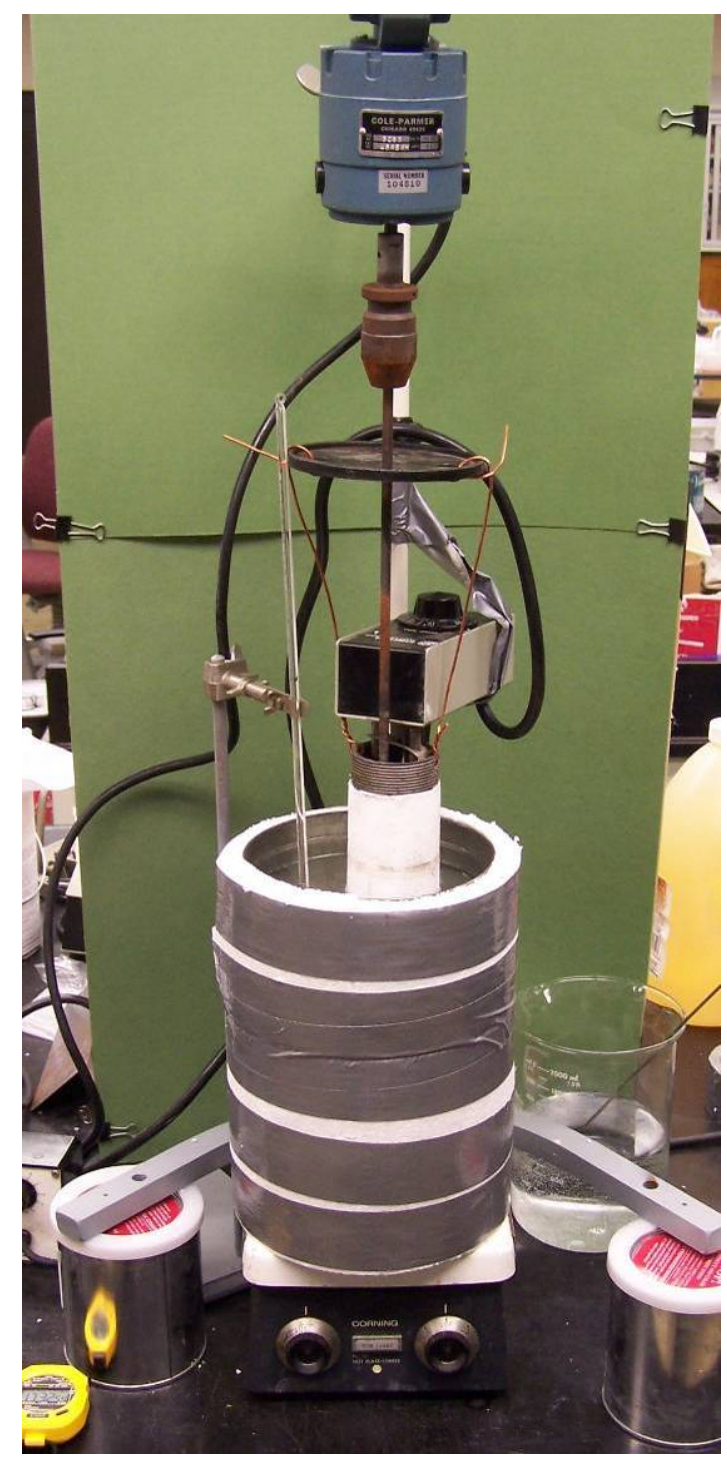

Figure 2.1. Test apparatus set up in lab.

Table 2.1. Test apparatus specifications.

\begin{tabular}{|l|l|l|}
\hline Item & Dimensional parameter & Measure \\
\hline \multirow{3}{*}{ Pipe: } & Outside diameter & 2.375 inches \\
\cline { 2 - 3 } & Immersion depth & 8.625 inches \\
\cline { 2 - 3 } & Immersion area & $68.78 \mathrm{sq}$. in. \\
\hline \multirow{3}{*}{ Insulated Container } & Diameter & 6.5 inches \\
\cline { 2 - 3 } & Height & 10.5 inches \\
\cline { 2 - 3 } & Insulation & 0.625 inch Styrofoam \\
\cline { 2 - 3 } & Water volume & $4,900 \mathrm{ml}$ \\
\hline \multirow{2}{*}{ Thermometer } & Mercury, $w / 0.2^{\circ}$ C divisions & \\
\hline
\end{tabular}


A detailed account of the experiment, including the test data and the analytic process, is shown in Appendix C. A summary is presented here.

The initial test cycle was performed on the pipe coated only with primer. This run was terminated early due to mechanical problems, and a duplicate run was performed to completion. Data for both runs are shown in Appendix C, Table 2. It should be noted that the first recorded temperature of the water on these runs is $68{ }^{\circ} \mathrm{C}$ because it took a long time for the heater to bring the water in the pipe to a rolling boil. The initial water temperature in tests using pipe coated with 50 mils of ceramic coating is much lower because the water in the pipe came to a boil quickly.

Appendix C, Table 2, shows two test cycles for the pipe coated with 50 mils of the TC Ceramic topcoat. After the first cycle, the specimen was left in the water bath for 21 hours, after which the test was repeated to determine whether immersion would saturate the coating and affect its thermal conductivity and film condition. The data show an impact on thermal conductivity, but the saturated coating still maintained a high percentage of its insulating capability. Saturation of the 50 mil coating specimen also adversely affected the paint film by raising a few blisters. Before the next test cycle, a number of D\#6 blisters (ASTM D 714) were identified. After about 3 minutes of boiling during the second test cycle, some F\#1 blisters appeared. All blisters remained unbroken throughout the test cycle, however. After several days of drying at laboratory ambient conditions, the blisters shrunk to a relatively smooth condition, but their location was still visible.

Appendix C, Table 2, also shows two test cycles for the pipe specimen with 85 mils of ceramic-filled coating. As with the 50 mil coating specimen, the pipe remained immersed at laboratory ambient temperature for 21 hours before performing a second test cycle. After the immersion period, no blistering was noted. However, F\#6 blisters did develop after several minutes of boiling during the second test cycle. No large blisters developed. It is thought that the difference in blister size and density between the two specimens is due to minor unobserved differences in application.

\subsubsection{Oven tests}

Laboratory temperature studies of the TC Ceramic topcoat were initiated as part of CPC Project IMA-2 (Marsh 2007), in which the subject topcoat was demonstrated on a low-temperature HDS at Fort J ackson, SC. In the Fort J ackson demonstration, typical plant output was reported to be 
$208^{\circ} \mathrm{F}$, and the temperature of lines was expected to drop relative to the distance from the plant. An oven test was set up using three different organic zinc primers: (1) epoxy zinc, (2) moisture cure urethane zinc, and (3) silicone zinc. Half-inch thick steel panels were primed with each primer and topcoated with TC Ceramic, creating a coating system thickness of approximately 50 mils. The panels were suspended in the oven maintained at $105^{\circ} \mathrm{C}\left(221^{\circ} \mathrm{F}\right)$ and observed on a weekly basis. Over time, the color of the topcoat changed from white to a light "cream" tint. Reflectance measurements (i.e., percentage of light reflected from the surface) were taken at 26 weeks and recorded (Table 2.2). No notable difference among the different primers was discernable. Other than the color, the physical properties of the topcoat appeared the same as observed on panels prepared the same way and maintained at laboratory conditions.

Table 2.2. Oven test data for TC Ceramic topcoat (primed metrics panels).

\begin{tabular}{|l|l|l|l|l|}
\hline Specimen & Temperature & Duration & Reflectance & Topcoat Condition \\
\hline Control & $25^{\circ} \mathrm{C}\left(77^{\circ} \mathrm{F}\right)$ & New & $89-90$ & Pliable \\
\hline Fort Jackson demo & $105^{\circ} \mathrm{C}\left(221^{\circ} \mathrm{F}\right)$ & 26 weeks & $75-80$ & Same as new \\
\hline Redstone demo & $182^{\circ} \mathrm{C}\left(360^{\circ} \mathrm{F}\right)$ & 6 weeks & $31-34$ & $\begin{array}{l}\text { Hard, acceptable } \\
\text { adhesion }\end{array}$ \\
\hline
\end{tabular}

In early discussions about the demonstration of the subject coating system at Redstone Arsenal, which uses the same topcoat that was applied at Fort J ackson, the typical operating temperature of the HDS pipes was estimated by the DPW to be about $182^{\circ} \mathrm{C}\left(360^{\circ} \mathrm{F}\right)$. Quarter-inch thick steel panels were prepared with a non-zinc silicone primer and topcoated with TC Ceramic to a system thickness of approximately 50 mils. These new panels, along with several epoxy-zinc-primed panels used for the Fort J ackson demonstration, work were suspended in the oven and maintained at a temperature of $182{ }^{\circ} \mathrm{C}\left(360{ }^{\circ} \mathrm{F}\right)$. They were inspected on a weekly basis. It was observed that the color of the topcoat progressively darkened to a shade of "tan," returning the lower reflectance values shown in Table 2.2. Mechanical pressure applied to the topcoat indicated that it became harder over time, losing its original flexibility. Coating adhesion and film integrity, however, were still considered acceptable.

\subsection{Field application}

The demonstration coating system was applied in the field during two weekends when the steam system could be shut down. The work consisted 
of removing the residual thermal insulation, then applying the primer and topcoat materials to pipes and appurtenances in nine valve pits (manholes) at Redstone Arsenal. It was expected that the insulation and jacketing would be reapplied to most of the pipes at the same time, but only a small amount of that work was completed during the first weekend. At the time of the surface preparation and painting, the steam was shut off, but the pipes were still warm. Temperatures at the time of the work, shown in Table 2.3, fell within the range prescribed for application by the TC Ceramic manufacturer. All surfaces of pipes exposed to heat (both feed and return lines as well as various small diameter pipes and valves) were abrasive blasted to the SSPC-SP6 (commercial) grade. The blast medium was silica sand having a designation of BX12. It had a wide gradation and produced a surface profile (replica tape) of 3.5 - 3.7 mils.

As noted previously, the primer was Hi-Temp 1027. Two coats were applied without thinning to produce an intended primer film thickness of 10 - 12 mils. Application on the first weekend was with an electrically operated airless spray unit using a 517 tip; the second weekend, a 317 tip was used to reduce overspray. The TC Ceramic topcoat also was applied without thinning using an electrically operated airless spray unit. A 519 tip was used the first weekend, resulting in considerable overspray. A 317 tip used the second weekend, which reduced the overspray considerably. The intended topcoat thickness was a minimum of 100 mils.

Table 2.3. Individual pit data.

\begin{tabular}{|c|c|c|c|c|c|c|c|c|c|}
\hline Pit Number & 1 & 2 & 3 & 4 & 5 & 6 & 7 & 8 & 9 \\
\hline Total area coated (sq ft) & 555 & 445 & 332 & 565 & 294 & 316 & 628 & 185 & 271 \\
\hline $\begin{array}{l}\text { Prime Application Feed } \\
\text { Temperature }\left({ }^{\circ} \mathrm{F}\right)\end{array}$ & 130 & 123 & 126 & 199 & 84 & 84 & 84 & 110 & 84 \\
\hline $\begin{array}{l}\text { Prime Application Return } \\
\text { Temperature }\left({ }^{\circ} \mathrm{F}\right)\end{array}$ & - & 120 & 113 & 126 & 84 & - & 84 & 95 & 84 \\
\hline $\begin{array}{l}\text { TC Application Feed } \\
\text { Temperature }\left({ }^{\circ} \mathrm{F}\right)\end{array}$ & 120 & 112 & 84 & 84 & 84 & 138 & 105 & 100 & 84 \\
\hline $\begin{array}{l}\text { TC Application Return } \\
\text { Temperature }\left({ }^{\circ} \mathrm{F}\right)\end{array}$ & - & 100 & 84 & 84 & 84 & - & 105 & 86 & 84 \\
\hline $\begin{array}{l}\text { Primer Typical Thickness } \\
\text { (mils) }\end{array}$ & $12-15$ & $14-15$ & $14-16$ & $12-14$ & $11-15$ & $10-12$ & $10-12$ & $10-13$ & $12-15$ \\
\hline $\begin{array}{l}\text { System Typical Thickness } \\
\text { (mils) }\end{array}$ & $\begin{array}{l}125- \\
150\end{array}$ & $40-50$ & $110-130$ & $110-130$ & $110-130$ & $\begin{array}{l}110- \\
120\end{array}$ & $100-120$ & $35-50$ & $90-120$ \\
\hline $\begin{array}{l}\text { Dry time before full heat } \\
\text { restored }\end{array}$ & $6 \mathrm{hrs}$ & $8 \mathrm{hrs}$ & $3 \mathrm{hrs} *$ & $3 \mathrm{hrs} *$ & $>30$ days & $12 \mathrm{hrs}$ & $8 \mathrm{hrs}$ & $12 \mathrm{hrs}$ & $>30$ days \\
\hline $\begin{array}{l}25 \text { Sep. Temperature }\left({ }^{\circ} \mathrm{F}\right) \\
\text { (Feed/Return) }\end{array}$ & $310 /-$ & $317 / 160$ & $280 / 220$ & $265 / 165$ & cold & $265 /-$ & $270 / 170$ & $340 / 176$ & cold \\
\hline
\end{tabular}


Work conducted the first weekend resulted in applying the total system in pits 3 and 4, applying both primer coats in pits 5 and 9, and applying a single coat of primer in pits 6 and 7. The steam in pits 5 and 9 had been shut down for some time and remained off for about a month after the final application. It was anticipated that the steam would be brought up gradually on the other pits after completion of work Sunday evening, such that the temperature would be held at approximately 120 - $150^{\circ} \mathrm{F}$ until early Monday morning. That schedule would have allowed the moisture to escape from the topcoat gradually. Unexpectedly, the steam was turned on at full pressure shortly after completion of the paint application, and the measured temperature Monday morning was over $300^{\circ} \mathrm{F}$. This system scheduling error resulted in severe topcoat blistering in pits 3 and 4 . Conversation with the manufacturer revealed the blistering would not have any significant negative impact on the performance of the product. The manufacturer stated that the blisters would be more vulnerable to physical damage, but if jacketed carefully the blisters would not present a problem. The offschedule heating did not damage the coating in pits where only primer had been applied.

On the second weekend, the pipes in the remaining pits were coated, and the coating systems in the pits blasted and primed previously were finished. The contractor ran short of topcoat, which resulted in a thinner system thickness in pits 2 and 8 . The reason for the shortage was the large amount of material loss due to overspray when coating the small pipes.

The painting contractor rented a SuperSucker ${ }^{\circledR}$ to remove refuse from the pits on Monday following the paint application. The steam was on, and temperatures at the (25 September 2006) are shown in Table 2.3. Work involved climbing around the confines of the pit with a very unwieldy 6 inch diameter suction hose. Short touching of the pipes with bare skin did not cause significant discomfort. The temperature in the pits was warm, but bearable. Walking or sitting on the blistered coatings did not appear to cause any damage to the blisters, and the coating was only damaged on sharp corners of a few small-diameter couplers and a valve handle.

Personnel contracted to insulate the pipes arrived on the afternoon of 23 September 2006. They did not coordinate with the painter or the onsite Corps contracting officer's technical representative, and began insulating pipes inside pit 9, which was still in the process of being coated. At the time of insulating, the topcoat had been checked for thickness and was de- 
termined to require an additional coat on some of the lower areas of the pipes. Most of the upper areas of pipe met the required thickness. Dry time of the final application of topcoat was less than 3 hours. The humidity was very high, with occasional light rain. The application of the insulation did not appear to damage the fresh topcoat, however. The remaining insulation and jacketing was completed several weeks later.

\subsection{Performance monitoring and data collection}

Metrics coupons were prepared to assess the corrosion rate and exposure effects on the thermal barrier coating system inside an operating manhole. Panels were prepared for one demonstration manhole and an uncoated control manhole as follows:

\section{3 x 9 in. Q-Panels* (bare)}

- A (curved), pit 3, inside jacket

- B (curved), control pit, inside jacket

- C, D (flat), pit 3, near pit wall

- E, F (flat), control pit, near pit wall

\section{$4 \times 6$ in. panels (cut from 4 in. diameter pipe)}

The specimen pipe was similar to the pipes coated in the field. The concave side and all edges were primed with an epoxy-zinc primer to prevent corrosion. The convex side was either bare or coated with the same system being demonstrated in the field. The specifics are listed below:

- $\mathrm{G}$ (bare), pit 3, inside jacket

- $\mathrm{H}$ (coated), pit 3, inside jacket

- I (bare), control pit, inside jacket

- J (coated), control pit, inside jacket

- K, L (bare), pit 3, near pit wall

- M, N (coated), pit 3, near pit wall

- $\mathrm{P}, \mathrm{Q}$ (bare), control pit near pit wall

- $\mathrm{R}, \mathrm{S}$ (coated), control pit, near pit wall

The coupons were installed in two manholes at Redstone on 5 December 2006, 12 weeks after the field coating application. One pit had previously

* Q-Panel is a trademark of Q-Lab, Cleveland, $\mathrm{OH}$, for weathering test substrate coupons. 
been improved with the thermal barrier coating system (pit 3) and the other was an unimproved control pit. Both pits were similar in size, adjacent to each other on the same steam line, and housed approximately the same amounts and sizes of pipe. Other than the coating system, the main difference between the two pits was the thermal insulation on the pipes: a formed solid material was in place in the control pit, and a formed fibrous material was used in pit 3. When the aluminum jacketing was opened in pit 3, reportedly the last pit to have been insulated, it appeared the contractor had run short of the formed insulation that had been specified and finished the last area with a soft bat material.*

In pit 3, a temperature probe attached to a data recorder was inserted between the thermal barrier coating and the added pipe insulation. A laboratory-coated panel and an abrasive-blasted panel also were placed between the topcoat and the insulation, and the jacketing was closed. Additional coated and uncoated metrics panels were hung in pit 3. In the selected control pit, located approximately 1 block from pit 3, the same general panel-installation procedure was followed.

At the time the panels were installed, data loggers were placed in both pits to record the temperature both inside and outside the jacketing (Figure 2.2). The devices included both an external temperature probe, attached to the data logger by a wire, and an internal temperature sensor in the body of the data logger. The external temperature probe was installed inside the jacketing in the control pit, under the insulation and in direct contact with the carrier pipe. The data logger (with its internal temperature sensor) was hung close to the pit wall, near the metrics coupons. The external probe in pit 3 was positioned on the surface of the coating, under the insulation. The temperature data were recorded for use in the project's return-oninvestment (ROI) study.

\footnotetext{
* The insulation contractor reopened the jacketing in pit 3 and replaced the defective insulation approximately 2 months later.
} 


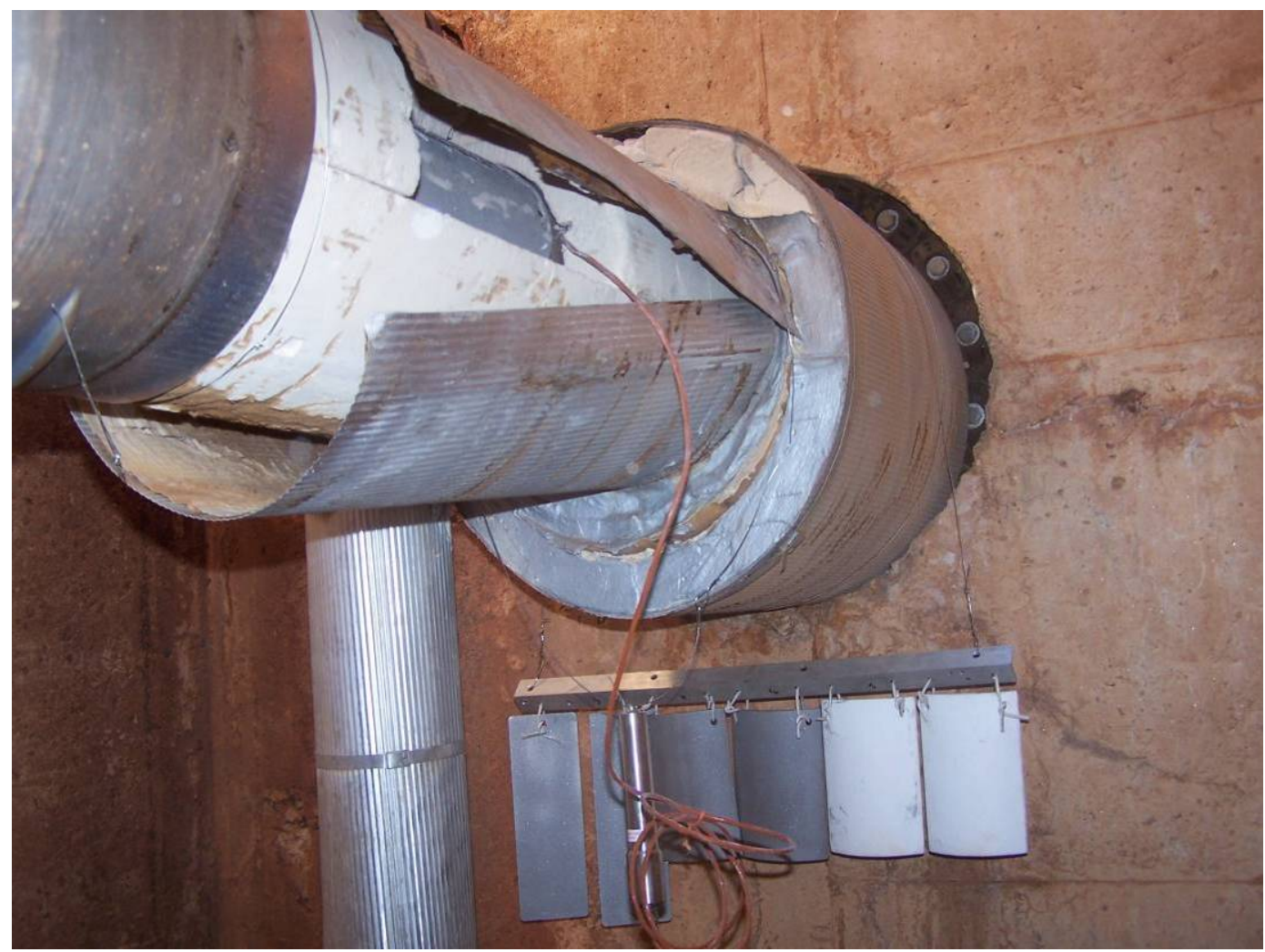

Figure 2.2. Metrics setup in control pit, showing panels hung near manhole wall, data logger, probe lead, and control coupon mounted in insulation cutout.

At the time the coupons and data loggers were installed in the two pits, the exposed ceramic-filled topcoat in pit 3 was light tan in color and showed no flexibility. Technically, the film was intact, but most of it was no longer adhered to the primer. Impacts from opening the insulation had cracked the topcoat film, and in some places it fell away from vertical surfaces. This observation clearly indicated a greater level of topcoat deterioration than had been observed in the laboratory oven exposure study (see Section 2.2.2), which was conducted at $360^{\circ} \mathrm{F}$. At this point, the temperature was measured in pit 3 and found to exceed $380^{\circ} \mathrm{F}$. The preliminary hypothesis by the researchers was that the topcoat had failed due to actual operating temperatures in excess of what had been estimated by the system operator. 


\section{Discussion}

\subsection{Metrics}

- ASTM E1349, Test Method for Reflectance Factor and Color by Spectrophometry Using Bi-Directional Geometry, was used to provide the data included in Table 3.2.

- ASTM D3359, Standard Test Method for Measuring Adhesion by Tape Test, is the common metric used in the field. This test could not be performed on the powdered coatings in place, but it informed the professional judgment applied during field inspections. All intact coatings in the pit area were judged to rate $5 \mathrm{~A}$ by this standard.

- ASTM D522, Standard Test Methods for Mandrel Bend Test of Attached Organic Coatings, is used to test coating flexibility on a flexible substrate. The test could not be performed on the powdered coatings in place. However, it was judged that all intact coatings in the pit could pass a $3 / 4$ in. mandrel bend but would fail a $1 / 2$ in. mandrel bend.

- There is no standard test for film integrity. Determination is based on subjective professional evaluation. The condition of the intact coatings in the pit area was essentially identical to when they were placed in exposure, while the coatings applied to the high-temperature components could be easily brushed from the primer coat.

\subsection{Results}

\subsubsection{Initial observed field performance}

As stated in section 2.4, during the 5 December 2006 site visit to install metrics panels in a demonstration pit and control pit, it was observed that the TC Ceramic topcoat had very rapidly degraded and, essentially, failed. During that visit, it also was observed that the Hi-Temp 1027 CUI primer coat was completely intact and in like-new condition.

\subsubsection{Follow-up observations of metrics panels}

On 12 April 2007 a follow-up site visit was undertaken to observe the metrics panels in pit 3 and the control pit. The condition of the panels in both pits after 19 weeks were very similar: 
- In both pits, the bare steel panel inserted inside the jacketing had turned a blue-black color.

- The bare, exposed panel hung in pit 3 had developed light rust on the rear (facing the concrete pit wall) but not on the front.

- The TC Ceramic topcoat on the laboratory-coated panels mounted inside the jacketing in both pits was virtually gone, with the panel in the control pit having only residual dust in the texture of the Hi-Temp 1027 CUI primer, and the panel in pit 3 having original thickness of TC Ceramic topcoat on about $15 \%$ of the surface. That residual paint was very weak and could be brushed from the surface with light finger pressure.

- In both pits, the Hi-Temp 1027 CUI primer was in excellent condition, and the epoxy zinc primer (MIL-DTL-24441 Formula 159) on the rear of the panel was in excellent condition.

Table 3.1 provides a summary of the observations.

Table 3.1. Summary of metrics panel observations at 19 weeks.

\begin{tabular}{|l|l|l|l|}
\hline & $\begin{array}{l}3 \times 9 \text { in. Q-Panels } \\
\text { (bare) }\end{array}$ & $\begin{array}{l}4 \times 6 \text { in. pipe panels } \\
\text { (bare) }\end{array}$ & $\begin{array}{l}4 \times 6 \text { in. pipe panels } \\
\text { (coated) }\end{array}$ \\
\hline $\begin{array}{l}\text { Pit 3 } \\
\text { inside jacket }\end{array}$ & $\begin{array}{l}\text { Dark bluish color } \\
\text { typical of heated steel } \\
\text { under a light mottled } \\
\text { rust }\end{array}$ & $\begin{array}{l}\text { Dark bluish color } \\
\text { typical of heated steel } \\
\text { under a light mottled } \\
\text { rust; epoxy primed } \\
\text { rear in new condition }\end{array}$ & $\begin{array}{l}\text { Ceramic topcoat is } \\
\text { powder, silicone } \\
\text { primer is intact; epoxy } \\
\text { primed rear in new } \\
\text { condition }\end{array}$ \\
\hline $\begin{array}{l}\text { Control pit } \\
\text { inside jacket }\end{array}$ & $\begin{array}{l}\text { Dark bluish color } \\
\text { typical of heated steel }\end{array}$ & $\begin{array}{l}\text { Dark bluish color } \\
\text { typical of heated } \\
\text { steel; epoxy primed } \\
\text { rear in new condition }\end{array}$ & $\begin{array}{l}\text { Ceramic topcoat is } \\
\text { powder, silicone } \\
\text { primer is intact; epoxy } \\
\text { primed rear in new } \\
\text { condition }\end{array}$ \\
\hline $\begin{array}{l}\text { Pit 3 } \\
\text { near pit wall }\end{array}$ & Very light rust & $\begin{array}{l}\text { Very light rust; epoxy } \\
\text { primed rear in new } \\
\text { condition }\end{array}$ & $\begin{array}{l}\text { Coating system in } \\
\text { new condition; epoxy } \\
\text { primed rear in new } \\
\text { condition }\end{array}$ \\
\hline $\begin{array}{l}\text { Control pit } \\
\text { near pit wall }\end{array}$ & Very light rust & $\begin{array}{l}\text { Very light rust; epoxy } \\
\text { primed rear in new } \\
\text { condition }\end{array}$ & $\begin{array}{l}\text { Coating system in } \\
\text { new condition; epoxy } \\
\text { primed rear in new } \\
\text { condition }\end{array}$ \\
\hline
\end{tabular}

As on the test panels, the TC Ceramic topcoat on pipes in pit 3 had turned to powder. Infrared temperature measurements of pipes in the control pit were in excess of $380^{\circ} \mathrm{F}$, duplicating the temperature measured on $5 \mathrm{De}$ cember 2006. 


\subsubsection{Laboratory verification of coating failure}

Upon observing, during the 5 December 2006 site visit, that the HDS operating temperature in pit 3 exceeded the Redstone DPW estimated operating temperature $\left(360^{\circ} \mathrm{F}\right.$ ) by $20^{\circ} \mathrm{F}$, it was decided to extend the laboratory oven temperature test of the TC Ceramic topcoat by elevating the oven temperature to $380^{\circ} \mathrm{F}\left(194^{\circ} \mathrm{C}\right)$.

Within 1 week at $380^{\circ} \mathrm{F}$, it was observed that the color of the TC Ceramic topcoat on oven specimens had significantly darkened compared with its previous condition, and the surface had turned to powder. Reflectance measurements shown in Table 3.2 document the darkening effect noted on the topcoat for oven specimens prepared for the Redstone demonstration, the earlier Fort J ackson demonstration, and experimental control. Although the Redstone specimens remained at $380^{\circ} \mathrm{F}$ for a total of 12 weeks, it is believed that the entire process of degradation actually occurred within the first week or two. The primers all remained intact on the surface of the panels.

Table 3.2. Final comparative oven test data for TC Ceramic topcoat (primed metrics panels).

\begin{tabular}{|l|l|l|l|l|}
\hline Specimen & Temperature & Duration & Reflectance & Topcoat Condition \\
\hline Control & $25^{\circ} \mathrm{C}\left(77^{\circ} \mathrm{F}\right)$ & New & $89-90$ & Pliable \\
\hline Fort Jackson demo & $105^{\circ} \mathrm{C}\left(221^{\circ} \mathrm{F}\right)$ & 26 weeks & $75-80$ & Same as new \\
\hline Redstone demo & $182^{\circ} \mathrm{C}\left(360^{\circ} \mathrm{F}\right)$ & 6 weeks & $31-34$ & $\begin{array}{l}\text { Hard, acceptable } \\
\text { adhesion }\end{array}$ \\
\hline Redstone demo & $194^{\circ} \mathrm{C}\left(380^{\circ} \mathrm{F}\right)$ & 12 weeks & $18-21$ & Powder \\
\hline
\end{tabular}

\subsection{Lessons learned}

The shutdown of steam lines in an HDS affects users and can delay mission-critical activity. Therefore, any planned shutdown for maintenance purposes must be as brief as possible, and carefully scheduled to avoid negative impacts either on the end user or the planned maintenance activity. Because an HDS-related coating project will generally involve a changing roster of installation and contractor personnel at various stages of planning and execution, fail-safe coordination is essential to the success of the project. In this demonstration, lapses in communication among project participants had significant negative impacts on the results. One example was the premature installation of pipe insulation and jacketing by the contractor; another example resulted in premature reopening of the 
demonstration steam line to full heat before the topcoat had fully cured. In the latter example, the result was blistering of the topcoat.

An important lesson learned is to verify the HDS operating temperature by direct measurement instead of relying on estimates provided by DPW personnel. System operators are accustomed to discussing system operating capacity in terms of steam pressure rather than temperature. The conversion from steam pressure to temperature is straightforward to make using saturated steam tables, but relatively small differences between estimated and actual pressure, in pounds per square inch, may translate to largerthan-expected temperature differences that could affect pipe coating performance. In the current demonstration, if the actual operating temperature (i.e., $380^{\circ} \mathrm{F}$ ) had been determined in advance by direct measurement, the laboratory oven test should have revealed potential topcoat durability problems at full heat. With that information, the manufacturer could have been consulted for alternate application recommendations. 


\section{Economic Summary}

\subsection{Overview}

An economic analysis of the subject technologies was performed following the seven-step process outlined in the Department of the Army Economic Analysis (EA) Manual and recommended by Department of Defense Instruction (DoDI) 7041.3. The full economic analysis is presented in Appendix D. The analysis estimates the benefits of using alternative maintenance procedures by comparing the maintenance cost of the status quo with the cost of three alternative maintenance scenarios over a period of 20 years.

\subsection{Assumptions}

The main assumption of the analysis are as follow:

- The start of the analysis period is FY06.

- The period of analysis is 20 years.

- The real discount rate is $4 \%$.

- Cost elements for each alternative are estimated using an average manhole. The average manhole is $10 \mathrm{x} 10 \mathrm{ft}$ and has two pipelines in it, supply and return. Inside the manhole there is a $\mathrm{T}$ in each line and a valve in each line. The total length of pipeline inside is assume to be (10 +5) $\mathrm{x} 2=30 \mathrm{ft}$ and the average diameter is $4 \mathrm{in}$. Manholes are $500 \mathrm{ft}$ apart and are connected by both supply and return lines.

- The analysis assumes four alternative maintenance methodologies. They are:

- Status Quo (SQ)

o Corrosion Protection Primer-Insulation Combination (P-I)--In this alternative the pipes are coated with a corrosion protection primer with a zinc-based paint and the deteriorated insulation is replaced.

o Corrosion Protection Primer-ExpectedCeramicPaint-Insulation Combination (P-ExPC-I) - In this alternative the pipes are coated with a corrosion protection primer and a ceramic paint before replacing the deteriorated insulation. Under this alternative, the ceramic paint is supposed to be able to add extra thermal insulation to the pipes. 
o Corrosion Protection Primer-ActualCeramicPaint-Insulation Combination (P-AcPC-I) -This alternative represents the actual field performance of the above (P-ExCP-I) alternative. In the field test conducted by CERL the ceramic paint did not perform as expected. The thermal barrier capability only lasted for 2 months, after which the ceramic paint didn't provide any extra insulation.

- In the SQ alternative, insulation is wrapped directly around the exterior side of the carrier pipe all through the section of pipe enclosed in the manhole. The economic life of the pipes under this alternative is 15 years. At the beginning of year 15 , the pipes are replaced with a similar pipe.

- In the P-I, alternatives the economic life of the pipe is extend to 30 years due to the corrosion protection provided by the zinc-based primer.

- In the P-ExCP-I and P-AcCP-I alternatives, the economic life of the pipes is also extended to 30 years by the presence of the zinc-based primer paint.

\subsection{Projected return on investment}

The economic analysis found that if the ceramic coating had performed as the manufacturer intended, this alternative would have produced a net savings of \$82,927 per manhole over a 20-year life cycle, resulting in a return on investment (ROI) of 72.7 and a Discounted Payback Period (DPP) of only 6.4 years. However, the field test of the ceramic paint reveled that the ceramic paint saved energy only for a few months, after which it became ineffective. In other words, the field test showed that the ceramic paint alternative only produced a net saving of $\$ 79,444$ per manhole over a 20 year life cycle, resulting in a ROI of 69.6 and a DPP of 15 years. In addition, the analysis showed that most of the savings came from the corrosion protection provided by the primer paint.

Given the inability of the ceramic paint to perform as intended by the manufacturer, the economic analysis shows that the next best alternative is the combination of just primer paint and insulation. This alternative produces a net savings of $\$ 79,794$ per manhole over a 20 -year life cycle, and results in a ROI of 150.3 although it takes 15 years to recover the investment - DPP of 15 years. Details are presented in Appendix D. 


\section{Conclusions and Recommendations}

\subsection{Conclusions}

The demonstration of this innovative coating system for HDS manhole pipes and appurtenances produced mixed results.

The thermal barrier portion of the coating system did not perform in accordance with the manufacturer's published product data. Although the TC Ceramic ceramic-filled topcoat material performed adequately in laboratory tests up to the estimated operating temperature of the Redstone $\mathrm{HDS}\left(360^{\circ} \mathrm{F}\right)$, it completely failed at an operating temperature only $20^{\circ} \mathrm{F}$ higher than that estimate. Follow-up oven testing in the laboratory replicated the failure of the TC Ceramic topcoat in pit 3 at Redstone. The evident failure mechanism was destruction of the topcoat's acrylic binder by excessive heat. It must be noted, however, that the manufacturer's product data sheet states that TC Ceramic topcoat will perform as specified up to $500{ }^{\circ} \mathrm{F}$ (Appendix B), so logic indicates that the acrylic matrix should have survived a temperature of $380^{\circ} \mathrm{F}$.

Due to the failure of the ceramic-filled topcoat in this high-temperature application, no conclusions can be drawn about its ability to reduce the interior temperature of manholes. No reliable inferences may be drawn based solely on the laboratory thermal conductivity testing.

Initial problems with topcoat adhesion, in the form of blistering, must be attributed to a premature return of the Redstone HDS to full heat. The topcoat did not have adequate time to dry before the system was returned to operating temperature, so water in the topcoat's acrylic binder boiled out instead of evaporating within the manufacturer's recommended temperature range. The character of this coating problem was localized to small scales, however, and should not have adversely affected overall coating adhesion performance.

The Hi-Temp 1027 CUI primer coat was observed to perform well regardless of the HDS system operating temperature or laboratory oven temperature. Because the majority of the projected ROI for this coating system (Appendix D) is attributable to the corrosion prevention and control impacts of the primer coat, the demonstration work at Redstone will provide 
a substantial continuing benefit for the installation without benefit of an intact topcoat.

\subsection{Recommendations}

\subsubsection{Applicability}

It is recommended that personnel responsible for specifying HDS maintenance and repair fully consider the application of the demonstrated primer coat material on pipes and appurtenances in HDS valve pits (manholes). Based on the results of this demonstration, the subject primer coat material is reasonably straightforward to apply, and it is durable enough to withstand exposure to system operation temperatures up to approximately $380^{\circ} \mathrm{F}$. Because coatings traditionally are not applied to pipes and appurtenances enclosed in HDS valve pits, the implementation of this technology throughout military installations could have an enormous role in lowering costs associated with repair and replacement of HDS components.

At this time, based on the results of this demonstration, the subject ceramic-filled topcoat material cannot be recommended for use in hightemperature HDS applications (approaching $380^{\circ} \mathrm{F}$ constant operating temperature). Direct observation indicates that the coating does not meet the specification (suitable performance up to $500{ }^{\circ} \mathrm{F}$ continuous or surge temperature) stated in the manufacturer's product data sheet.

It should be noted that this recommendation does not affect lowertemperature applications, such as documented in the successful Fort J ackson demonstration of the same topcoat.

\subsubsection{Implementation}

It is recommended that this technology be adopted and implemented by inclusion in Unified Facilities Guide Specifications (UFGS) 33-60-01, Valves, Piping, and Equipment in Valve Manholes (J uly 2006). In addition, the UFGS 33-61-13, Pre-Engineered Underground Heat Distribution System (April 2006), may require modification if the conduit end plates are to be coated. Inclusion in the original design of new systems would also be aided by implementing this technology into the language of Unified Facilities Criteria (UFC) 5-810-17, Heating and Cooling Distribution. Suggested implementation language is presented in Appendix E. 


\title{
Appendix A: Project Management Plan for CPC Project FAR-11
}

\author{
TRI SERVICE PROGRAM \\ U.S. Army Facilities \\ CORROSION PREVENTION AND CONTROL PROJECT PLAN \\ Innovative Thermal Barrier Coatings to Prevent \\ Corrosive Environmental Effects and Improve Energy \\ Efficiency in Heat Distribution Manholes - at Redstone \\ Aresenal \\ 19 Julv 2005 \\ (23 May 2006: funding revision) \\ Submitted By: \\ Charles Marsh \\ U. S. Army Enqineer Research \& Development Center (ERDC) \\ Construction Enqineering Research Laboratory (CERL)
}

Comm: 217-373-6764

(Project Number to be assigned by OSD when approved) 


\title{
TRI SERVICE PROGRAM / ARMY FACILITIES
}

\author{
Innovative Thermal Barrier Coatings to Prevent Corrosive \\ Environmental Effects and Improve Energy Efficiency in Heat \\ Distribution Manholes - at Redstone Aresenal
}

\section{STATEMENT OF NEED}

PROBLEM STATEMENT: Redstone Arsenal, IMA and ACSIM have identified heat distribution systems as a critical part of the infrastructure needed to support the installation mission. During their normal service life piping in heat distribution system (HDS) manholes throughout the Army and the Tri-Services routinely experience an environment that is both hot and humid. This results in an ongoing and severely corrosive environment to which bare and often un-insulated steel piping is exposed. ${ }^{1}$ Add to this multiple occurrences of leaking valves, pinhole leaks in condensate lines, ground water ingress, and occasional flooding and this accelerated degradation often results in the piping quickly reaching half of the useful life cycle (typically 25 years $^{2}$ ) within five to eight years. In addition, flooded manholes are at a near optimal temperature for nucleate boiling and can result in excessive and additional heat loss. For example a boiling manhole is estimated to lose from $\$ 50,000$ to $\$ 125,000$ worth of heat per year if not repaired ${ }^{3}$ while also prematurely degrading via corrosion the critical internal piping connections and appurtenances. Boiling manholes can easily go uncorrected for six or more years, and their eventual replacement repair, due to their shortened useful life, will also be expensive. Given that the manholes are both necessary and required, but also represent a reliability weakness, a means to better protect the manhole piping is needed. Even in normal operation the warm-to-hot and often humid manhole environment is inherently prone to accelerated corrosive degradation.

IMPACT STATEMENT: Implementation of this project will result in avoided adverse impact to mission critical basic and/or proficiency training through loss of building space heating and hot water supply. Similar impacts to other base operations will also be avoided. Other benefits will include significant reduction in operational and replacement expenses ${ }^{4}$ allowing more budgetary lee way for mission support, as well as improved system reliability and extended useful service life. Another plus is that maintenance worker safety will also be improved through less chance of burns, water hammer, catastrophic valve failure, and lack-of-oxygen confined space fatalities. More specifically, the expected benefits of innovative corrosion resistant coatings are to protect internal manhole piping connections (i.e., hot water/steam supply and retum line take offs from the main feeder trunk line) and valves from corrosion in a typically highly corrosive

1 "Causes and Control of Corrosion in Buried-Conduit Hent Distribution Systems", USACERI Technical Report M91/08 (July 1991), James R. Myers, Ellen G. Segan, Charles P. Marsh, Vincent F. Hock.

2 In addition, for long lived systems mandated by 10 CFR 436.14 (d)(2) not to exceed 25 years

3 "Boiling Manhole Heat-Loss Calculations", USACERL Technical Report 98/62 (Jure 1998). Charles Marsh and Temill Laughton. Note: these calculations use an old Army "Red Book" [FY94, Vol I] cost of energy value of $\$ 6.79$ per MBtu.

Replacement costs typically run $\$ 300-\$ 800 / \mathrm{ft}$. (1 mile $=\$ 1.6 \mathrm{M}$ and up). A relatively recent Army Utilities Modemization program was funded at $5 \mathrm{x} \$ 60 \mathrm{M} / \mathrm{yr}=\$ 300 \mathrm{M}$ 


\title{
TRI SERVICE PROGRAM / ARMY FACILITIES
}

\author{
Innovative Thermal Barrier Coatings to Prevent Corrosive \\ Environmental Effects and Improve Energy Efficiency in Heat \\ Distribution Manholes - at Redstone Aresenal
}

environment. An additional advantage of the intended innovative coating is to lower the hot pipe surface temperature and provide burn protection to the maintenance worker. This also means that a modest amount of effective insulation is added in a small added

thickness. Since heat distribution systems are in fact collections of interacting components ${ }^{5}$ the overall system condition will also be maintained. Taken all together these advantages result in a longer, energy efficient service life, lower life cycle cost operating costs, increases the likelihood of maintenance procedures being performed and an extended time between overall system replacement.

\section{PROPOSED SOLUTION}

TECHNICAL DESCRIPTION: This project will use a liquid ceramic coating to coat newly constructed, bare, manhole piping in heat distribution systems (e.g., Utility Modernization jobs). With as little as 180 mils a $350 \mathrm{~F}$ pipe can be rendered non-painful for contact with bare skin. This class of coatings has over 10 years of experience in industrial settings but is not currently used within the Army for HDS manhole piping. It is not covered in any DoD criteria documentation, nor in any industry wide specification. However, the main benefit is that the overall environment will be rendered significantly less corrosive while directly protecting the piping. In addition, depending on the specific application situation, an indicator coating may also be applied. This will consist of either a distinctively colored intermediate layer to easily show by visual inspection that it's time for recoating, or, a thermal indicator coating which shows a color change above a specific graded temperature. Either of these indicator coatings will yield an easily perceived "test result" showing the current status of the manhole piping and prompt appropriate maintenance procedures as needed. Further, the addition of well distributed fiber reinforcement will be selectively used to improve the durability of what effectively will be a ceramic matrix composite coating.

\section{Technical Maturity:}

This technology is mature and so low risk, with many years of proven experience. As one recent example a steam generation and distribution company in Detroit, MI is currently in the process of coating piping (including all appurtenances such as valves, fittings, and connectors) in their 900 manholes with 60 mils of this type of coating. One beneficial effect has been to decrease the ambient working condition temperatures which allow crews to work longer and without excessive ventilation.

5 "Condition Prediction Nodel and Component Interaction Fault Tree for Heat Distribution Systems", Marsh., Temple, Kim, ERDC/CERL TR-01-35 (July 2001) 


\title{
TRI SERVICE PROGRAM / ARMY FACILITIES
}

\author{
Innovative Thermal Barrier Coatings to Prevent Corrosive \\ Environmental Effects and Improve Energy Efficiency in Heat \\ Distribution Manholes - at Redstone Aresenal
}

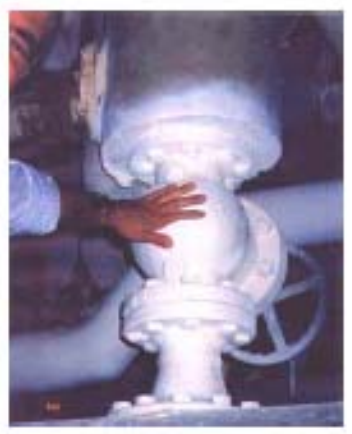

Figure 1: Commercial valve and piping coated with a liquid ceramic coating.

\section{RISK ANALYSIS:}

This is a low risk project in that the coating products are commercially available from multiple manufacturers. Ongoing, widespread industry experience over at least the last 10 years strongly indicates that successful application and long term performance should be expected. In addition, based on past working relationships Redstone Arsenal is receptive to heat distribution system improvements. Prior work resulted in significant improvements in the applicable heat distribution system related guide specifications, TM 5-810-17 and AR 420-49. This project will be implemented at Redstone Arsenal without the need of a phased approach.

\section{EXPECTED DELIVERABLES AND RESULTS/OUTCOMES:}

Depending upon manhole size and the associated internal piping surface area, from 9 to 25 manholes will be upgraded with the application of liquid ceramic coatings. As needed an appropriate indicator coating will also be included. In addition, supplied to the installation will be draft contract language and specifications (e.g., surface preparation, product acceptance requirements, safety procedures, etc.) for use on additional applications. The expected outcome is that there will be less operational distribution heat loss, significantly less corrosion will occur on upgraded manhole piping and a more reliable and longer service heat distribution system should result. Follow up coating assessments will be used to further assure and document expected performance.

PROGRAM MANAGEMENT: The Project Manager will be: Dr. Charles Marsh (ERDC-CERL Semior Researcher and Materials Engineer). The Associate Project Manager will be: Mr. David Kessler. The stakeholders will be Mr. Steve Jackson (IMA- 


\title{
TRI SERVICE PROGRAM / ARMY FACILITIES
}

\author{
Innovative Thermal Barrier Coatings to Prevent Corrosive \\ Environmental Effects and Improve Energy Efficiency in Heat \\ Distribution Manholes - at Redstone Aresenal
}

SERO), and Mr. Tom Tehada (USN) and Ms. Nancy Coleal (USAF). Customers are: Mr. Timothy Smith, Department of Logistics and Engineering, Redstone Arsenal. The approach will include contacting mechanisms such as Indefinite Delivery Indefinite

Quantity (IDIQ) Contract. An IDIQ Task Order and/or a technically qualified 8A contract for this project are expected to be awarded by 1 month after receipt of funds. Direct Cite funds will be used for contracts for implementing innovative manhole piping coatings at Redstone Arsenal.

The Army will be providing matching funds ( $\$ 290 \mathrm{~K})$ through HQ-IMA. Coordination with the Army Corrosion Program Office will be through Mr. Hilton Mills (HQ-AMC).

This is a Tri-service Project. Funds have been requested for travel of Air Force and Navy representatives to participate in the evaluation of technology implementation. The approach will include contacting mechanisms such as Indefinite Delivery Indefinite Quantity (IDIQ) Contract.

\section{COST/BENEFITS ANALYSIS}

a. Funding (\$K):

$\begin{array}{lcc}\text { Funding Source } & \text { OSD } & \text { Matching } \\ \text { Labor } & 143.2 & 170 \\ \text { Materials } & 50 & 50 \\ \text { Travel } & 15 & 15 \\ \text { Report } & 15 & 15 \\ \text { Air Force/Navy Participation } & -.- & -. \\ \text { SUBTOTAL } & 250 & 250 \\ \text { Overhead } & 38 & 40 \\ & & \\ \text { COMBINED TOTAL (\$K) } & 261.2 & 290\end{array}$

\section{Development Project Budget}

The $\$ 551.2 \mathrm{~K}$ budget is realistic and adequate for the scope of the project. ERDCCERL has an historic and ongoing familiarity with the Redstone Arsenal heat distribution system. 


\section{TRI SERVICE PROGRAM / ARMY FACILITIES}

\section{Innovative Thermal Barrier Coatings to Prevent Corrosive Environmental Effects and Improve Energy Efficiency in Heat Distribution Manholes - at Redstone Aresenal}

\section{b. Return-On-Investment Computation}

Using the required OMB spreadsheet, and in accordance with OMB Circular A-94, a return-on-investment (ROI) of 10.27 was calculated (see Appendix 1 below along with installation specific supporting notes and cited references). The associated savings were $\$ 5.7 \mathrm{M}$. This ROI value is based on current best practices, as well as projected

maintenance and rehabilitation practices and costs. In addition, conservative values for average energy costs and mostly labor based expenses for leak repair have been chosen since they are well documented. In addition, for comparison purposes, a nondiscounted ROI value (i.e., using a discount rate of zero percent) was calculated for this project using an otherwise identical situation. The non-discounted ROI value for this project is 18.55 .

\section{c. Mission Criticality}

The operational benefits of implementation of this technology for these mission critical systems are enhanced thermal efficiency, improved life cycle costs, lower ongoing operating costs, improved worker safety and increased system wide reliability for heat distribution systems.

\section{SCHEDULE}

\begin{tabular}{|c|c|}
\hline EVENT & $\begin{array}{l}\text { TIME } \\
\text { (months after } \\
\text { receipt of funds) }\end{array}$ \\
\hline Award Contract & 1 \\
\hline $\begin{array}{l}\text { Site Visit to Select Manholes } \\
\text { Select Liquid Ceramic and Indicator Coating } \\
\text { Products }\end{array}$ & 2 \\
\hline Begin On Site Coating Application & 3 \\
\hline $\begin{array}{l}\text { Complete Coating Application } \\
\text { Complete Draft Contract Language and } \\
\text { Procurement Documents for Installation }\end{array}$ & 5 \\
\hline Perform Follow Up Assessment & 14 \\
\hline $\begin{array}{l}\text { Complete Documentation (includes Final } \\
\text { Report, Procurement Specification, Ad Fliers) }\end{array}$ & 16 \\
\hline Complete ROI Validation & 18 \\
\hline
\end{tabular}




\title{
TRI SERVICE PROGRAM / ARMY FACILITIES
}

\author{
Innovative Thermal Barrier Coatings to Prevent Corrosive \\ Environmental Effects and Improve Energy Efficiency in Heat \\ Distribution Manholes - at Redstone Aresenal
}

a. Note: If project is approved, bi-monthly status reports will be submitted (i.e. starting the first week of the second month after contract award and every two months thereafter until final report is completed). This report will be submitted to the DoD CPC Policy \& Oversight office. Report will include project number, progress summary (and/or any issues), performance goals and metrics and upcoming events.

b. Examples of performance goals and metrics: include achieving specific milestones, showing positive trend toward achieving the forecasted ROI, reaching specific performance quality levels, meeting test and evaluation parameters, and/or successfully demonstrating a new system prototype.

\section{IMPLEMENTATION}

a. Transportability/Transition approach: Unified Facilities Guide Specifications (UFGS), Engineering Instructions (EI), Technical Instructions (TI), and Technical Manuals (TM), including updates, along with a final report describing the details of the project, will be developed and posted to the OSD Corrosion Exchange website under "Spec \& Standards" and "Facilities SIG." In addition, the guidance will be ERDC-CERL Corrosion Prevention and Control Program (CPCP) website. Coordination with potential users will be an essential part of the transition of the technology. It is the intent of the Project Management Plan (PMP) to implement this corrosion prevention and control technology at multiple regions and installations in the future given the availability of installation funding. The UFGS, EIs, TIs, and TMs, including updates to existing guidance documents, developed for Anmy-wide implementation during this project, will be utilized to facilitate the planned future implementation. This project has the potential for far-reaching impact across the Army and the Tri-Services, as similar corrosion problems are present throughout the Tri-Services. It is the intent of the Project Management Plan (PMP) to implement this corrosion prevention and control technology at multiple Army regions and installations in the future, as well as to other Tri-Service sites.

b. Potential ROI validation. ROI will be validated by comparison of coated manhole piping with otherwise identical but un-coated manhole piping. The calculated ROI for this project, which is based on current best practices, projected maintenance and rehabilitation cost, has the potential to increase over the multiple year implementation due to the reduction in down time, which will result in increased indirect savings. In subsequent years, the extension of useful and energy efficient service life of the heat distribution system, along with any 


\title{
TRI SERVICE PROGRAM / ARMY FACILITIES
}

\author{
Innovative Thermal Barrier Coatings to Prevent Corrosive \\ Environmental Effects and Improve Energy Efficiency in Heat \\ Distribution Manholes - at Redstone Aresenal
}

\begin{abstract}
applicable indirect savings, will be used to further refine and validate the ROI calculation. Third party validation will be used to document the ROI savings performance of this project. This validation work will be performed by an impartial and technically qualified individual such as a NACE-certified Corrosion Expert or by an expert in heat transfer such as Mr. Bob O'Brien of Washington State University.

c. Final Report: A final report will be written 60 days after the project is completed. The report will reflect the project plan format as implemented and will include lessons learned.
\end{abstract}

\section{Projected Benefits}

Based on extensive industry experience over many years this coating system should reduce corrosion in what typically can be an adverse and high corrosion environment (i.e., high temperature and high humidity). Additional benefits of increased energy efficiency and enhanced worker safety are also expected. Overall this project will help to prevent heat distribution system wide premature failure and excessive heat loss over and above the designed value. A more reliable supply of space heating and hot water, which often is also used in industrial process applications, will result in a positive impact to mission requirements and continued operational readiness at Redstone Arsenal.

\section{Management Support}

This project is supported by the Redstone Arsenal DPW Office as well as the IMA-SERO Region (see coordination sheet signatures). In addition, the Army (HQ-IMA and HQACSIM) have reviewed this project and provided matching funds for FY06. See the attached Memorandum from ACSIM Director for Facilities and Housing in Appendix 2. 


\section{TRI SERVICE PROGRAM / ARMY FACILITIES}

Innovative Thermal Barrier Coatings to Prevent Corrosive Environmental Effects and Improve Energy Efficiency in Heat Distribution Manholes - at Redstone Aresenal

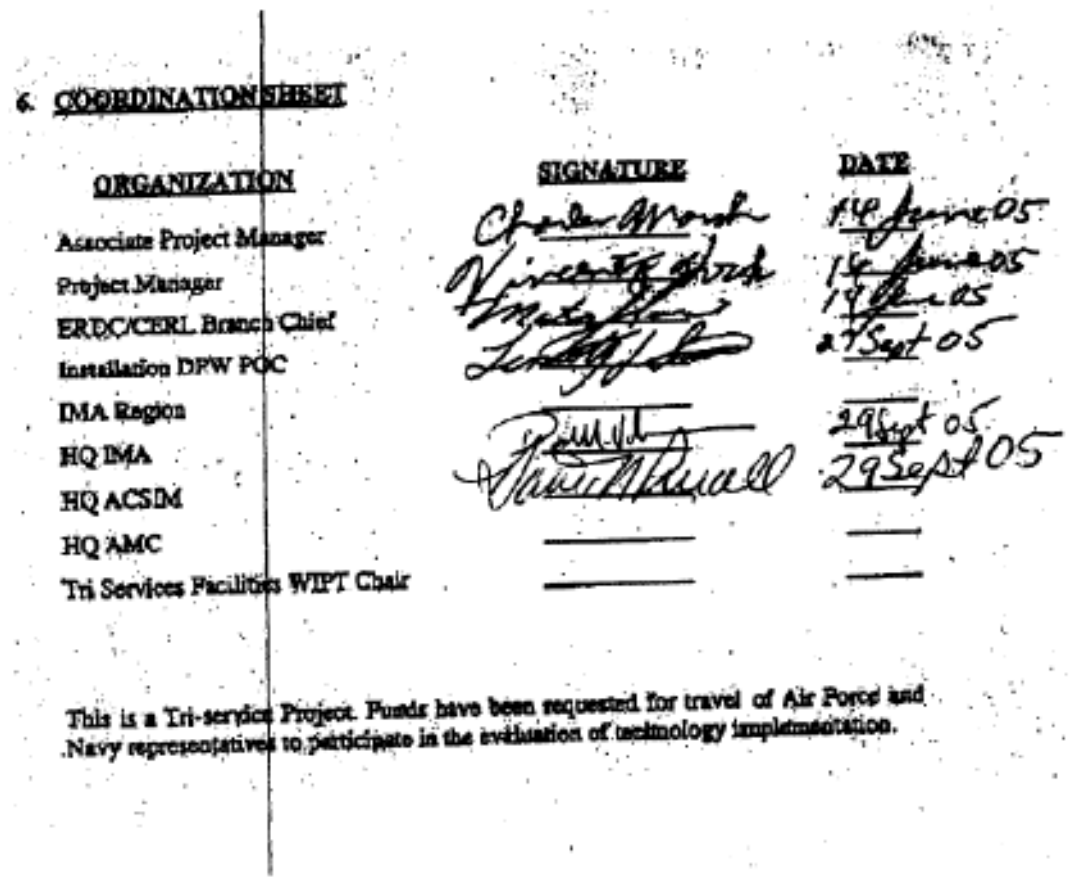


TRI SERVICE PROGRAM / ARMY FACILITIES

Innovative Thermal Barrier Coatings to Prevent Corrosive Environmental Effects and Improve Energy Efficiency in Heat Distribution Manholes - at Redstone Aresenal

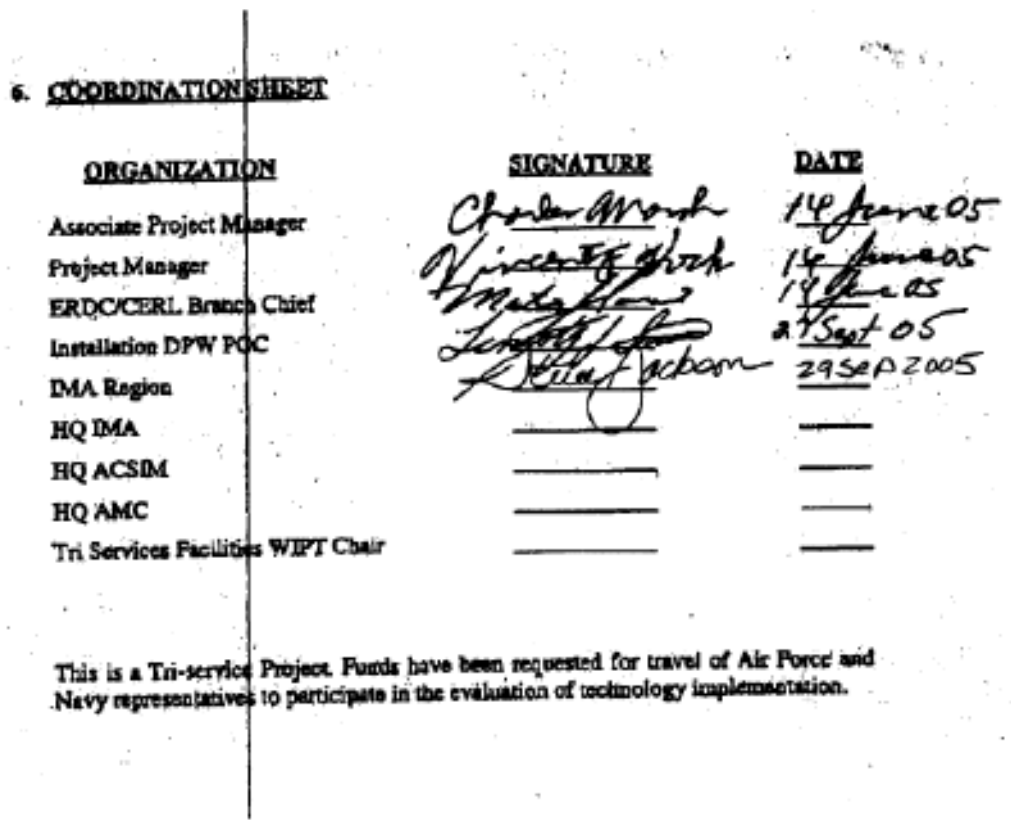




\section{TRI SERVICE PROGRAM/ ARMY FACILITIES}

Innovative Thermal Barrier Coatings to Prevent Corrosive Environmental Effects and Improve Energy Efficiency in Heat Distribution Manholes - at Redstone Aresenal

6. COOHDISATION SHEEI

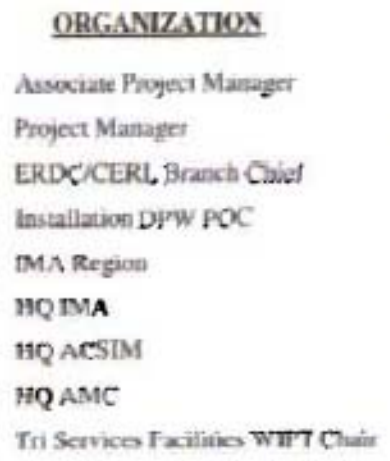

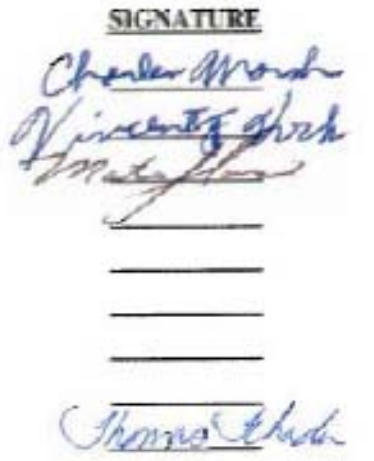

DAII

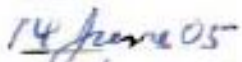

14 dineres

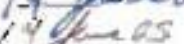

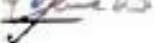

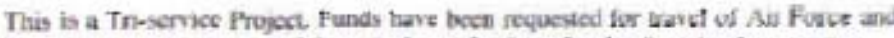
Navy represcmatives to participute m the evaluasionet rectrootogy inmplementation. 
TRI SERVICE PROGRAM / ARMY FACILITIES

Innovative Thermal Barrier Coatings to Prevent Corrosive Environmental Effects and Improve Energy Efficiency in Heat Distribution Manholes - at Redstone Aresenal

APPENDIX 1: Return on Investment (ROI) Calculations based on OMB Circular A-94

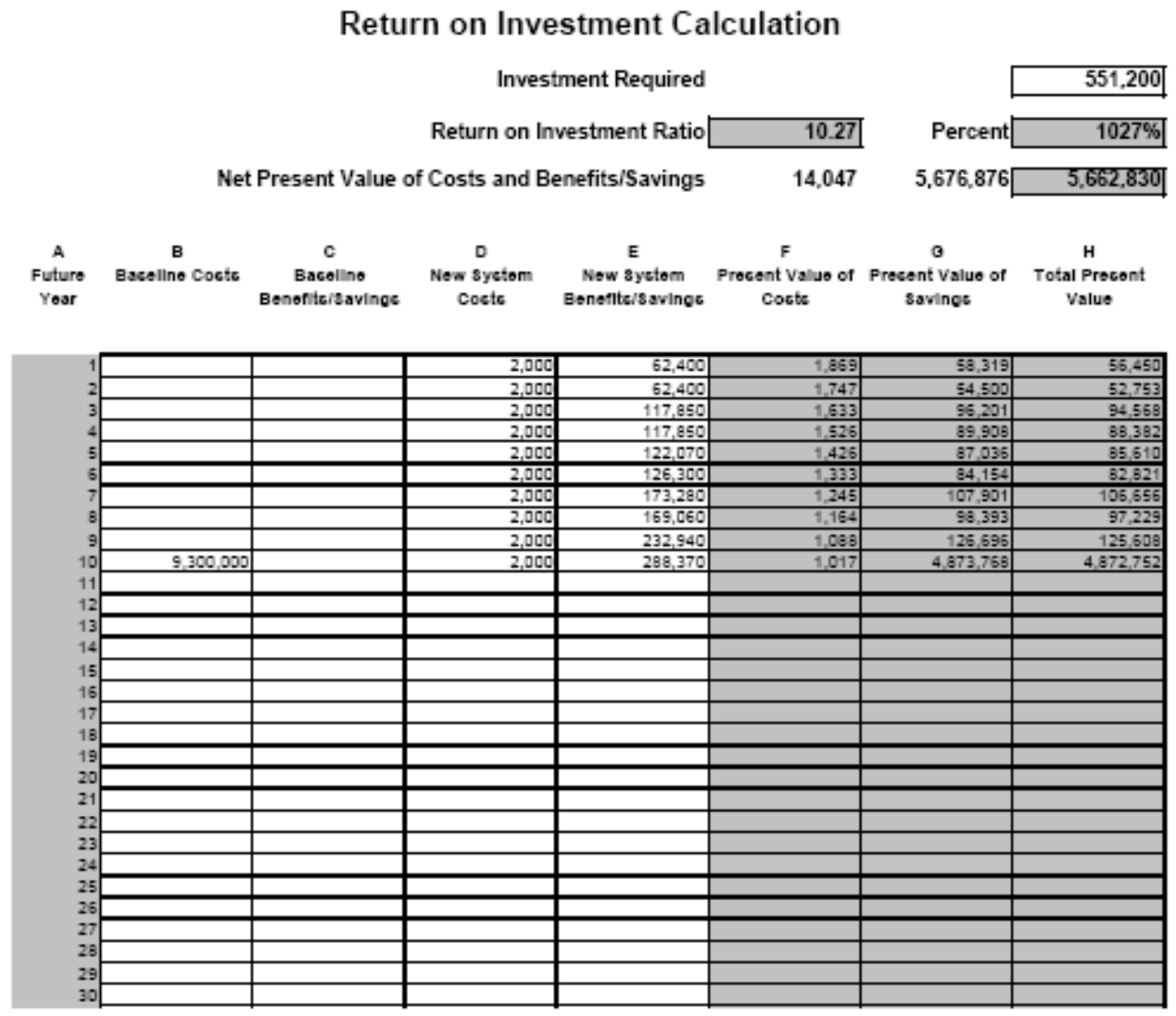




\section{TRI SERVICE PROGRAM / ARMY FACILITIES}

\section{Innovative Thermal Barrier Coatings to Prevent Corrosive Environmental Effects and Improve Energy Efficiency in Heat Distribution Manholes - at Redstone Aresenal}

Explanatory note (Column B):

Column B is required to estimate all annual operating and support costs, as well as replacement costs. A well designed, perfectly maintained and non-degraded heat distribution system will lose no more than $100 \mathrm{Btu} / \mathrm{ft}-\mathrm{hr}(876,000 \mathrm{Btu} / \mathrm{ft}-\mathrm{yr})$ for its so called distribution losses. The greater majority of the thermal energy is delivered to users. Using $31,000 \mathrm{ft}$ of system this works out to $27,156 \mathrm{MBtu}$ per year. At $\$ 16$ per Mbtu this works out to a yearly energy cost, for distribution losses only, of $\$ 434,496$ (with the delivered energy being the same in either case, and so a "wash" for comparison purposes). The balance of the $5500 \mathrm{~K}$ is for normal operation. As the system ages it is likely that the distribution losses will increase and the price of energy will rise. As such this estimated, lifetime average value is probably very conservative.

Supporting calculations for Avoided Costs (Column E):

COL. E: AVOIDED COSTS

NOTE: HDS SYSTEM REPLACEMENT (yr 11 and after)

\begin{tabular}{|c|c|c|c|c|c|c|c|c|c|}
\hline \multicolumn{3}{|c|}{ System length $(\mathrm{ft})$ : } & \multicolumn{2}{|l|}{31000} & \multirow[b]{2}{*}{$\begin{array}{l}\text { No of } \\
\text { leaks }\end{array}$} & \multirow[b]{2}{*}{$\begin{array}{l}\text { Leak } \\
\text { repair } \\
\text { costs }{ }^{x}\end{array}$} & \multirow[b]{2}{*}{$\begin{array}{l}\text { Total leak } \\
\text { repair costs } \\
\text { (K\$) }\end{array}$} & \multirow[b]{2}{*}{$\begin{array}{l}\text { Manhours } \\
\text { for yearly } \\
\text { manhole } \\
\text { inspection }\end{array}$} & \\
\hline YEAR & $\begin{array}{l}\text { ergy } \\
\text { st } \\
\text { Mbtu) }\end{array}$ & $\begin{array}{l}\text { \# man } \\
\text { holes } \\
\text { boiling }\end{array}$ & $\begin{array}{l}\text { excess MH } \\
\text { heat loss } \\
\text { (Mbtu/yr) }\end{array}$ & $\begin{array}{l}\text { excess MH } \\
\text { energy loss } \\
\text { per year } \\
\text { (KS/MH) }\end{array}$ & & & & & $\begin{array}{l}\text { No } \\
\text { ma } \\
\text { hol }\end{array}$ \\
\hline 1 & 6.79 & 1 & 7542.00 & 51.21 & 2 & 4.22 & 8.45 & & 2 \\
\hline 2 & 6.79 & 1 & 7542.00 & 51.21 & 2 & 4.22 & 8.45 & & 2 \\
\hline 3 & 6.79 & 2 & 7542.00 & 102.42 & 3 & 4.22 & 12.87 & & 2 \\
\hline 4 & 6.79 & 2 & 7542.00 & 102.42 & 3 & 4.22 & 12.67 & & 2 \\
\hline 5 & 6.79 & 2 & 7542.00 & 102.42 & 4 & 4.22 & 16.89 & & 2 \\
\hline 6 & 6.79 & 2 & 7542.00 & 102.42 & 5 & 4.22 & 21.12 & & 2 \\
\hline 7 & 6.79 & 3 & 7542.00 & 153.63 & 4 & 4.22 & 16.89 & & 2 \\
\hline 8 & 6.79 & 3 & 7542.00 & 153.63 & 3 & 4.22 & 12.67 & & 2 \\
\hline 9 & 6.79 & 4 & 7542.00 & 204.84 & 8 & 4.22 & 25.34 & & 2 \\
\hline 10 & 6.79 & 5 & 7542.00 & 256.05 & 7 & 4.22 & 29.56 & & 2 \\
\hline
\end{tabular}

The ongoing expense of implementing this technology (Column D) consist only of inspection calculated as 2 man-hours per manhole per year, at $\$ 20 /$ man-hour for 44 manholes $=\$ 1,760$. In the ROI spreadsheet this has been rounded up to $\$ 2,000$ to include incidentals and any recoating touch-ups needed. In addition to the avoided costs detailed above, the over-and-above savings of this technology (included in Column E) are 


\section{TRI SERVICE PROGRAM / ARMY FACILITIES}

\section{Innovative Thermal Barrier Coatings to Prevent Corrosive Environmental Effects and Improve Energy Efficiency in Heat Distribution Manholes - at Redstone Aresenal}

conservatively estimated at $\$ 1 \mathrm{~K} / \mathrm{yr}$ for not having to instead run space heaters and/or rent portable boilers, possibly for multiple buildings, to provide alternate sources of space heating and/or domestic hot water in the event of a service interruption.

The estimated number of leaks is meant to be representative and is here chosen to be generally increasing toward the end of the useful life of a heat distribution system while still retaining some variability.

No attempt has been made to estimate impacts on productivity, morale, or training hours. As well, energy costs are here assumed to be constant with a well documented and conservative value being chosen. Alternatively, if a more complete analysis were to be done using the latest energy escalation factors (projected rising energy costs over and above that of inflation/discount rate) for the southeast region the expected result would be to slightly increase the current ROI estimate.

\section{Supporting Notes for ROI Calculation for Redstone Arsenal HDS}

Redstone Arsenal has at least 31,000-ft of direct buried (DB) heat distribution system (HDS) piping.

The typical approximate replacement cost, in 2005 dollars, is $\$ 300 / \mathrm{ft}$. Without the application of this corrosion prevention technology a replacement is projected to be needed in 10 years time. In current dollars this would be a total of $\$ 9.3 \mathrm{M}$.

Assuming a conservative average of 500 -ft. of trunk line and 200 -ft. of "take off' to feed one or more buildings per manhole, this implies a total of 44 manholes. As existing, original system degrades some small but significant number of these manholes will flood and proceed to boil. As described in detail in an applicable Technical Report ${ }^{6}$ each of these can lose $\$ 51 \mathrm{~K} / \mathrm{yr}$. It is worth noting that this value is derived using an energy cost from FY94 of just $\$ 6.79$ per MBtu. If recent history is any guide a more representative value is likely to increase. In the calculation of this ROI any ongoing elevated heat loss, over and above acceptable designed transmission losses, of conduit sections between manholes is not accounted for bere. However, a beat distribution system is a complicated collection of interacting components where the effects of a local failure can cause adverse effects throughout the system. To better understand these interactions please see the referenced ERDC/CERL Technical Report?. The value used for leak repair is a documented value ${ }^{8}$ from Ft. Jackson and is in 1991 dollars. The appropriate section of the conference paper is reproduced below.

\footnotetext{
6 "Boiling Manhole Heat-Loss Calculations", Marsh, Laughton, USACERL Technical Report 98/62 (June 1998).

7 "Condition Prediction Model and Component Interaction Fault Tree for Hent Distribution Systems", Marsh. Temple, Kim, ERDC/CERL TR-01-35 (July 2001)

"Charles Marsh, "Lessons Learned to Date From the Ft Jackson, SC FEAP Heat Distribution Systems Demonstration Project", Corps of Engineers Electrical and Mechanical Training Conference, Dallas, TX, July 1992.
} 


\section{TRI SERVICE PROGRAM / ARMY FACILITIES}

Innovative Thermal Barrier Coatings to Prevent Corrosive Environmental Effects and Improve Energy Efficiency in Heat Distribution Manholes - at Redstone Aresenal

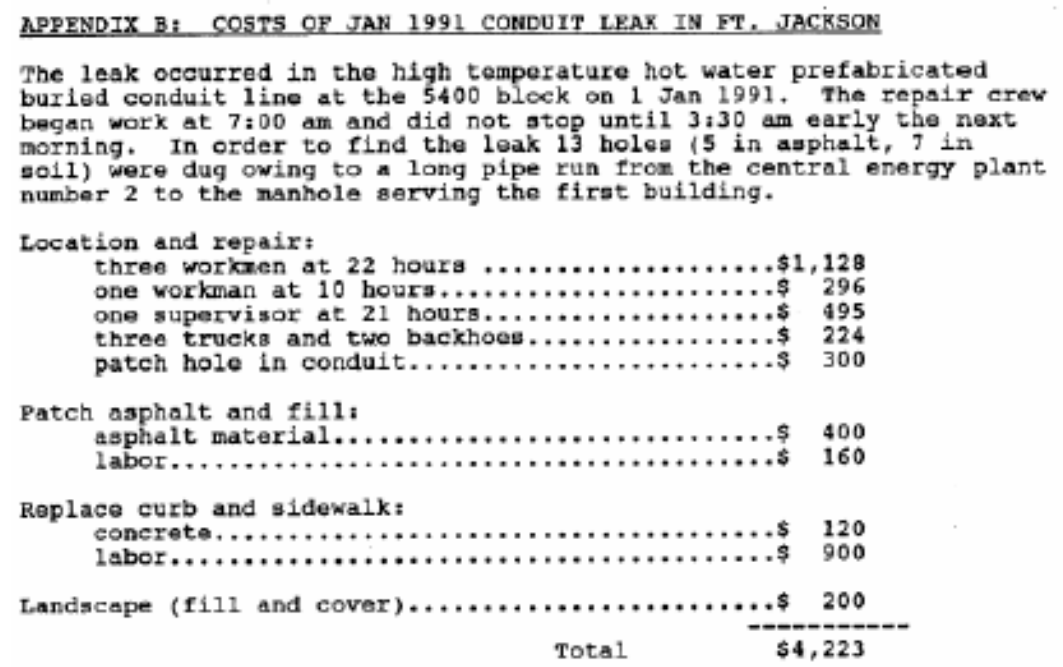




\title{
Appendix B: Coating System Technical Data
}

\author{
Technical data for Hi-Temp $1027 \mathrm{CUI}$
}

\section{HII=TEMP COATINGS \\ TECHNOLOGY}

\section{HI-TEMP 1027 CUI}

Product Description

Hi-Temp 1027 is a single component coating specifically formulated to prevent corrosion of carbon steel under thermal insulation. The coating is a high solid system which can be applied to a dry film thickness of $10-18$ mils.* and has a VOC content of $3.5 \mathrm{lb} / \mathrm{gal}$. It is an ambient temperature cure system that does not require a heat cure. 1027 has the ability to withstand thermal cyclic conditions to $1200^{\circ} \mathrm{F}\left(649^{\circ} \mathrm{C}\right)$ with peaks to $1400^{\circ} \mathrm{F}\left(753^{\circ} \mathrm{C}\right)$. The coating is resistant to continuous repetition of severe cyclic tests; dry heat of $1000^{\circ} \mathrm{F}$ $\left(538^{\circ} \mathrm{C}\right)$, followed by immersion in boiling water, followed by dry heat of $1000^{\circ} \mathrm{F}\left(538^{\circ} \mathrm{C}\right)$, etc.

*While applying to hot steel, 1027 has the ability to be applied to a d.f.t. of 30 mils. when the maximum heat resistance required is only $500^{\circ} \mathrm{F}\left(260^{\circ} \mathrm{C}\right)$.

*While applying to hot steel, 1027 has the ability to be applied to a d.f.t. of 45 mils. when the maximum heat resistance required is only $400^{\circ} \mathrm{F}\left(208^{\circ} \mathrm{C}\right)$.

Hi-Temp 1027 can be applied to ambient steel or directly to hot operating equipment having a metal temperature of $500^{\circ} \mathrm{F}\left(260^{\circ} \mathrm{C}\right)$ during application. Owners of equipment can: 1) strip insulation, 2) prepare the surface, 3) apply the coating and 4) re-insulate, without having to interrupt their business. Hi-Temp 1027 allows for the repair and maintenance of critical equipment which cannot be shut down, and yet is experiencing corrosion under insulation.

Hi-Temp 1027 is UV resistant and has an open

recoat window whether it has been applied to ambient or hot steel.

The high film build capability of the 1027 , whether applied to ambient or hot metal, allows one to cover the peaks and valleys of badly pitted steel under insulation; as well as properly protect difficult to coat areas such as flanges and bolts. The ability to apply high film thicknesses is important when confined to tight spaces where it is difficult to control the dry film thickness during application.

Hi-Temp 1027 CUI, 1027 Stainless, 1027 Cryogenic, 1027 DTR and 1027 Primer are all the same product. All are delivered with the same label - HiTemp 1027.
- Prevents Corrosion Under Insulation

- Boiling Water Resistant

- Dry/Wet/Dry Cycling to $1000^{\circ} \mathrm{F}$

- Apply Direct to Hot/Ambient Steel

- Single Component/No Heat Cure

Characteristics

- Resistant to boiling water

- Resistant to $1200^{\circ} \mathrm{F}\left(649^{\circ} \mathrm{C}\right)$

- Resistant to severe dry heatboiling

water/dry heat cyclic conditions

- One component, open recoat window

- High build $10-18$ mils. d.f.t. to $1200^{\circ} \mathrm{F}\left(649^{\circ} \mathrm{C}\right)$, ambient applied

$10-30$ mils. d.f.t. to $500^{\circ} \mathrm{F}\left(260^{\circ} \mathrm{C}\right)$ hot applied

$10-45$ mils. d.f.t. to $400^{\circ} \mathrm{F}\left(208^{\circ} \mathrm{C}\right)$ hot applied

- Apply directly to ambient or hot steel

having a metal temperature up to $500^{\circ} \mathrm{F}\left(260^{\circ} \mathrm{C}\right)$

- Ambient temperature cure.

Uses

- Power Plants

- Refineries

- Chemical Facilities

- Offshore/Marine

- Cement Plants

- Pulp \& Paper

Specification Data

Components

Type

Dry Temperature Resistance

Continuous

Peak

Colors

Finish

Dry Time@ @ $0 \%$ R.H., 70 F

$$
\begin{aligned}
& \text { To Touch } \\
& \text { To Recoat } \\
& \text { To ship }
\end{aligned}
$$

Cure

One

Proprietary

$1200^{\circ} \mathrm{F}\left(649^{\circ} \mathrm{C}\right)$

$1400^{\circ} \mathrm{F}\left(753^{\circ} \mathrm{C}\right)$

Black/Gray

Flat

Metal Temperature During Application

Thinner

Volume Solids

\section{2 hour}

6 hours

24 hours

N/A

Theoretical Coverage (@) 1 mil.df.t.

(a) 25 microns

$50^{\circ} \mathrm{F}-500^{\circ} \mathrm{F}\left(10^{\circ} \mathrm{C}-260^{\circ} \mathrm{C}\right)$ Hi-Temp \#5

$49 \%$

788 sq.ft.gal.

$19.7 \mathrm{sqm} .1$.

HI-TEMP COATINGS TECHNOLOGY • P.O. Box 2347 • Acton, MA 01720

Tel: 978-635-1110 • Fax: 978-635-1124• info@hitempcoatings.com • www.hitempcoatings.com 


$$
\begin{aligned}
& \text { VOC Content } \\
& \text { Weight per gallon } \\
& \text { Hi-Temp } 1027 \\
& \text { Storage Temperature }
\end{aligned}
$$

Shelf Life

\section{Surface Preparation Carbon Steel}

Surfaces to be coated must be dry and free of all chlorides, weld splatter, oil, dirt, grease and all other contaminants. Round off all rough welds and sharp edges. Abrasive blast to an SSPC-SP 6 "Commercial Blast". Blast profile should be 1.5-2.5 mils. (38-63 microns) in depth. If "Commercial Blast" is not possible, an SSPC-SP 11 "Power Tool" is approved. Performance of Hi-Temp 1027 is relative to the surface preparation accomplished.

\section{Application Instructions*}

Surface temperature must be a minimum of $5^{\circ} \mathrm{F}\left(3^{\circ} \mathrm{C}\right)$ above the dew point. Do not apply to steel temperatures below $50^{\circ} \mathrm{F}\left(10^{\circ} \mathrm{C}\right)$.

All of the following application instructions are based upon spraying the Hi-Temp 1027. For all brush and roll applications please contact HTC technical service.

*Do not exceed maximum dry film

thickness recommendations.

System 1): Hot Steel Application Insulated Carbon Steel

Hot steel application from $150-300^{\circ} \mathrm{F}\left(61-122^{\circ} \mathrm{C}\right)$ : Allow 20 minutes in between coats. Hot steel application from $300-500^{\circ} \mathrm{F}\left(122-260^{\circ} \mathrm{C}\right)$ Allow 15 minutes in between coats.

Heat resistant to $1200^{\circ} \mathrm{F}\left(649^{\circ} \mathrm{C}\right)$

1st coat $\quad$ DFT

Hi-Temp $1027 \quad 5.0-6.0$ mils.

(125-150 microns)

2nd coat

Hi-Temp 1027

5.0-6.0 mils. (125-150 microns)

$3 r d$ coat

Hi-Temp 1027

5.0-6.0 mils.

(125-150 microns)
HI-TEMP 1027 CUI

Total dry film thickness

Maximum dry film thickness

(applied in three coats at

$15.0-18.0$ mils. ( $375-450$ microns)

$5-6$ mils. per coat)

(375-450 microns)

System 2): Ambient Steel Application Insulated Carbon Steel

Heat resistant to $1200^{\circ} \mathrm{F}\left(649^{\circ} \mathrm{C}\right)$

1st coat

DFT

Hi-Temp 1027

5.0-6.0 mils.

(125-150 microns)

2nd coat

Hi-Temp 1027

5.0-6.0 mils.

(125-150 microns)

Total Dry Film thickness

10.0-12.0 mils.

(250-300 microns)

Maximum Dry Film thickness

15.0 mils.

(375 microns)

System 3): Maximum temperature resistance needed is only $500^{\circ} \mathrm{F}\left(260^{\circ} \mathrm{C}\right)$ and $400^{\circ} \mathrm{F}\left(208^{\circ} \mathrm{C}\right)$ respectively.

For both temperatures follow the standard specification for ambient or hot steel application.

Maximum dry film thickness while applying directly to hot steel up to $500^{\circ} \mathrm{F}\left(260^{\circ} \mathrm{C}\right)$ is $24.0-30.0$ mils. $(600-750$ microns) in 3 coats at 8.0-10.0 (200-250 microns) per coat.*

Maximum dry film thickness while applying directly to hot steel up to $400^{\circ} \mathrm{F}\left(208^{\circ} \mathrm{C}\right)$ is $40.0-45.0$ mils. (10001125 microns) in 4 coats at 9.0-11.0 mils. (225-275 microns) per coat.*

*When applying such thicknesses per coat directly to hot steel, it is important not to apply all the material at once in one pass but to apply it in multiple thin passes.

When applying 20-30 mils. df.t. in 3 coats allow $45 \mathrm{~min}-$ utes between coats.

When applying $30-45$ mils. df.t. in 4 coats allow 1 hour between coats. 
Application Instructions to Hot Steel

1. IMPORTANT! It is essential to apply thin coats of the Hi-Temp 1027 during an application to hot steel. This aids in allowing the solvent to escape the coating without leaving pinholes behind. This application is similar to mist coating.

2. Flush equipment with Hi-Temp \#5 Thinner before using equipment.

3. Hi-Temp 1027 is normally not thinned. If the situation warrants thinning, use only Hi-Temp \#5 Thinner.

4. Hi-Temp \#5 Thinner is specifically formulated for Hi-Temp 1027. It is a slow evaporating solvent allowing for good film integrity as the coating is being applied to hot operating equipment.

5. WARNING! Do not thin Hi-Temp 1027 with any other solvent. A fire hazard could occur if using a different solvent system. Dry spray and poor film characteristics may occur as well.

6. Do not apply a heavy coat to a hot surface or blistering will occur. If this happens, immediately take a brush, (use wood handled brushes with China bristles only, do not use a brush with synthetic bristles), and brush out the blister before it sets.

7. Application to hot surfaces tends to promote dry spray.

8. To avoid dry spray, apply coatings without reaching.

Equipment

Conventional or airless spray is recommended. For conventional spray use a DeVilbiss MBC-510 (or equal) gun with an "E" fluid tip and a 704 air cap (or equal). For airless spray use a Graco 205-591, 208-663 (or equal) gun with fluid tip of 163-610, 163-315 and a Graco Bulldog Pump at 30:1.

Adjust pressure as needed. Hold gun 10"-12" from the surface at right angles. Lap each pass $50 \%$. When brushing and rolling contact HTC technical service for specific recommendations.

\section{HI-TEMP 1027 CUI}

\section{Mixing}

Use mechanical agitation for mixing and during application. Mix materials until uniform in consistency.

\section{Thinning}

Thinning is not normally needed, however if a condition warrants thinning, thin only with Hi-Temp \#5 Thinner. Thin according to local air regulations.

Clean-up

Use Hi-Temp \#5 Thinner.

\section{Precautions}

This product is for use only by professional applicators in accordance with information in this bulletin and the Material Safety Data Sheet (MSDS). Refer to this product's MSDS before using this material.

All use and application of this product should be performed in compliance with all relative Federal, State and local Health, Safety \& Environmental regulations.

\section{Warranty}

HTC warrants that its products are free from defects in material and workmanship. HTC's sole obligation and buyer's exclusive remedy shall be limited to replacement of products not conforming to this warranty. Any claim for replacement product must be made within one year from the delivery date.

HTC makes no other warranties, expressed or implied, such as warranties of merchantability or fitness for a particular purpose. HTC products are intended for Buyers with the knowledge and skills to evaluate the suitability of HTC's products for Buyer's intended use. In no event shall HTC be liable for consequential or incidental damages. 


\section{MATERIAL SAFETY DATA SHEET}

\begin{tabular}{|c|c|c|c|}
\hline \multicolumn{4}{|c|}{$\begin{array}{l}\text { Date Sept, } 2006 \\
\text { Product Name: Gray \& Black } \\
\text { Product Code: } 1027-90,1027-00\end{array}$} \\
\hline SECTION I & \multicolumn{3}{|c|}{ Manufactures Identification } \\
\hline Manufactures Name: & \multicolumn{3}{|c|}{$\begin{array}{l}\text { Hi-Temp Coating Technology } \\
629 \text { Massachusetts Ave. } \\
\text { Boxborough, MA } \\
01719\end{array}$} \\
\hline $\begin{array}{l}\text { Emergency Phone: } \\
\text { Information Phone }\end{array}$ & \multicolumn{3}{|c|}{$\begin{array}{l}978-302-0626 \\
978-635-1110\end{array}$} \\
\hline \multirow[t]{2}{*}{ SECTION II } & \multicolumn{3}{|c|}{ Hazardous Ingredients } \\
\hline & CAS \# & $\%$ Wgt & Exposure level \\
\hline METHYL AMYL KETONE & $110-43-0$ & 8 & $\begin{array}{l}\text { OSHA PEL } 100 \mathrm{ppm} \\
\text { ACGIH TLV } 50 \mathrm{ppm}\end{array}$ \\
\hline XYLENE & $1330-20-7$ & 2.6 & $\begin{array}{l}\text { OSHA PEL } 100 \mathrm{ppm} \\
\text { ACGIH TLV } 100 \mathrm{ppm}\end{array}$ \\
\hline ETHYLBENZENE & $100-41-4$ & 1 & $\begin{array}{ll}\text { OSHA PEL } & 100 \mathrm{ppm} \\
\text { STEL } & 125 \mathrm{ppm} \\
\text { ACGIH TLV } & 25 \mathrm{ppm}\end{array}$ \\
\hline
\end{tabular}

AROMATIC HYDROCARBON $\quad 64742-94-5 \quad 10 \quad$ no limits established

SECTION III Physical/Chemical Characteristics

Boiling Range: $300-527 \mathrm{~F}$

Specific Gravity (water=1): 1.95

Volatiles By Volume: $51 \%$

Nonvolatile By Weight $76 \%$

Vapor Density: Heavier than air

Evaporation Rate: 0.1

voc: $\quad 3.5 \mathrm{lbs} / \mathrm{gal}$

BuAce=1

LEL: 1.0 UEL: 7.9 .0

Flash Point: $65 \mathrm{~F}$ 
Hazardous Products of Combustion

May form: carbon dioxide and carbon monoxide and various organic compounds.

\section{Fire and Explosion Hazards}

Vapors are heavier than air and may travel along the ground of may be moved by ventilation and ignited by pilot lights, or other sources of ignition, such as flame, sparks and static discharge. Never use welding or cutting torch near drum (or empty) because product (even residue) can ignite explosively.

\section{Extinguishing Media}

Regular foam, carbon dioxide, dry chemical. Water may be ineffective, but may be used to cool exposed containers to prevent pressure buildup and possible auto-ignition or explosion when exposed to extreme heat.

\section{Fire Fighting Instructions}

Wear a self-contained breathing apparatus with full face piece operated in the positive pressure demand mode with appropriate tum-out gear and chemical resistant personal protective equipment.

\section{Unusual Fire and Explosive Hazards}

During emergency conditions, overexposure to decomposition products may cause a health hazard. Symptoms may not be immediately apparent. Obtain medical attention.

SECTION V

Stability Stable

Conditions to Avoid Excessive heat and ignition sources, such as sparks and flames.

Incompatibility (Materials to Avoid) Strong acids, bases, and oxidizing agents.

Hazardous Polymerization Will not occur.

SECTION VI Health Hazard Data
Inhalation
ACUTE: May cause irritation of the respiratory tract. High concentrations may cause
central nervous system depression characterized headaches, dizziness nausea and confusion.
CHRONIC; Preexisting disorders of the following organs may be aggravated by exposure
to this material, skin, lung, kidney and auditory system. Individuals with preexisting heart disorders
may be more susceptible to arrhythmias, if exposed to high concentrations of this material.

Eye

ACUTE; May cause mild eye irritation. Symptoms include stinging, tearing, and redness. 


SECTION VI Health Hazard Data

Skin

Acute: Can cause skin irritation. Symptoms include redness, burning, and drying. Chronic: Cracking of skin and other skin damage.

\section{Ingestion}

Acute: Swallowing small amounts of this material is unlikely to occur during normal handling. But should not be harmful if small amounts are ingested. Swallowing large amounts may cause gastrointestinal irritation, nausea and vomiting and may be harmful. This material can enter the lungs during swallowing or vomiting and cause chemical pneumonitis which can be fatal.

\section{Carcinogen NTR IARC OSHA REGULATED May contain less then $.1 \%$ silica, \\ Emergency and First Aid Procedures}

Eyes: Flush thoroughly with running water for 15 minutes, including under eyelids. Get medical attention.

Skin: Promptly remove contaminated clothing and wash affected areas thoroughly with soap and water. If irritation occurs get medical attention. Wash contaminated clothing thoroughly before reuse.

Inhalation: If overcome by vapor, remove to an area free from risk of further exposure. If breathing is difficult, administer oxygen, or artificial respiration if breathing has stopped .Keep person warm and quiet and get medical attention.

Ingestion: If swallowed, call a physician immediately. Only induce vomiting at the instructions of a physician. Never give anything by mouth to an unconscious person.

Intentional misuse by deliberately concentrating and inhaling the contents may be harmful or fatal.

\begin{tabular}{|c|c|c|}
\hline SECTION VI & Reactivity Data & \\
\hline $\begin{array}{l}\text { Stability [ ] Unstable } \\
\text { Hazardous Polymerization: }\end{array}$ & [X] Stable $[$ ] May occur & [X] Will not occur \\
\hline
\end{tabular}
formed.

\section{SECTION VII Spill or Leak Procedures}

Steps to be taken in case material is released or spilled:

Before attempting cleanup, refer to hazard caution information in other section of this sheet. 


SECTION VII Spill or Leak Procedures

Persons not wearing protective equipment should be excluded from area of spill until clean-up has been completed.

Large spills : Notify safety personal. Eliminate potential sources of ignition. Wear appropriate respiration and protective clothing. Soak up with an absorbent. Place in non-leaking containers and seal tightly for proper disposal. Ventilated confined spaces. Open all doors and windows. Minimize skin contact. Keep product out of sewers and water courses by diking and impounding. Observe precautions for flammable volatile vapors from absorbed material.

Small spills : Take up with absorbent material and place in non-leaking containers for proper disposal.

Waste disposal method:

Assure conformity with applicable Federal, state and local regulations.

SECTION VIII Special Protection Information

Respiratory Protection:

Use NIOSH approved respirators as required to prevent overexposure.

Example $3 \mathrm{M}$ Series 7000 or equivalent with an organic vapor cartridge.

In confined space observe regulations, Refer to OSHA 29 CFR 1910.134,"Respiratory Protection".

Ventilation:

Provide sufficient ventilation to keep air contaminant concentrations below current applicable OSHA permissible exposure limits and ACGIH's TLV limit.

Protective gloves:

Use chemical resistant gloves to prevent skin contact. Examples, Neopreme or Nitrile.

Eye protection:

Use chemical splash goggles or face shield to prevent eye contact.

Other protective equipment:

Use chemical resistant or other protective outerwear to protect against clothing contamination and skin contact.

\begin{tabular}{|c|c|}
\hline \multicolumn{2}{|l|}{ SECTION IX } \\
\hline TSCA Status & \\
\hline $\begin{array}{l}\text { SARA Title III: } \\
\text { Section } 313\end{array}$ & \\
\hline Xylene & $2.6 \%$ \\
\hline Ethyl Benzene & $1 \%$ \\
\hline Zinc Compound & $6 \%$ \\
\hline
\end{tabular}




\section{SECTION $X$}

Other Precautions

Precautions to be taken in handling, transportation, and storing:

Handling and storage conditions must be suitable for flammable liquids. Store in cool, well

ventilated, fire resistant storage area. Protect containers against physical damage. Keep away from heat, flame and strong oxidizing agents. Do not store above $100 \mathrm{~F}$. Use only with adequate ventilation. Keep containers closed when not in use. Bond and ground containers of this material when pouring to avoid static sparks which creates a fire hazard.

This information and recommendations contained herein are based on data believed to be correct. However, Hi-Temp Coatings Technology makes no warranty expressed or implied regarding the accuracy of this data. Hi-Temp Coatings Technology assumes no responsibility for personal injury or property damage caused by the use of the material described herein. It is the responsibility of the purchaser or user to ensure that this material properly and safely used. 


\section{Technical data for TC Ceramic}

\section{TC Ceramic}

Capstone MFG., LLC Technical Data Sheet

\section{PRODUCT DESCRIPTION}

CHEMICAL DESCRIPTION Single Component, Waterborne Acrylic Polymer with Silicon Microspheres

PRODUCT USAGE

Ceramic (previously known as Thermal-Coat) is a liquid insulation, consisting of a mixture of various silicon and ceramic beads blended into a high quality acrylic polymer. TC Ceramic is designed to provide both thermal and acoustical insulation for a variety of industrial applications, providing an effective, inexpensive alternative to the high cost of typical insulation systems. Due to its excellent reflectivity and emissivity, TC Ceramic excels at insulating structures and equipment from radiant energy gain. $99 \%$ of the radiant energy that comes in contact with TC Ceramic is either reflected or re-emitted, meaning only $1 \%$ of the radiant energy is absorbed. TC Ceramic also performs very well at protecting personnel from burn hazards on hot or cold structures and equipment. Because it physically adheres to the surface, TC Ceramic significantly reduces corrosion and rust formation. TC Ceramic is extremely lightweight and pliable, therefore, it expands and contracts with the surface to which it is applied. The use of TC Ceramic, in place of other insulation, reduces both the space and weight for any given structure or piece of equipment.

COLORS Standard color is white. Special colors available upon request.

PRODUCT CERTIFICATIONS Passes ASTM C1055-99 standard for protection from burn injuries.

PRODUCT ADVANTAGES

- Excellent radiant reflectivity and emissivity properties - significantly reduces radiant energy gain

- Low thermal conductivity - good conductive insulation properties

- Very good burn safety characteristics - excellent for personnel protection

- Light weight - less weight than other insulations

- Good adhesion - bonds well to a variety of substrates

- Moisture resistant - helps to prevent corrosion and rust formation

- Easy application/installation - installs in much less time than other insulations

- Reduces or eliminates condensation

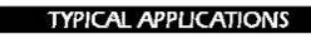

- Pipe and Valve Insulation

- Tank Insulation

- Roof Coating

- Interior and Exterior Wall Insulation

- Interior and Exterior Ducting

SURFACE PREPARATION

Preparation requirements vary. Contact Capstone Mfg. for assistance.

COATING SYSTEMS

PRIMERS Steel: self-priming or corrosion resistant primer

Non-Ferrous Metals and Galvanized Steel: self-priming

Concrete: self-priming

Wood: self-priming

TOPCOATS Acrylic Latex Compatible Systems: not recommended for burn safety applications.

The information contained is offered without change for technically qualified personnel at their discretion and risk. All statements, technical information and recommendations contained herein are based on te sts and data which we believe to be reliable, but the accuracy or completeness thereof is not guaranteed and no warranty of any kind is made with respect thereto. We guarantee our products to conform to Capstone Mfg. quality control. Since conditions and methods of appication are beyond our control, buyer assumes all nisk of use or handing. CAPSTONE MAKES NO WARRANTY. EXPRESS OR IMFLIED, FORA PARTI TAR PEPPOSE SR THE USE OF THE GOODS OR THEPERFORMANCE OF THE GOODS AND MAKES NO WARRANTIES OF FTNESS limited to replacement of products. Data may be modified without prior notice.

Capstone Mfg. $\cdot 18225-47^{\text {th }}$ Place NE・Seattle, WA 98155・Phone 206.363.5010・FAX 206.364.5183 •mlantz@nwlink.com 
CAPSTONE MFG., LLC

TC Ceramic

\section{TECHNICALDATA}

SOLIDS VOLUME

RECOMMENDED DRY FILM

THICKNESS

DRY TIME (50\% R.H.)

\begin{tabular}{r|c|c|c|c|} 
DRY TIME (50\% R.H.) & Temperature & Dry To Touch & Recoat Time & To Normal Use \\
\cline { 2 - 5 } & $75^{\circ} \mathrm{F}$ & $180 \mathrm{~min}$. & $12 \mathrm{hrs}$. & $24 \mathrm{hrs}$. \\
\cline { 2 - 4 } THEORETICAL COVERAGE & Spray Application: $60 \mathrm{sq} . \mathrm{ft} / \mathrm{gallon} @ 15 \mathrm{mils}(0.4 \mathrm{~mm})$ \\
NET WEIGHT PER GAUION & Wet: 5.6 pounds $(2.54 \mathrm{~kg}) / \mathrm{gallon}$, Dry: 3.2 pounds $(1.45 \mathrm{~kg}) / \mathrm{gallon}$ \\
STORAGE TEMPERATURE & Minimum $40^{\circ} \mathrm{F} / 5^{\circ} \mathrm{C}$, Maximum $80^{\circ} \mathrm{F} / 26^{\circ} \mathrm{C}$; cool storage is recommended \\
SHELF UFE & 12 months at recommended storage temperatures.
\end{tabular}
handling and safety information.

PHYSICAL PROPERTIES Cross Hatch Adhesion (ASTM 3359)

100\% passed, no failure

\begin{tabular}{|l|r|}
\hline Flame Spread (ASTM E84-98) & 25 \\
\hline
\end{tabular}

Smoke Developed (ASTM E84-98)

\begin{tabular}{ll} 
Accelerated Aging (ASTM G53), no primer & No discoloration at 200 hours \\
\hline
\end{tabular}

\begin{tabular}{|l|l}
\hline Brookfield Viscosity, \#3 Spindle, $30 \mathrm{rpm}$ & 3564 centipoise \\
\hline
\end{tabular}

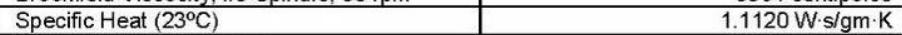

\begin{tabular}{l|l} 
Thermal Diffusivity $\left(23^{\circ} \mathrm{C}\right)$ & $0.00239 \mathrm{~cm}^{2} / \mathrm{sec}$ \\
\hline
\end{tabular}

\begin{tabular}{|l|l}
\hline Thermal Conductivity $\left(23^{\circ} \mathrm{C}\right)$ & $0.00097 \mathrm{~W} / \mathrm{cm} \cdot \mathrm{K}$ \\
\hline
\end{tabular}

$0.0563 \mathrm{Btu} / \mathrm{hr} \cdot \mathrm{ft} \cdot{ }^{\circ} \mathrm{F}$

\begin{tabular}{l|r}
\hline Solar Reflectance (ASTM E903) & 0.83 \\
\hline Emittance (ASTM E408-71) & 0.94 \\
\hline
\end{tabular}

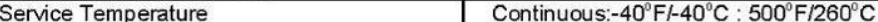

Maximum Surge: $500^{\circ} \mathrm{F} / 260^{\circ} \mathrm{C}$

APPUCATION

MIXING Power mix contents of container using a mud paddle at $300 \mathrm{rpm}$ or less for $3-5$ minutes, making sure to blend in all solids on top of container.

SURFACE TEMPERATURE Minimum $50^{\circ} \mathrm{F} / 10^{\circ} \mathrm{C}$, Maximum $300^{\circ} \mathrm{F} / 150^{\circ} \mathrm{C}$. Coating will not dry below $50^{\circ} \mathrm{F} / 10^{\circ} \mathrm{C}$ Prior to applying to substrates at temperatures greater than $150^{\circ} \mathrm{F} / 68^{\circ} \mathrm{C}$, please contact Capstone Mfg. for assistance.

METHODS \& EQUIPMENT Apply TC Ceramic on a dry, clean, substrate which is free from oil, grease, wax, dirt, rust or corrosion. Use airless sprayer with $3000 \mathrm{PSI}, 1.25 \mathrm{GPM}, 28: 1$ ratio with a .021 tip size. An AR-1 Spray Gun using shop air may be used for small applications. Allow product to completely dry between coats. This is a one-coat system with dry time of 12 hours under room temperature conditions. Elevating temperature of substrate will accelerate recoat time. Brush may be used for touch up, but is not recommended for full application, except for under $500 \mathrm{ft}^{2}$. (See Application Specifications \& Instructions)

The information contained is offered without charge for technically qualified personnel at their discretion and risk. All statements, technical information and recommend ations contained herein are based on tests and data which we believe to be reliable, but the accuracy or completeness thereof is not guaranteed and no warranty of any kind is made wen respect thereto. We guarantee our products to conform to Capstone Mig. quality control Since conditions and methods of application are beyond our contro GOODS OR THE PERFCPUANCE OF THE GOODS AND MAKES NO DARPANTIES OF FITNESS FORA PARTICULAR PURPOSE OR MERCHANTAQUTTYUNESS OTHERMMSE STATED IN WRITING BY AN OFFICER OF CAPSTONE. Liability, if any, is limited to replacement of products. Data may be modified without prior notice.

Capstone Mfg. $\cdot 18225-47^{\text {th }}$ Place NE・Seattle, WA 98155 Phone 206.363.5010•FAX 206.364.5183 •mlantz@nwlink.com 
MATERIAL SAFETY DATA SHEET

I. CHEMICAL PRODUCT INFORMATION

PRODUCT NAME: TC Ceramic and TC Ceramic HB

Capstone Manufacturing LLC

$18225-47^{\text {th }}$ Place NE

Seattle, WA 98155

206-363-5010, FAX 206-364-5183

II. HAZARDOUS INGREDIENTS

INGREDIENT(S):

Ammonia

Acrylate esters

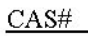

CAS\#

7664-41-7

Mixture

OSHA PEL

$50 \mathrm{ppm}$

Unknown

Effective Date

$01 / 02 / 2007$

This MSDS complies with the OSHA Communication Standard (29 CFR 1910.1200). Unlisted ingredients are not 'Hazardous' per this OSHA Standard and are considered to be trade secrets of Capstone Manufacturing. LLC. Consult Section 12 for the nature of the hazard(s).

\section{PRECAUTIONARY INFORMATION}

Product not considered hazardous under normal conditions. Direct contact of product with eye can cause irritation. Prolonged or repeated contact with skin may cause irritation.

\section{EMERGENCY AND FIRST AID PROCEDURES}

EYE: $\quad$ Flush immediately with water for 15 minutes. Consult a phy sician if irritation persists.

SKIN: $\quad$ Wash affected area with soap and water. Wash contaminated clothing before reuse.

INHALED: Remove subject to fresh air.

FIRE: Product is non-flammable in the liquid state. Use water spray, foam, dry chemical or carbon dioxide on dried product.

SPILL: Collect and remove using inert absorbent. Contain spill to prevent entering sewers. Notify appropriate agencies.

\section{PERSONAL PROTECTION EQUIPMENT}

EYE: Wear chemical safety goggles to reduce the potential for eye contact. Eye wash fountain should be available.

SKIN: $\quad$ Impermeable chemical gloves and wear appropriate protective clothing. Launder contaminated clothing before reusing

RESPIRATORY: Respiratory protection is not normally required. Use NIOSH/MSHA approved respirator if conditions warrant

VENTILATION: Standard industrial ventilation is recommended.

\section{FIRE PROTECTION}

FLASH POINT: Non-flammable

Extinguishing MEdia: Non-flammable in liquid state: use water spray, foam, dry chemical. Use carbon dioxide on dried product.

UNUSUAL FIRE AND EXPLOSION HAZARD: Personnel exposed to products of combustion should wear selfcontained breathing apparatus and full protective equipment. Containers exposed in a fire should be cooled with water to prevent vapor pressure buildup leading to a rupture.

\section{REACTIVITY INFORMATION}

STABILITY: Stable.

INCOMPATIBILITY: Not Established.

HAZARDous DECOMPOSITION PRODUCTS: Combustion of the dried product can yield low molecular weight hy drocarbons such as carbon monoxide and carbon dioxide.

HAZARDOUS POLYMERIZATION: Will not occur.

\section{EFFECT OF OVEREXPOSURE}


EYES: Eye contact with liquid may cause irritation.

SKIN: Repeated or prolonged skin contact with liquid may cause irritation.

INHALATION: No expected effects.

CHRONIC: No anticipated effects. This product does not contain regulated levels of NTP, IARC or OSHA listed carcinogens.

EXISTING HEALTH CONDITIONS AFFECTED By EXPOSURE: No known effects on other illnesses.

\section{PHYSICAL DATA}

Physical STAte: Liquid

WEIGHT / GALLON: $5.6 \mathrm{lbs}$.

SOLIDS: $80 \%+/-1 \%$ by volume

PH: $8.5-9.5$

VISCOSITY (BROOKFIELD): $3564+/-100 \mathrm{cps,}$

BOLING POINT: $>220^{\circ} \mathrm{F}$

SOLUBIITY IN WATER: Dilutable

\section{$\mathrm{X}$ SPILL AND DISPOSAL INFORMATION}

SMALL SPILLS: Should be contained using absorbent material, such as clay, soil, or any commercially available absorbent. Shovel reclaimed liquid and absorbent into recovery or salvage drums for disposal.

LARGE SPLLL: Should be diked to prevent further movement and reclaim into recovery or salvage drums for disposal.

DISPOSAL: This product does not meet the definition of hazardous waste under the US EPA Hazardous Waste Regulations 40 CFR 261. Consult y our state or local authorities for proper disposal in the event more restrictive requirements apply.

\section{STORAGE}

Protect from freezing - product stability may be affected.

\section{REGULATORY INFORMATION}

TOSCA: This product meets the compositional requirements of the Toxic Substances Control Act and contains only chemical ingredients that are listed on the TOSA inventory.

\section{SARA TITLE III, SECTION 313:}

This product does not contain toxic chemical(s) at or above the minimum concentrations subject to the reporting requirements of section 313 of Title III of the Superfund Amendments and Reauthorization Act of 1986 (SARS) and $40 \mathrm{CFR}$ part 372

CHEMICAL NAME

NA

\section{CAS NUMBER}

NA

\section{PERCENT}

ABBREVIATIONS:

NA - Not Applicable, NE - Not Established, NSR - No Special Requirement, ND - Not Determined

\section{DISCLAIMER}

All information appearing herein is based upon data obtained from the manufacturer and/or recognized technical sources. While the information is believed to be accurate, Capstone Manufacturing, LLC makes no representation as to its accuracy or sufficiency. Conditions of use are bey ond Capstone Manufacturing, LLC control, and therefore users determine whether the product is suitable for their particular purposes and assume all risks of their use, handling, and disposal of the product, or from the publication, use of or reliance upon information contained herein. This information relates only to the products designated herein. 


\section{Appendix C: Thermal Conductivity Testing of Ceramic-Filled Coating}

\section{Introduction}

The objective of this technical project is to determine the thermal conductivity of a ceramic porous coating on heat distribution steel pipes. The experimental setup was designed to acquire experimental data from a test rig, which to evaluate the porous layer's performance using the properties of prototypical materials used in the field.

In this report, a physical model representing the experiment to determine the thermal conductivity of the porous layer and its effective heat transfer coefficient are modeled analytically. Although solutions for these relations are obtained, the experimental data is utilized to evaluate the heat transfer coefficient and thermal conductivity.

The report includes sections on: physical model, analytical solutions, data analysis and results. The physical setup is shown in Figure 1, and the data are included in the appendix.

\section{Physical Model}

The heat transfer equations, which describe the whole heat transfer system in the experiment, are the following,

$$
\begin{aligned}
& q^{\prime \prime}=h_{\text {cond }}\left(T_{s a t}-T_{w, i}\right) \\
& q^{\prime \prime}=k_{s} \frac{\left(T_{w, i}-T_{w, o}\right)}{\delta_{w}} \\
& q^{\prime \prime}=k_{p} \frac{\left(T_{w, o}-T_{p, o}\right)}{\delta_{p}} \\
& q^{\prime \prime}=h_{\text {conv }}\left(T_{p, o}-T_{c}\right)
\end{aligned}
$$

By solving simultaneously these four equations, the thermal conductivity is obtained.

\section{Pre-Solutions}

\subsection{Determination of heat flux, $q$ "}

Considering that the water temperature inside the pipe is constant at the saturation temperature, and that the water temperature in the insulated container is relatively uniform, and then it can be assumed that the heat flux is uniformly distributed on the pipe surface. That means, the q" is not a function of position, but only a function of time, $t$. 


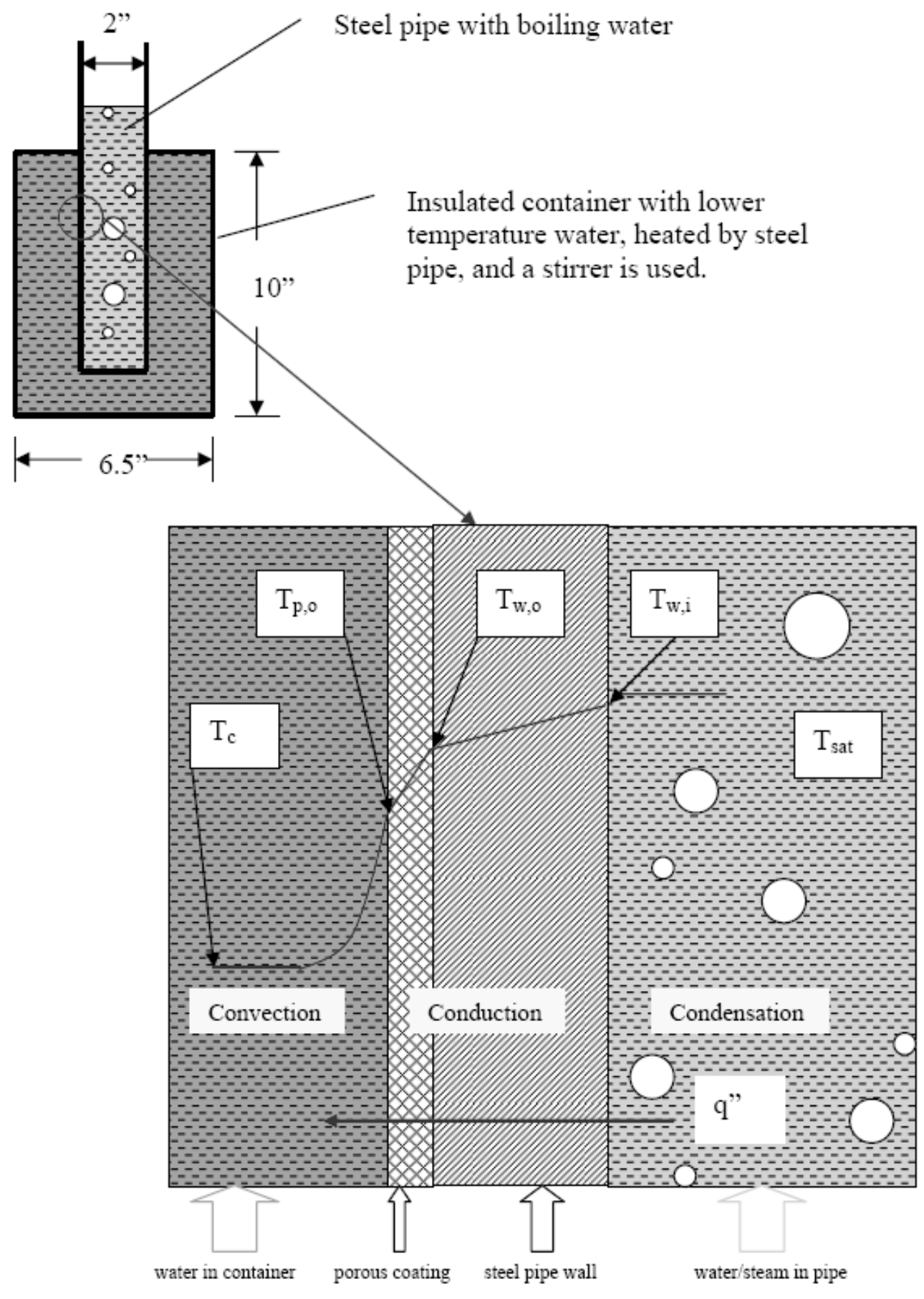

Figure 1. Schematic of the experimental test facility 
In any time interval between minute $\mathrm{N}$ and minute $\mathrm{N}+1$, all energy (heat) passing through the pipe interface heats the water inside the insulated container. So,

$$
Q=q^{\prime \prime} \cdot A \cdot \Delta t=C_{p} \cdot \rho \cdot V \cdot \Delta T_{c}
$$

where, $\mathrm{Q}$ is the heat absorbed by water in the container during the time interval between minute $\mathrm{N}$ and minute $\mathrm{N}+1$. A is the immersion area, $68.78 \mathrm{sq}$. in. $\Delta \mathrm{t}$ is the time interval, 1 minute. $\mathrm{Cp}$ and $\rho$ are the specific heat capacity and density of water, respectively. V is the volume of water in the container. $\Delta \mathrm{Tc}$ is the temperature difference of water in the container from minute $\mathrm{N}$ to minute $\mathrm{N}+1$.

Using equation [5], the heat flux at any time can be calculated from the experimental data.

\subsection{Determination of pipe wall temperatures, $T_{w, i}$ and $T_{w, o}$}

To calculate $T_{w, i}$, it is necessary to find the condensation heat transfer coefficient, $h_{\text {cond, }}$, from equation [1]. Condensation is a kind of heat transfer mechanism with very high efficiency, often even higher than boiling heat transfer.

So, we can assume that, the temperature difference between water in pipe and the inner side pipe wall temperature, $T_{w, i}$, is very small, which means $T_{w, i}$ can be approximately set to $T_{5 a t}$.

Then, the outside pipe wall temperature, $T_{w, 0}$, can be calculated by using the equation [2].

\subsection{Determination of convection heat transfer coefficient, $h_{\text {conv }}$}

\subsubsection{Analytical method}

Before we can solve the equation [3] to find the thermal conductivity of the porous coating, we need to know the outside porous coating temperature, $T_{p, o}$, which can be calculated by considering the equation [4].

In equation [4], there is still an unknown, $\mathrm{h}_{\text {conv }}$, which we need to find by considering experimental data sets 1 and 2 (the no-coating cases). In these two cases, the heat transfer equations become,

$$
\begin{aligned}
& q^{\prime \prime}=h_{\text {cond }}\left(T_{s a t}-T_{w, i}\right) \\
& q^{\prime \prime}=k_{s} \frac{\left(T_{w, i}-T_{w, o}\right)}{\delta_{w}} \\
& q^{\prime \prime}=h_{\text {conv }}\left(T_{w, o}-T_{c}\right)
\end{aligned}
$$

where, q" can be determined by the method presented in section 2.1 and where $\mathrm{k}_{\mathrm{s}}$ is the thermal conductivity of steel, which can be found from standard heat transfer or material reference books. $\mathrm{T}_{\mathrm{w}, \mathrm{o}}$ can be calculated from equation [7], and then, $\mathrm{h}_{\mathrm{couv}}$ can be determined from equation [8]. 


\subsubsection{Mathematical method}

By using the analytical method in section 2.3.1, the convection heat transfer coefficient can be determined at any time from the data set. However, this can introduce very large errors in the calculation because of uncertainty of the data collected from the experiments. Alternatively, estimates of the values of $\mathrm{h}_{\text {conv }}$ can be predicted directly using the analytical procedure for selected times from the initiation of the process.

In order to reduce the error, another method of estimating the heat transfer coefficient can be used. In this method, how the water temperatures vary with time need to be known, that is, a time varying curve of water temperature. However, before that, some analytical work is necessary.

Because $T_{w, i}$ is almost the same as $T_{5}$, equation [7] can be approximated as:

$q^{\prime \prime}=k_{s} \frac{\left(T_{s}-T_{w, o}\right)}{\delta_{w}}$

which gives,

$T_{w, o}=T_{s}-\frac{q^{\prime \prime} \delta_{w}}{k_{s}}$

Substituting equation [10] into equation [8], gives,

$q^{\prime \prime}=h_{\text {conv }}\left(T_{s}-\frac{q^{\prime \prime} \delta_{w}}{k_{s}}-T_{c}\right)$

And rewriting equation [11] as,

$q^{\prime \prime}=\frac{k_{s}}{k_{s}+h_{\text {conv }} \delta_{w}} h_{\text {conv }}\left(T_{s}-T_{c}\right)$

Then from equation [5], q" can be written as,

$q^{\prime \prime}=\frac{C_{p} \rho V}{A} \frac{\Delta T_{c}}{\Delta t}$

which, in an approximated differential form, is,

$q^{\prime \prime}=\frac{C_{p} \rho V}{A} \frac{d T_{c}}{d t}$

Now, equating equations [12] and [16] produces,

$\frac{k_{s}}{k_{s}+h_{\text {conv }} \delta_{w}} h_{\text {conv }} d t=\frac{C_{p} \rho V}{A} \frac{d T_{c}}{\left(T_{s}-T_{c}\right)}$ 
Integrate equation [17] from $t_{0}$ (the starting time) to $t$ (the selected time), and using $T_{c, 0}$ (initial water temperature in container, corresponding to $\left.t_{0}\right)$ to $T_{c}$ (its corresponding temperature at $t$ ), leads to,

$$
\begin{aligned}
& \frac{k_{s}}{k_{s}+h_{\text {conv }} \delta_{w}} h_{c o n v} \int_{t_{0}}^{t} d t=\frac{C_{p} \rho V}{A} \int_{I_{c, 0}}^{T_{s}} \frac{d T_{c}}{\left(T_{s}-T_{c}\right)} \\
& \frac{k_{s} h_{\text {conv }}}{k_{s}+h_{\text {conv }} \delta_{w}}\left(t-t_{0}\right)=\left.(-1) \frac{C_{p} \rho V}{A} \ln \left(T_{s}-T_{c}\right)\right|_{I_{e, 0}} ^{T_{e}} \\
& \frac{k_{s} h_{\text {conv }}}{k_{s}+h_{\text {conv }} \delta_{w}}\left(t-t_{0}\right)=(-1) \frac{C_{p} \rho V}{A}\left[\ln \left(T_{s}-T_{c}\right)-\ln \left(T_{s}-T_{c, 0}\right)\right] \\
& =(-1) \frac{C_{p} \rho V}{A} \ln \left(\frac{T_{s}-T_{c}}{T_{s}-T_{c .0}}\right)
\end{aligned}
$$

A non-dimensional form can be obtained by defining the following variables:

Non-dimensional temperature, $\theta$,

$$
\theta=\frac{T_{s}-T_{c}}{T_{s}-T_{c, 0}}
$$

Non-dimensional time, $\tau$,

$$
\tau=\frac{t-t_{0}}{t_{e}-t_{0}}
$$

where $t_{e}$ is the end time of the experiment.

The non-dimensional equation for $\theta$ and $\tau$ is obtained from equation [20],

$$
\ln \theta=-C_{0} \tau
$$

where,

$$
C_{0}=\frac{k_{s} h_{\text {conv }}\left(t_{e}-t_{0}\right)}{k_{s}+h_{\text {conv }} \delta_{w}} \frac{A}{C_{p} \rho V}
$$

The value of $\mathrm{C}_{0}$ can be obtained by plotting the non-dimensional temperature $\theta$ and nondimensional time $\tau$ on a log-linear scale display, and estimating the slope of the curve. After that, the convective heat transfer coefficient can be obtained from,

$$
h_{\text {conv }}=\frac{1}{\frac{A\left(t_{e}-t_{0}\right)}{C_{0} C_{p} \rho V}-\frac{\delta_{w}}{k_{s}}}
$$

It must be noticed that, when experimental time approaches the end time, the error becomes large. This is because the amount of heat lost from the container surface becomes not trivial, and finally it is equal to the amount of heat gained from the boiling pipe. Therefore, in the procedure of curve fitting, the data approaching end of experiment should be ignored. 
Figure 2 shows the curve fitting for a nonporous layer case. The slope is obtained from

Figure 2 as,

$-C_{0}=-2.09$

Parameters in equation [25] are as follows,

$A=68.78$ sq. in.$=4.437 \times 10^{-2} \mathrm{~m}^{2}$

$t_{e}-t_{0}=3600-60=3540 \mathrm{~s}$

$C_{p}=4185 \mathrm{~J} /(\mathrm{kg} \cdot \mathrm{K})$

$\rho=970 \mathrm{~kg} / \mathrm{m}^{3}$

$T_{s}-T_{c, 0}=100-68=32^{\circ} \mathrm{C}=32 \mathrm{~K}$

$V=4900 \mathrm{ml}=4.9 \times 10^{-3} \mathrm{~m}^{3}$

$\delta_{w}=r_{o}-r_{i}=0.03016-0.02625=0.00391 \mathrm{~m}$

$k_{s}=40 \mathrm{~W} / \mathrm{m} \cdot \mathrm{K}$

Substitute all these values into equation [25], and the value of the convective heat transfer coefficient is obtained as,

$$
\begin{aligned}
h_{\text {conv }} & =\frac{1}{2.092 \times 4185\left[\frac{\mathrm{J}}{\mathrm{kg} \cdot \mathrm{K}}\right] \times 970\left[\frac{\mathrm{kg}}{\mathrm{m}^{3}}\right] \times 4.9 \times 10^{-3}\left[\mathrm{~m}^{3}\right]}-\frac{0.00391[\mathrm{~m}]}{40\left[\frac{\mathrm{W}}{\mathrm{m} \cdot \mathrm{K}}\right]} \\
& =272.0\left[\frac{\mathrm{W}}{\mathrm{m}^{2} \cdot \mathrm{K}}\right]
\end{aligned}
$$

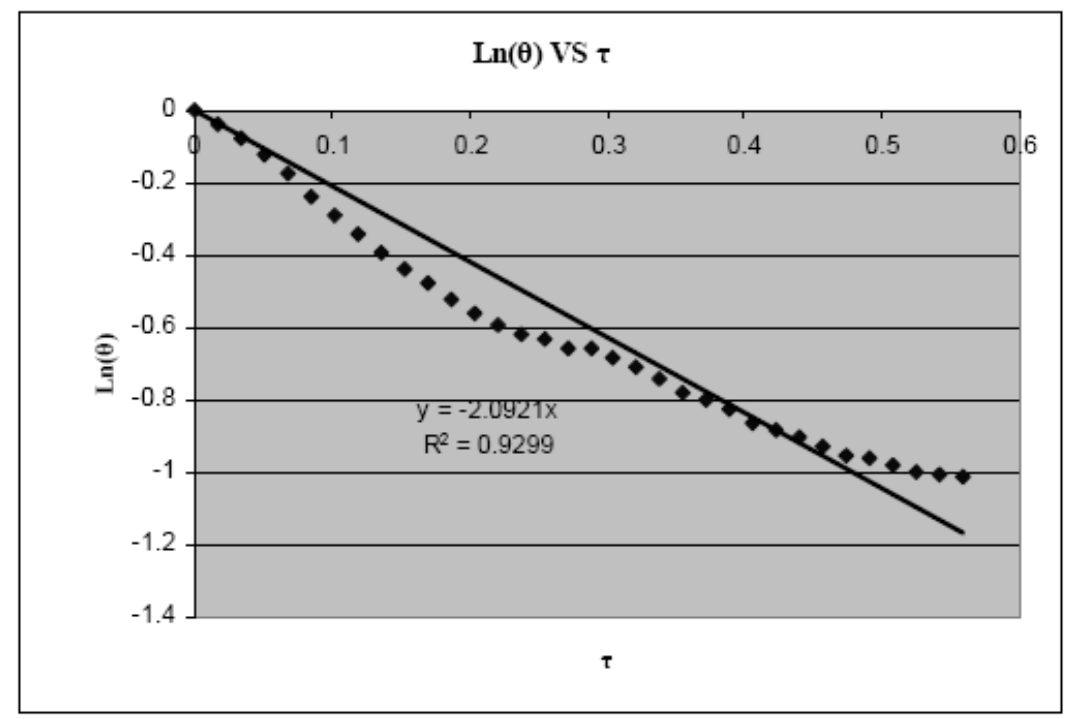

Figure 2. Linear curve fitting for no porous deposition case 


\section{Solutions}

In this section, the solutions of this problem will be given.

Equations [1-4] will be used to estimate the thermal conductivity of the porous coating.

$$
\begin{aligned}
& q^{\prime \prime}=h_{\text {cond }}\left(T_{s a t}-T_{w, i}\right) \\
& q^{\prime \prime}=k_{s} \frac{\left(T_{w, i}-T_{w, o}\right)}{\delta_{w}} \\
& q^{\prime \prime}=k_{p} \frac{\left(T_{w, o}-T_{p, o}\right)}{\delta_{p}} \\
& q^{\prime \prime}=h_{\text {conv }}\left(T_{p, o}-T_{c}\right)
\end{aligned}
$$

Equation [2] can be approximated as,

$$
q^{\prime \prime}=k_{s} \frac{\left(T_{s}-T_{w, o}\right)}{\delta_{w}}
$$

which gives,

$$
T_{w, o}=T_{s}-\frac{q^{\prime \prime} \delta_{w}}{k_{s}}
$$

Equation [4] gives,

$$
T_{p, o}=\frac{q^{\prime \prime}}{h_{c o n v}}+T_{c}
$$

Substituting equations [26] and [27] into equation [3], gives,

$$
q^{\prime \prime}=\frac{k_{p}}{\delta_{p}}\left(T_{s}-\frac{q^{\prime \prime} \delta_{w}}{k_{s}}-\frac{q^{\prime \prime}}{h_{\text {conv }}}-T_{c}\right)
$$

Rewriting equation [29] as,

$$
q^{\prime \prime}=\frac{1}{\left[1+\frac{k_{p}}{\delta_{p}}\left(\frac{\delta_{w}}{k_{s}}+\frac{1}{h_{\text {conv }}}\right)\right]} \frac{k_{p}}{\delta_{p}}\left(T_{s}-T_{c}\right)
$$


and combining with equation [16] yields,

$q^{\prime \prime}=\frac{C_{p} \rho V}{A} \frac{d T_{c}}{d t}$

We now have,

$$
\frac{1}{\left[1+\frac{k_{p}}{\delta_{p}}\left(\frac{\delta_{w}}{k_{s}}+\frac{1}{h_{\text {conv }}}\right)\right]} \frac{k_{p}}{\delta_{p}} d t=\frac{C_{p} \rho V}{A} \frac{d T_{c}}{\left(T_{s}-T_{c}\right)}
$$

Integrating equation [32], similar to that in section 2.3.2, yields,

$\ln \left(\frac{T_{s}-T_{c}}{T_{s}-T_{c .0}}\right)=(-1) \frac{A}{C_{p} \rho V} \frac{\left(t_{e}-t_{0}\right)}{\left[\frac{\delta_{p}}{k_{p}}+\frac{\delta_{w}}{k_{s}}+\frac{1}{h_{c o n v}}\right]} \frac{\left(t-t_{0}\right)}{\left(t_{e}-t_{0}\right)}$.

Similar to equation [20], equation [33] can be non-dimensionalized by using non-dimensional variables $\theta$ and $\tau$, as defined in equations [21] and [22], giving

$\ln \theta=-C_{1} \tau$

where,

$$
C_{1}=\frac{A}{C_{p} \rho V} \frac{\left(t_{e}-t_{0}\right)}{\left[\frac{\delta_{p}}{k_{p}}+\frac{\delta_{w}}{k_{s}}+\frac{1}{h_{c o n v}}\right]} .
$$

And, then the thermal conductivity of porous coating can be calculated from equation [34] as,

$$
k_{p}=\frac{\delta_{p}}{\frac{A\left(t_{e}-t_{0}\right)}{C_{1} C_{p} \rho V}-\frac{\delta_{w}}{k_{s}}-\frac{1}{h_{\text {cowv }}}} .
$$

The four sets of experimental data are plotted in Figure 2. To reduce the error, parts of the data are ignored. As shown in Figure 3, the $\mathrm{x}$-axis represents the non-dimensional time, $\tau$, and the $\mathrm{y}$ axis represents the logarithm of non-dimensional temperature, $\operatorname{Ln}(\theta)$. The values of slop, $C_{1}$, and goodness of fit, $\mathrm{R}^{2}$, for these four sets of data, and corresponding calculated thermal conductivity of each porous coating are listed in Table 1. 


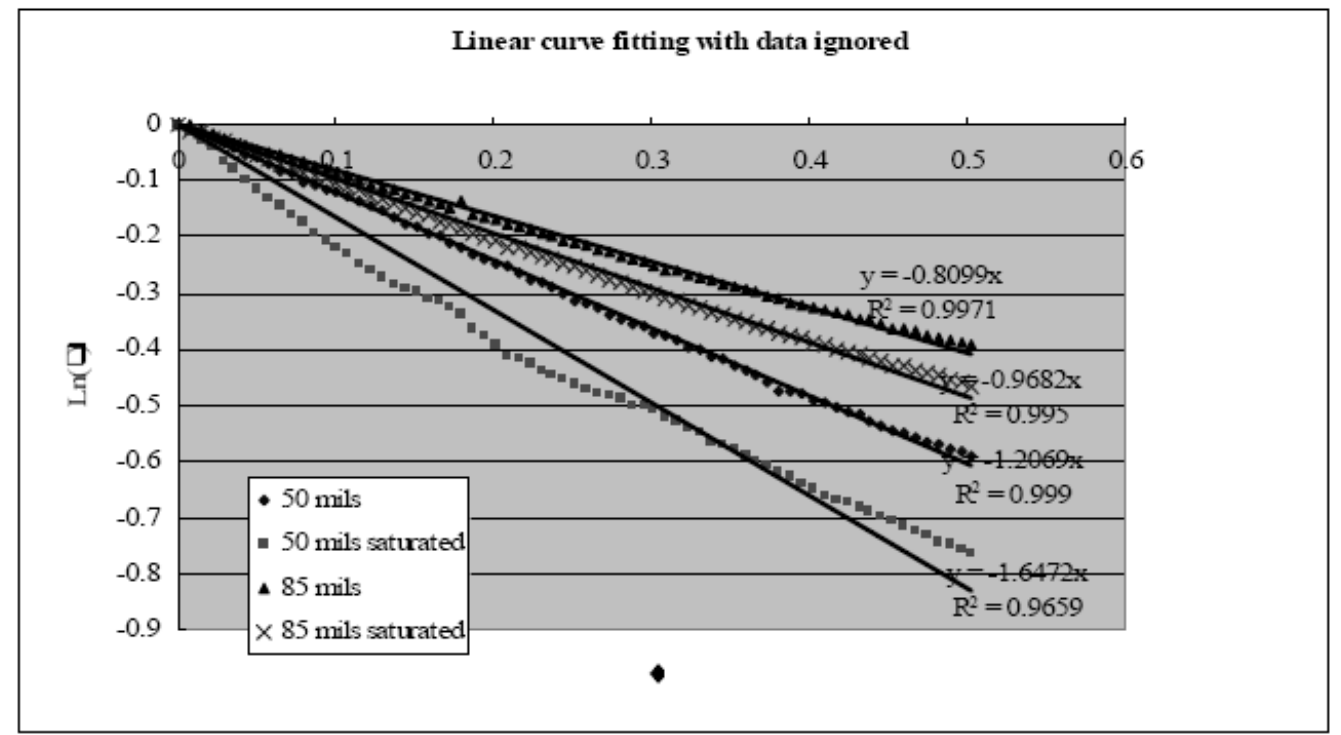

Figure 3. Linear curve fitting for experimental data with data nearing the end of the experiment being ignored

Table 1. Values of slop and calculated porous coating thermal conductivities

\begin{tabular}{|l|c|c|}
\hline \multicolumn{1}{|c|}{ Data Set } & Slop Value & Thermal Conductivity (W/K/m) \\
\hline 50 mils non-saturated & 1.2069 & 0.1091 \\
\hline 50 mils saturated & 1.6472 & 0.1689 \\
\hline 85 mils non-saturated & 0.8099 & 0.1125 \\
\hline 85 mils saturated & 0.9682 & 0.1398 \\
\hline
\end{tabular}

\section{Results and Discussion}

An analytical method is presented, which can estimate the value of thermal conductivity for porous coatings at selected times during the experimental run. However, the error in this direct determination could be very large and, therefore, another curve fitting method is suggested to estimate the thermal conductivity value for porous coating, which results in considerably smaller error. To reduce the error, two non-dimensional variables, temperature and time, are used in this study, and the experimental data are plotted in these non-dimensional units. Different thermal conductivity values for porous coating are obtained from four sets of experiments, two nonsaturated and two saturated porous coatings. The four values are: $0.1091 \mathrm{~W} / \mathrm{m} / \mathrm{K}$ for 50 mils non-saturated porous coating, $0.1689 \mathrm{~W} / \mathrm{m} / \mathrm{K}$ for 50 mils saturated porous coating, 0.1125 $\mathrm{W} / \mathrm{m} / \mathrm{K}$ for 85 mils non-saturated porous coating, and $0.1398 \mathrm{~W} / \mathrm{m} / \mathrm{K}$ for 85 mils saturated porous coating. The error between the two sets of normal (non-saturated condition) experimental condition is $3.12 \%$, and the error between the two sets of saturated porous coating condition is $20.82 \%$.

It is worth noting that the thermal conductivity of saturated porous coatings is higher than that of non-saturated porous coatings. The average thermal conductivity of saturated porous coating is calculated as $0.1544 \mathrm{~W} / \mathrm{m} / \mathrm{K}$, and the average thermal conductivity of non-saturated porous coating is calculated as $0.1108 \mathrm{~W} / \mathrm{m} / \mathrm{K}$. The former value is about $39.35 \%$ higher than the later one, which indicates a higher thermal conductivity for saturated porous coating. 


\section{Appendix - Experimental data}

Table 2. Experimental data

\begin{tabular}{|c|c|c|c|c|c|c|}
\hline Minutes & $\begin{array}{c}\text { Primed } \\
\text { Metal } \\
\left({ }^{\circ} \mathrm{C}\right)\end{array}$ & $\begin{array}{l}\text { Primed } \\
\text { Metal } \\
\text { (Dup) } \\
\left({ }^{\circ} \mathrm{C}\right)\end{array}$ & $\begin{array}{c}\text { Ceramic } \\
\text { coating } \\
50 \text { mils } \\
\left({ }^{\circ} \mathrm{C}\right)\end{array}$ & $\begin{array}{c}\text { Ceramic } \\
\text { coating } \\
50 \text { mils - } \\
\text { Saturated } \\
\left({ }^{\circ} \mathrm{C}\right)\end{array}$ & $\begin{array}{c}\text { Ceramic } \\
\text { coating } \\
85 \text { mils } \\
\left({ }^{\circ} \mathrm{C}\right)\end{array}$ & $\begin{array}{c}\text { Ceramic } \\
\text { coating } \\
85 \text { mils - } \\
\text { Saturated } \\
\left({ }^{\circ} \mathrm{C}\right)\end{array}$ \\
\hline 1 & 68.0 & 68.0 & 25.8 & 25.8 & 22.2 & 21.5 \\
\hline 2 & 69.8 & 69.2 & 26.0 & 26.6 & 22.3 & 22.5 \\
\hline 3 & 71.2 & 70.4 & 26.7 & 27.8 & 22.9 & 22.6 \\
\hline 4 & 72.8 & 71.7 & 27.4 & 28.8 & 23.6 & 23.5 \\
\hline 5 & 74.0 & 73.2 & 28.2 & 30.6 & 24.0 & 23.7 \\
\hline 6 & 75.6 & 74.8 & 28.9 & 31.4 & 24.8 & 24.5 \\
\hline 7 & 77.0 & 76.0 & 29.6 & 32.8 & 25.0 & 25.0 \\
\hline 8 & 78.1 & 77.2 & 30.0 & 33.8 & 25.7 & 25.6 \\
\hline 9 & 79.2 & 78.4 & 30.7 & 35.0 & 26.1 & 26.2 \\
\hline 10 & 80.3 & 79.3 & 31.7 & 35.9 & 26.4 & 26.8 \\
\hline 11 & 81.0 & 80.2 & 32.1 & 36.8 & 26.9 & 27.2 \\
\hline 12 & 81.7 & 81.0 & 33.0 & 37.6 & 27.3 & 27.9 \\
\hline 13 & 82.3 & 81.8 & 33.3 & 38.8 & 27.8 & 28.2 \\
\hline 14 & 83.0 & 82.3 & 33.9 & 39.6 & 28.2 & 28.7 \\
\hline 15 & 83.6 & 82.8 & 34.1 & 40.4 & 28.6 & 29.1 \\
\hline 16 & 83.8 & 83.0 & 34.6 & 41.1 & 29.0 & 29.7 \\
\hline 17 & 84.1 & 83.4 & 35.2 & 42.0 & 29.4 & 30.2 \\
\hline 18 & 84.7 & 83.4 & 35.9 & 42.9 & 30.0 & 30.9 \\
\hline 19 & 85.2 & 83.8 & 36.4 & 43.4 & 30.4 & 31.3 \\
\hline 20 & 85.7 & 84.3 & 37.0 & 44.1 & 30.8 & 31.9 \\
\hline 21 & 86.2 & 84.8 & 37.8 & 44.7 & 31.2 & 32.4 \\
\hline 22 & & 85.3 & 38.2 & 44.9 & 31.6 & 32.9 \\
\hline 23 & & 85.6 & 38.8 & 45.5 & 32.1 & 33.2 \\
\hline 24 & & 86.0 & 39.2 & 45.8 & 32.5 & 33.9 \\
\hline 25 & & 86.5 & 39.8 & 46.5 & 32.9 & 34.3 \\
\hline 26 & & 86.8 & 40.5 & 47.2 & 32.2 & 34.8 \\
\hline 27 & & 87.0 & 41.0 & 48.3 & 33.7 & 35.3 \\
\hline 28 & & 87.4 & 41.7 & 49.0 & 34.1 & 35.8 \\
\hline 29 & & 87.7 & 42.0 & 49.8 & 34.4 & 36.2 \\
\hline 30 & & 87.8 & 42.3 & 50.8 & 34.8 & 36.8 \\
\hline 31 & & 88.0 & 43.0 & 51.2 & 35.1 & 37.0 \\
\hline 32 & & 88.2 & 43.7 & 51.6 & 35.5 & 37.4 \\
\hline 33 & & 88.3 & 44.0 & 52.0 & 35.9 & 38.0 \\
\hline 34 & & 88.4 & 44.4 & 52.5 & 36.2 & 38.3 \\
\hline 35 & & 88.8 & 45.0 & 52.9 & 36.7 & 38.8 \\
\hline 36 & & 88.8 & 45.7 & 53.2 & 37.0 & 39.1 \\
\hline
\end{tabular}




\begin{tabular}{|c|c|c|c|c|c|}
\hline 37 & 88.9 & 46.0 & 53.6 & 37.2 & 39.6 \\
\hline 38 & 89.0 & 46.5 & 54.0 & 37.7 & 40.0 \\
\hline 39 & 89.2 & 47.0 & 54.3 & 38.0 & 40.4 \\
\hline 40 & 89.2 & 47.5 & 54.5 & 38.4 & 40.8 \\
\hline 41 & 89.2 & 48.0 & 55.0 & 38.7 & 41.1 \\
\hline 42 & 89.3 & 48.2 & 55.0 & 39.1 & 41.6 \\
\hline 43 & 89.3 & 48.8 & 55.4 & 39.4 & 42.0 \\
\hline 44 & 89.3 & 49.1 & 55.9 & 39.9 & 42.3 \\
\hline 45 & 89.5 & 49.5 & 56.2 & 40.1 & 42.7 \\
\hline 46 & 89.6 & 50.0 & 56.8 & 40.4 & 43. \\
\hline 47 & 89.7 & 50.3 & 57.2 & 40.8 & 43.4 \\
\hline 48 & 89.7 & 50.8 & 57.8 & 41.1 & 43. \\
\hline 49 & 89.7 & 51.2 & 58.0 & 41.4 & 44.1 \\
\hline 50 & 89.7 & 51.7 & 58.3 & 41.7 & 44.5 \\
\hline 51 & 89.7 & 52.0 & 58.8 & 42.0 & 44.8 \\
\hline 52 & 89.7 & 52.5 & 59.2 & 42.3 & 45.1 \\
\hline 53 & 89.7 & 53.1 & 59.6 & 42.6 & 45 \\
\hline 54 & 89.7 & 53.8 & 60.0 & 43.0 & 45.8 \\
\hline 55 & 89.7 & 53.8 & 60.4 & 43.3 & 46. \\
\hline 56 & 89.7 & 54.1 & 60.8 & 43.6 & 46.4 \\
\hline 57 & 89.7 & 54.6 & 61.2 & 43.8 & 46 \\
\hline 58 & 89.7 & 54.8 & 61.6 & 44.1 & 47.0 \\
\hline 59 & 89.7 & 55.2 & 62.0 & 44.4 & 47.3 \\
\hline 60 & 89.7 & 55.6 & 62.1 & 44.6 & 47.7 \\
\hline 61 & & 55.8 & 62.4 & 44.9 & 47.9 \\
\hline 62 & & 56.2 & 62.7 & 45.1 & 48. \\
\hline 63 & & 56.6 & 63.1 & 45.4 & 48.5 \\
\hline 64 & & 56.9 & 63.4 & 45.8 & 48. \\
\hline 65 & & 57.2 & 63.7 & 46.0 & 49.0 \\
\hline 66 & & 57.5 & 64.0 & 46.2 & 49.4 \\
\hline 67 & & 57.8 & 64.3 & 46.5 & 49. \\
\hline 68 & & 58.0 & 64.7 & 46.8 & 49.8 \\
\hline 69 & & 58.3 & 64.9 & 47.0 & 50. \\
\hline 70 & & 58.6 & 65.2 & 47.2 & 50.4 \\
\hline 71 & & 58.9 & 65.4 & 47.5 & 50.8 \\
\hline 72 & & 59.2 & 65.9 & 47.8 & 50.9 \\
\hline 73 & & 59.5 & 65.9 & 48.0 & 51.2 \\
\hline 74 & & 59.8 & 66.2 & 48.2 & 51. \\
\hline 75 & & 60.0 & 66.4 & 48.5 & 51.7 \\
\hline 76 & & 60.2 & 66.8 & 48.8 & 51.9 \\
\hline 77 & & 60.5 & 66.9 & 49.0 & 52. \\
\hline 78 & & 60.8 & 67.1 & 49.2 & 52. \\
\hline 79 & & 61.0 & 67.4 & 49.4 & 52.7 \\
\hline 80 & & 61.2 & 67.7 & 49.6 & 53.0 \\
\hline 81 & & 61.5 & 67.8 & 49.9 & 53. \\
\hline
\end{tabular}




\begin{tabular}{|c|c|c|c|c|}
\hline 82 & 61.8 & 67.9 & 50.1 & 53.2 \\
\hline 83 & 62.0 & 68.1 & 50.3 & 53.4 \\
\hline 84 & 62.2 & 68.3 & 50.6 & 53.6 \\
\hline 85 & 62.4 & 68.5 & 50.8 & 53.8 \\
\hline 86 & 62.6 & 68.7 & 51.0 & 54.0 \\
\hline 87 & 63.0 & 69.0 & 51.1 & 54.3 \\
\hline 88 & 63.1 & 69.0 & 51.2 & 54.5 \\
\hline 89 & 63.6 & 69.2 & 51.5 & 54.7 \\
\hline 90 & 63.8 & 69.4 & 51.8 & 54.8 \\
\hline 91 & 63.9 & 69.5 & 51.9 & 55.0 \\
\hline 92 & 64.0 & 69.7 & 52.2 & 55.1 \\
\hline 93 & 64.2 & 69.8 & 52.5 & 55.3 \\
\hline 94 & 64.5 & 69.9 & 52.7 & 55.5 \\
\hline 95 & 64.7 & 70.1 & 52.9 & 55.7 \\
\hline 96 & 64.9 & 70.3 & 53.0 & 55.9 \\
\hline 97 & 65.0 & 70.4 & 53.1 & 56.1 \\
\hline 98 & 65.2 & 70.6 & 53.3 & 56.2 \\
\hline 99 & 65.4 & 70.8 & 53.4 & 56.4 \\
\hline 100 & 65.7 & 70.8 & 53.7 & 56.6 \\
\hline 101 & 65.8 & 71.0 & 53.9 & 56.7 \\
\hline 102 & 66.0 & 71.1 & 54.0 & 56.9 \\
\hline 103 & 66.1 & 71.3 & 54.2 & 57.0 \\
\hline 104 & 66.3 & 71.4 & 54.3 & 57.2 \\
\hline 105 & 66.3 & 71.6 & 54.6 & 57.4 \\
\hline 106 & 66.5 & 71.7 & 54.7 & 57.6 \\
\hline 107 & 66.6 & 71.8 & 54.9 & 57.7 \\
\hline 108 & 66.8 & 71.8 & 55.1 & 57.9 \\
\hline 109 & 67.0 & 71.9 & 55.3 & 58.0 \\
\hline 110 & 67.1 & 72.0 & 55.4 & 58.2 \\
\hline 111 & 67.2 & 72.0 & 55.5 & 58.3 \\
\hline 112 & 67.4 & 72.1 & 55.7 & 58.5 \\
\hline 113 & 67.6 & 72.2 & 55.9 & 58.7 \\
\hline 114 & 67.7 & 72.3 & 56.0 & 58.8 \\
\hline 115 & 68.0 & 72.4 & 56.2 & 58.8 \\
\hline 116 & 68.0 & 72.7 & 56.3 & 59.0 \\
\hline 117 & 68.1 & 72.7 & 56.4 & 59.1 \\
\hline 118 & 68.2 & 72.8 & 56.5 & 59.2 \\
\hline 119 & 68.3 & 72.9 & 56.7 & 59.3 \\
\hline 120 & 68.4 & 72.9 & 56.9 & 59.5 \\
\hline 121 & 68.6 & 73.0 & 57.0 & 59.6 \\
\hline 122 & 68.7 & 73.1 & 57.1 & 59.7 \\
\hline 123 & 68.9 & 73.2 & 57.2 & 59.8 \\
\hline 124 & 68.9 & 73.4 & 57.3 & 59.9 \\
\hline 125 & 69.0 & 73.4 & 57.4 & 60.0 \\
\hline 126 & 69.0 & 73.4 & 57.5 & 60.1 \\
\hline
\end{tabular}


127

128

129

130

131

132

133

134

135

136

137

138

139

140
69.1

69.2

69.2

69.3

69.5

69.6

69.7

69.8

69.8

69.9

70.0

70.0

70.1

70.1
73.5

73.5

73.5

73.6

73.7

73.7

73.8

73.9

73.9

74.0

74.0

74.0

74.1

74.1
57.8

58.0

58.0

58.2

58.3

58.4

58.5

58.6

58.7

58.8

58.9

60.0

60.1

60.2
60.2

60.3

60.4

60.5

60.6

60.8

60.9

61.0

61.1

61.2

61.3

61.4

61.4

61.4 


\title{
Appendix D: Independent Return on Investment (ROI) Analysis
}

\author{
Economic Analysis
}

of the

\section{Heat Distribution System Ceramic Paint Coating At Redstone Arsenal}

\author{
Submitted to \\ US Army Engineer Research and Development Center \\ US Army Construction Engineering Research Laboratory \\ ATTN: Dr. Charles Marsh \\ 2902 Newmark Drive \\ Champaign, Illinois 61822-1076 \\ By \\ The PERTAN Group \\ 44 Main Street, Suite 403 \\ Champaign, Illinois 61820-3636 \\ Phone: 217-356-1348; Fax: 217-356-7961 \\ www.pertan.com
}

May 01, 2008

Final Report 


\section{Executive Summary}

Underground Heat Distribution Systems (HDS) are critical to support the installations' mission at many US Army garrisons. Current maintenance and repair practices reduce their service life considerably. Alternative maintenance and repair practices to extend the economic life of the HDS were tested at Redstone. This analysis compares the costs and benefits of two alternative coating methods with the status quo practice. The two alternative maintenance methodologies contemplate coating the carrier pipes inside the manholes with a coat of corrosion protection primer paint and new insulation. In addition, one of the methodologies contemplates adding two coats of ceramic based paint between the primer and the insulation. The economic analysis found the best alternative is the combination of just primer paint and insulation. This alternative produces a net savings of $\$ 79,794$ per manhole over a 20 -year life cycle, and results in a SIR of 150.3 . However, the analysis also found that it takes 15 years to recover the investment - DPP of 15 years. 
Table of Contents

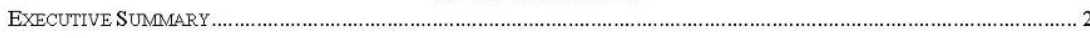

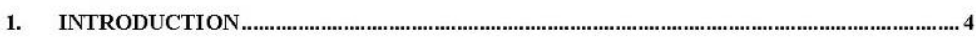

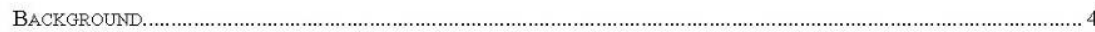

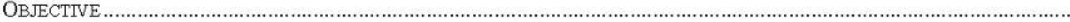

APPROACH

Determine Costs and Benefits.

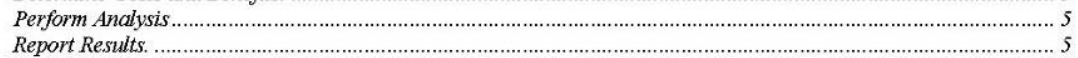

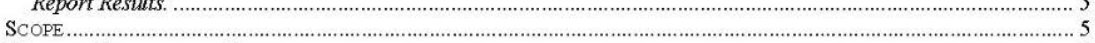

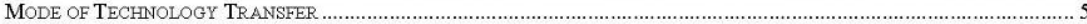

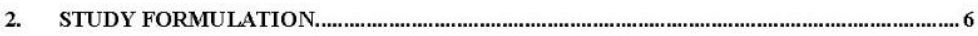

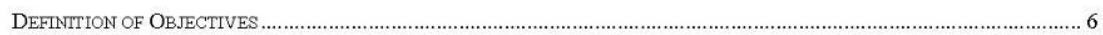
Problem

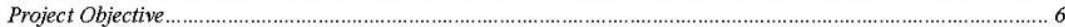

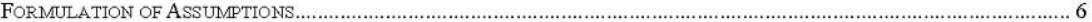

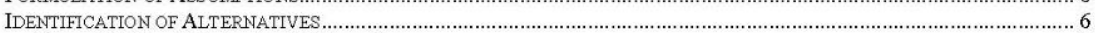

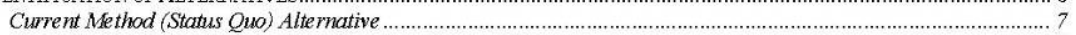

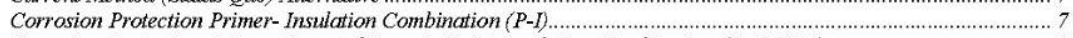

Corrosion Protection Primer-ExpectedCeramic Paint-Insulation Combination (P-ExCP-I) ................................. 7

Corrosion Protection Primer-ActualCeramic Paint-Insulation Combination (P-AcCP-I) ...................................

3. COST AND BENEFITS.................................................................................................... 8

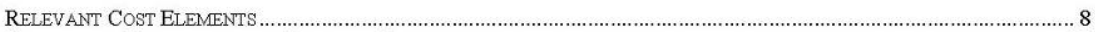

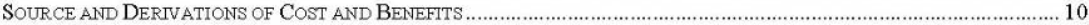

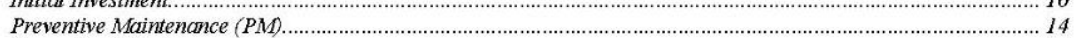

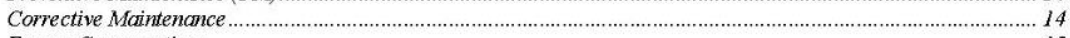

Energy Conservation :

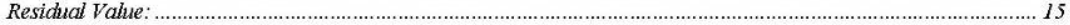

4. COMPARING COST AND BENEFITS ….......................................................................17

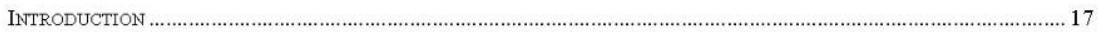

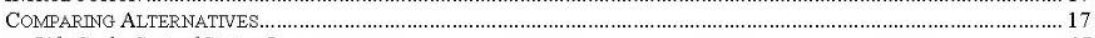

Life Cycle Cost of Status Quo ................................................................................................................. 17

Life Cycle Cost of Corrosion Protection

Life Cycle Cost of Corrosion Protection Primer-ExpectedCeramicPaint-Insulation (P-ExCP-I) Combination 18

Life Cycle Cost of Corrasion Protection Primer-ActualCeramicPaint-Insulation (P-AcCP-I) Combination............. 18

SENSTTIVITY ANALYSIS..

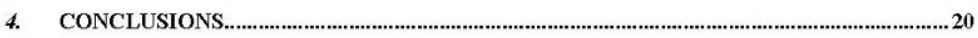

APPENDIX 1: DIFFERENNTIAL COST ANALYSIS OF ANNUAL ENERGY LOSSES THROUGH CARRIER

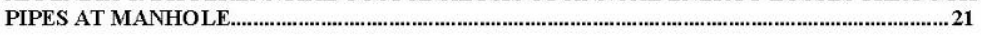

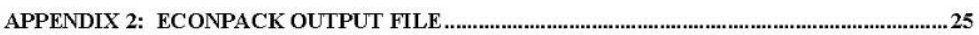




\title{
1. INTRODUCTION
}

\section{Background}

Many U.S. Army installations rely upon central district Heat Distribution Systems (HDS's) to provide heating and hot water to their facilities. Redstone Arsenal has identified HDS as a critical part of the infrastructure to support the installation mission. HDS's are large complex systems made up of numerous components highly interdependent on one another. The deterioration of one component affects the performance and deterioration rate of other nearby components.

Manholes in a HDS house many of the critical components and also connect the different pipe sections of the system. The environment inside the manholes is often hot and humid and hence conducive to corrosion. Carrier pipes inside manholes are usually wrapped with insulation to prevent heat losses and protect service personnel entering the manhole. Water enters the manholes from leaking valves, rain, and ground water ingress. The water then gets trapped into the insulation and in between the insulation and the pipe. This condition makes the corrosive environment around the carrier pipe more severe and speeds the deterioration of the carrier pipe.

The corrosion of the carrier pipe in the manholes has a ripple effect though the other components in the same manhole and the connecting pipes ${ }^{1}$. Protecting the carrier pipe inside the manholes against corrosion extends the service life of the entire HDS considerably. It is then desirable to have a cost effective coating alternatives able to protect the carrier pipes against corrosion while keeping the outside temperature of the pipes low enough to protect service personnel entering the manhole.

\section{Objective}

The objective of this analysis is to provide quantitative documentation of economic Return on Investment (ROI) performance of the heat distribution system coating system under consideration at Redstone Arsenal, AL.

\section{Approach}

This analysis follows the seven-step process outlined in the Department of the Army Economic Analysis (EA) Manual and recommended by DODI 7041.3. The process is depicted in figure 1 below. These seven steps are divided into four major categories: Study Formulation, Determine Costs and Benefits, Perform Analysis, and Report Results.

${ }^{1}$ Underground Heat Distribution Sy stems; Robert O. Couch, Rickwil Piping Systems; 1993 Federal Section Comference; IDCA; May 20-21, 1993; Arlington, VA:

\author{
The PERTAN Group
}




\section{Study Formulation}

The first three steps of the Economic Analysis process involve the formulation of the study. They are: Definition of Objectives, Formulation of Assumptions, and Identification of Alternatives.

\section{Determine Costs and Benefits.}

This step of the Economic Analysis (EA) process is the determination and estimation of the different costs and benefits of each alternative. It involves the selection of the different cost elements involved and the gathering of the corresponding values.

\section{Perform Analysis}

The next two steps of the AIS EA Handbook involves (1) the evaluation and comparison of the different alternatives according to the costs and benefits obtained before and (2) performance of a sensitivity analysis.

\section{Report Results.}

The final step of the EA process is the reporting of the results. This step involves documenting all estimates and explaining recommendation(s).

\section{Scope}

This study is an economic analysis, not a budget analysis. Economic analysis and budget analysis are different processes. While an economic analysis is used for determining the most cost-

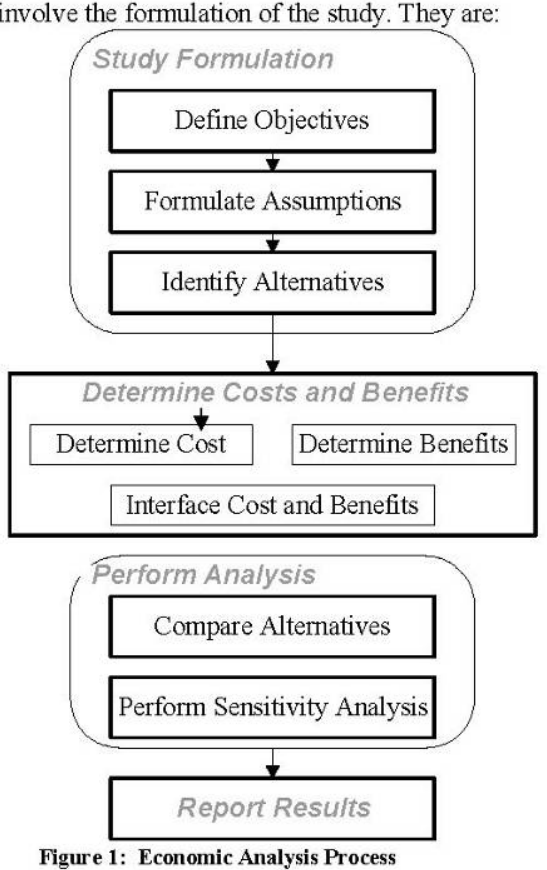

effective alternative that meets an organization's requirement, a budget analysis provides an organization with the total cost impact of an alternative. The data presented in an economic analysis may or may not be useful in a future budget process. Some costs are omitted from the economic analysis because they are wash costs (a cost that is identical for all alternatives). Also, some costs included in the economic analysis may refer to several organizations, making it difficult to use them in the budgeting process.

\section{Mode of Technology Transfer}

The recommendation of this report will be used to specify corrosion protection treatment in Heat Distribution Systems at Redstone. 


\section{STUDY FORMULATION}

\section{Definition of Objectives}

This is the first step of the EA and also the most important. A clear and concise objective will set the boundaries of the study and will define the goal to be accomplished in measurable terms. Clearly, an improperly stated objective will lead to an improper solution.

\section{Problem}

Carrier pipes in the manholes of HDS are routinely exposed to a corrosive environment of humidity and heat. That corrosive environment is exacerbated by leaking valves, ground water ingress, and occasional manhole flooding. Current corrosion protection systems aim to protect the conduit pipe. Moreover, current design/construction practices wrap insulation around the carrier pipes in the manhole to prevent heat loses and to protect maintenance personnel working in the manhole from high temperature pipes. However, after the manhole is flooded, insulation traps moisture around the carrier pipe and speeds up corrosion.

\section{Project Objective}

The objective of this project is to identify an alternative to the current practice of wrapping insulation around pipes. The alternative should be cost effective and provide a better corrosion protection without compromising safety.

\section{Formulation of Assumptions}

In order to perform an EA, several assumptions about future events need to be made. Following is the list of assumptions used in this analysis:

- The start year of the analysis is FY-2006.

- The lead-time (period extending from the start year to the completion of installation) is 1 year. At the end of the first year all $100 \%$ of the benefits are achieved.

- The period of analysis is 20 years.

- The real discount rate is $4 \%$.

- Cost elements for each alternative are estimated using an average manhole. The average manhole is 10 feet by 10 feet and has two pipelines in it, supply and return. Inside the manhole there is a T in each line and a valve in each line. The total length of pipeline inside is assume to be $(10+5) \mathrm{x}$ $2=30$ feet and the average diameter is 4". Manholes are 500 feet apart and are connected by both supply and return lines.

\section{Identification of Alternatives}

Currently, underground direct buried drainable dryable steel conduit HDS are protected against corrosion by several means. The soil-side surface of the conduit pipe is protected by a special coating and/or cathodic protection. The interior side of the carrier pipe is protected by chemical water treatment performed continuously at the central plant. Corrosion in the annuli between the conduit pipe and the carrier pipe can be prevented by properly monitoring the moisture condition of this space 
through the drains and vents at the end plates inside the manholes. However, the sections of carrierpipe inside the manholes are not well protected against corrosion. Those sections are wrapped with insulation and protected with an aluminum jacket. Moisture entering the manhole through the top gets trapped between the insulation and the outer side of the carrier pipe speeding up the corrosion process.

Current Method (Status Quo) Alternative

In this alternative, insulation is wrapped directly around the exterior side of the carrier pipe all through the section of pipe enclosed in the manhole. Current maintenance practices call for visual inspection of the insulation periodically and the substitution of the insulation when it is missing or highly deteriorated. However, this practice can not inspect the surface between the insulation and the pipe when the insulation is not missing even if it is saturated with moisture. Moreover, maintenance personnel shortages make the inspections unlikely and lack of maintenance funds make the insulation replacement prohibitive.

Corrosion Protection Primer-Insulation Combination (P-I)

In this alternative, when the insulation is deteriorated, the pipes are coated with a corrosion protection primer and the deteriorated insulation is replaced. More specifically, after removing the deteriorated insulation, the exterior side of the carrier pipe inside the manhole is first treated with a zinc-based paint to protect against corrosion. Then, insulation is wrapped around the pipes and protected with an aluminum jacket.

Corrosion Protection Primer-ExpectedCeramic Paint-Insulation Combination (P-ExCP-I) This alternative is the expected outcome of the alternative using a Ceramic Paint coating. In this alternative when the insulation is deteriorated, the pipes are coated with a corrosion protection primer and a ceramic paint before replacing the deteriorated insulation. More specifically, after removing the deteriorated insulation, the exterior side of the carrier pipe inside the manhole is first treated with a zinc-based paint to protect against corrosion. Then, it is painted with a ceramic paint to insulate the pipes. Finally, insulation is wrapped around the pipes and protected with an aluminum jacket. Under this alternative, the ceramic paint is supposed to be able to add extra thermal insulation to the pipes.

Corrosion Protection Primer-ActualCeramic Paint-Insulation Combination (P-AcCP-I) This alternative represents the actual field performance of the above alternative. In the field test conducted by CERL the ceramic paint didn't perform as expected. The thermal barrier capability only lasted for two months, after which the ceramic paint didn't provide any extra insulation. 


\section{COST AND BENEFITS}

Determining the costs and benefits associated with each alternative is the fourth step of an EA. This part of the analysis focuses on the collection and the comparison of the costs of implementing each alternative and the benefits associated with each course of action. Two issues worth considering before estimating costs and benefits are (1) relevance of the cost element and (2) level of accuracy of the estimate.

When comparing alternatives, not all cost elements are necessarily used in the analysis. The goal of the economic analysis is to only determine the most cost-effective alternative to the government that meets the organization's requirement. The outcome of the analysis is a ranking of the two alternatives Only the differential costs between alternatives are considered in the analysis. Cost elements that don't affect the order of the ranking and are common to all alternatives are not considered here. In other words, costs that are identical for both alternatives (wash costs) are excluded from the evaluation and only the relative differences between alternatives are developed and compared.

The same rationale applies to the level of accuracy that is required for the estimates to be relevant. Many of the estimates used in this analysis are expert's opinions and are not expected to be $100 \%$ accurate. To test the impact of the estimates' accuracy on the final ranking, a sensitivity analysis is performed after comparing cost and benefits. That analysis tests what changes in assumed values are necessary to impact the final ranking of the alternative.

\section{Relevant Cost Elements}

There are five Cost Elements that capture the economic differences relevant to selecting the most costefficient maintenance alternative. They are Initial Investment, Preventive Maintenance, Corrective Maintenance, Energy Consumption, and Salvage Value. Following is a description of each cost element and how they impact the total cost.

1. Initial Investment. This is the total investment cost required to implement each maintenance alternative. For this analysis, there isn't any initial investment for the status quo alternative. However, for the Primer-Insulation combination (P-I) alternative, the initial investment is the cost of removing deteriorated insulation, sanding the pipes inside the manhole, applying the primer, and installing new insulation; and for the Primer-ExpectedCeramic Paint-Insulation combination (P-ExCP-I) and Primer-ActualCeramic Paint-Insulation combination (P-AcCP-I) alternatives, the initial investment is the cost of removing deteriorated insulation, sanding the pipes inside the manhole, applying the primer, applying two coats of ceramic paint, and installing new insulation.

2. Preventive Maintenance (PM). This cost element captures the cost of doing PM on the carrier pipe inside the manhole. For this analysis, the preventive maintenance includes the cost of performing periodic inspections of the carrier pipe. The inspections are very similar under all four alternatives. Therefore, the costs of these inspections are considered wash costs in the analysis. 
3. Corrective Maintenance (CM). This cost element captures the cost of activities involving breakdown maintenance, including materials and investigative time to determine the cause of a failure or incident.

\section{Status Quo Alternative}

For the Status Quo alternative, it includes the cost of repair by replacement. Under the Status Quo alternative, the life of the HDS is 15 years $^{2}$. That is the number of years that takes the Condition Index (CI) of a direct buried drainable dryable HDS to fall below $25 \%$. At that point the system is beyond repair and has to be replaced - Repair by replacement. This analysis assumes that the pipe is replaced at the beginning of year 15 with a similar pipe with another 15 years of economic life remaining. As a consequence, this cost element reflects the cost of replacing the pipes at the beginning of year 15 .

\section{Primer-Insulation Alternative (P-I)}

Under the Primer-Insulation (P-I) combination alternative, the time for the CI to fall below $25 \%$ is more than 30 years. That is so because protecting the carrier pipe inside the manhole against rust prevents leaks and extra moisture in the manhole which in turn prevents flooding of the manhole. Flooding of manholes is the main cause of failure for $\mathrm{HDS}^{3}$ and increases the stress in the pipe segments entering the manhole considerably. In other words, the prevention of leaks in the manhole makes the conditions inside the manhole similar to those of inside manholes with cover raised. The CI for direct buried drainable dryable HDS with raised covers in the manholes, after 30 years is $60 \%$ - Good Condition.

\section{Primer-ExpectedCeramic Paint-Insulation Alternative (P-ExCP-I)}

Under the Primer-ExpectedCeramic Paint-Insulation (P-ExCP-I) combination the expected economic life of the HDS is also 30 years. This is so because the effect of extending the economic life to 30 years is providing by the corrosion protection primer.

\section{Primer-ActualCeramic Paint-Insulation Alternative (P-AcCP-I)}

Under the Primer-ActualCeramic Paint-Insulation (P-AcCP-I) combination alternative, the expected life of the HDS is also 30 years, even though the ceramic paint didn't perform as expected. This is because the effect of extending the economic life to 30 years is due to the corrosion protection primer which did perform well in the field test.

4. Energy Consumption. This cost element captures the cost of energy lost in the pipe inside the manhole for each alternative. It is included in the analysis to identify any energy saving or extra cost associated with the P-I, P-ExCP-I, and P-AcCP-I combinations. The energy cost is

\footnotetext{
${ }^{2}$ Engineering Management System For Heat Distribution System; NMD and Associates; Alexandria, VA; August 1995

${ }^{3}$ Underground Heat Distribution Sy stems, 1993 Federal Section Conference; May 20-21, 1993; Arlington, VA The PERTAN Group
} 
estimated by assuming that the boiler plant has an Efficiency Factor (EF) of 0.8 and that the cost of natural gas to the installation is $\$ 0.6$ per Therm.

5. Salvage Value. This cost element represents the value of the HDS at the end of the analysis period. Under the Status Quo alternative, at the end of the 20 year analysis the replaced buried pipe still has 10 years of economic life left since the analysis assumes that it was replaced at year 15 with a pipe with an economic life of 15 years. ( 15 years less 5 years $=10$ years). Under the P-I combination alternative, at the end of the 20 years analysis, the buried pipe still has more than 10 year of economic life left -30 years less 20 years. This is also the case for the P-ExCP-I and P-AcCP-I alternatives. Since the economic life left under all four alternatives are very similar, the salvage value is a wash cost.

Table 1 below summarizes the above cost element for each alternative

\begin{tabular}{|c|c|c|c|c|}
\hline Cost Elements & Status Quo & $\begin{array}{c}\text { Primer-Insulation } \\
\text { (P-I) }\end{array}$ & $\begin{array}{c}\text { Primer- } \\
\text { ExpectedCeramicPaint- } \\
\text { Insulation } \\
\text { (P-ExCP-I) }\end{array}$ & $\begin{array}{c}\text { Primer-ActualCeramic } \\
\text { Paint-Insulation } \\
\text { (P-AcCP-I) }\end{array}$ \\
\hline Initial Investment & $\begin{array}{l}\text { No new equipment } \\
\text { required }\end{array}$ & $\begin{array}{ll} & \text { Remove Insulation } \\
& \text { in MH } \\
- & \text { Sand blast pipes } \\
- & \text { Apply Primer } \\
- & \text { Install New } \\
& \text { Insulation in MH }\end{array}$ & $\begin{array}{ll} & \text { Remove Insulation in } \\
& \text { MH } \\
- & \text { Sand blast pipes } \\
- & \text { Apply Primer } \\
- & \text { Apply } 1^{\text {st }} \text { coat paint } \\
\text { - } & \text { Apply } 2^{\text {nd }} \text { coat paint } \\
\text { - } & \text { Install New } \\
& \text { Insulation in MH }\end{array}$ & $\begin{array}{ll} & \text { Remove Insulation } \\
& \text { in MH } \\
\text { - } & \text { Sand blast pipes } \\
\text { - } & \text { Apply Primer } \\
\text { - } & \text { Apply } 1^{\text {st }} \text { coat paint } \\
\text { - } & \text { Apply } 2^{\text {nd }} \text { coat paint } \\
\text { - } & \text { Install New } \\
& \text { Insulation in } \mathrm{MH} \\
\end{array}$ \\
\hline $\begin{array}{l}\text { Preventive } \\
\text { Maintenance }\end{array}$ & Null & Null & Null & Null \\
\hline $\begin{array}{l}\text { Corrective } \\
\text { Maintenance }\end{array}$ & $\begin{array}{ll} & \text { Remove Insulation in } \\
& \text { MH } \\
- & \text { Replace Pipes in } \mathrm{MH} \\
- & \text { Replace Valves in } \mathrm{MH} \\
- & \text { Install New Insulation in } \\
& \text { MH } \\
-\quad & \text { Replace Pipe outside } \\
& \text { MH }\end{array}$ & None & None & None \\
\hline $\begin{array}{l}\text { Energy } \\
\text { Consumption }\end{array}$ & $\begin{array}{l}\text { Energy lost while } \\
\text { insulation is saturated with } \\
\text { water + energy lost while } \\
\text { insulations is dry }\end{array}$ & $\begin{array}{l}\text { Energy lost while } \\
\text { insulation is saturated } \\
\text { with water + energy lost } \\
\text { while insulations is dry }\end{array}$ & $\begin{array}{l}\text { Energy conservation } \\
\text { through ceramic paint. }\end{array}$ & $\begin{array}{l}\text { Energy lost through } \\
\text { ceramic paint. }\end{array}$ \\
\hline Salvage Value & Wash & Wash & Wash & Wash \\
\hline
\end{tabular}

\section{Source and Derivations of Cost and Benefits}

\section{Initial Investment:}

This is the total investment cost required to implement each maintenance alternative. The initial investment cost for the Status Quo alternative is $\$ 0$. The initial investment cost for the Primer-Insulation (P-I) alternative is $\$ 563$. The initial costs for the Primer-ExpectedCeramic 
Paint-Insulation (P-ExCP-I) and Primer-ActualCeramic Paint-Insulation (P-AcCP-I) alternatives are $\$ 1,210$. The details for finding initial costs are found below.

\section{Status Quo Alternative}

The Status Quo alternative considered here does not require new equipment or training to be implemented. Therefore, the initial investment cost for this alternative is $\$ 0$.

\section{Primer- Insulation Alternative (P-I)}

Under the P-CP-I combination alternative, applying the paint requires removing old insulation, sanding the pipes, applying the primer, and applying two coats of the ceramic paint. The costs of those activities have two components labor and materials.

\section{Materials:}

1. Primer Paint

Primer Paint cost: $\$ 50 /$ Gallon

Paint Efficiency Rate for pipes for no less than 3 Mils dry film $=200 \mathrm{SqFt} / \mathrm{Gal}$

Total Primer Cost per manhole $=(35.32 \mathrm{SqFt} / 200 \mathrm{SqFt} /$ Gall $) \times \$ 50 /$ Gall $=\$ 8.83$

Total Primer Cost per manhole $=\$ 8.83$

Total Materials Cost per $\mathrm{MH}=\$ 8.83$

Labor:

In September 2005 at Ft. Jackson, it took a crew of two people to perform the necessary activities to implement the P-I part of the alternative in three manholes four days. The labor included sanding the pipes, applying the primer and replacing the insulation. This cost is similar to the cost of performing the sandblasting and painting at Redstone.

$$
\text { Labor Hours per } \mathrm{MH}=(2 \text { days } * 8 \text { Hours/Day } * 2 \text { person }) / 3 \mathrm{MH}=10.7 \text { Hours }
$$

Hourly Labor Rate $=\$ 35 /$ Hour in $1996 \times 1.48$ escalation factor to $2005=\$ 51.8 /$ Hour

Labor Cost $=10.7$ Hours $x \$ 51.8 /$ Hour $=\$ 554.26$ per MH

Initial Investment Cost:

Initial Investment Cost $=$ Labor Cost + Material Cost

Initial Investment Cost $=\$ 554+\$ 8.83=\$ 562.83$

Primer-ExpectedCeramic Paint-Insulation Alternative (P-ExCP-I) 
Under the P-ExCP-I combination alternative, applying the paint requires removing old insulation, sanding the pipes, applying the primer, and applying two coats of the ceramic paint. The costs of those activities have two components labor and materials.

\section{Materials:}

2. Ceramic Paint

Ceramic Paint cost: $\$ 44.5 /$ Gallon

Paint Efficiency Rate for no less than 45 mils dry film $=16 \mathrm{SqFt} /$ Gallon

30 feet of pipe per manhole

4" internal diameter $=4.5$ external diameter $=4.5 \times 3.14 / 12=1.177 \mathrm{Ft}$ exterior circumference

Total pipe surface in a manhole $=1.177 \times 30=35.32 \mathrm{SqFt}$

Cost per manhole $=(35.32 \mathrm{SqFt} / 16 \mathrm{SqFt} /$ Gallon $) * \$ 44.5$ Gallons $=\$ 98.25$

Total Ceramic Paint Cost per manhole $=\$ 98.25$

3. Primer Paint

Primer Paint cost: $\$ 50 /$ Gallon

Paint Efficiency Rate for pipes for no less than 3 Mils dry film $=200 \mathrm{SqFt} / \mathrm{Gal}$

Total Primer Cost per manhole $=(35.32 \mathrm{SqFt} / 200 \mathrm{SqFt} / \mathrm{Gall}) \times \$ 50 /$ Gall $=\$ 8.83$

Total Primer Cost per manhole $=\$ 8.83$

Total Materials Cost per $\mathrm{MH}=\$ 98.25+\$ 8.83=\$ 107.08$

Labor:

In September 2005 at Ft. Jackson, it took a crew of two people to perform the necessary activities to implement the P-CP part of the alternative in three manholes four days. The labor included sanding the pipes, applying the primer and the two coats of paint. This cost is similar to the cost of performing the sandblasting and painting at Redstone.

$$
\text { Labor Hours per } \mathrm{MH}=(4 \text { days } * 8 \text { Hours/Day } * 2 \text { person }) / 3 \mathrm{MH}=21.3 \text { Hours }
$$

Hourly Labor Rate $=\$ 35 /$ Hour in $1996 \times 1.48$ escalation factor to $2005=\$ 51.8 /$ Hour

Labor Cost $=21.3$ Hours $x \$ 51.8 /$ Hour $=\$ 1,103$ per MH

\section{Initial Investment Cost:}

Initial Investment Cost $=$ Labor Cost + Material Cost

Initial Investment Cost $=\$ 1,103+\$ 107.8=\$ 1,210.8$ 


\section{Primer-ActualCeramic Paint-Insulation Alternative (P-AcCP-I)}

Under the P-AcCP-I combination alternative, applying the paint requires removing old insulation, sanding the pipes, applying the primer, and applying two coats of the ceramic paint. The costs of those activities have two components labor and materials.

\section{Materials:}

Ceramic Paint

Ceramic Paint cost: $\$ 44.5 /$ Gallon

Paint Efficiency Rate for no less than 45 mils dry film $=16 \mathrm{SqFt} / \mathrm{Gallon}$

30 feet of pipe per manhole

4 " internal diameter $=4.5$ external diameter $=4.5 \times 3.14 / 12=1.177$ Ft exterior circumference

Total pipe surface in a manhole $=1.177 \times 30=35.32 \mathrm{SqFt}$

Cost per manhole $=(35.32 \mathrm{SqFt} / 16 \mathrm{SqFt} /$ Gallon $) * \$ 44.5$ Gallons $=\$ 98.25$

Total Ceramic Paint Cost per manhole $=\$ 98.25$

Primer Paint

Primer Paint cost: $\$ 50 /$ Gallon

Paint Efficiency Rate for pipes for no less than 3 Mils dry film $=200 \mathrm{SqFt} / \mathrm{Gal}$

Total Primer Cost per manhole $=(35.32 \mathrm{SqFt} / 200 \mathrm{SqFt} / \mathrm{Gall}) \times \$ 50 /$ Gall $=\$ 8.83$

Total Primer Cost per manhole $=\$ 8.83$

Total Materials Cost per $\mathrm{MH}=\$ 98.25+\$ 8.83=\$ 107.08$

Labor:

In September 2005 at Ft. Jackson, it took a crew of two people to perform the necessary activities to implement the P-CP part of the alternative in three manholes four days. The labor included sanding the pipes, applying the primer and the two coats of paint. This cost is similar to the cost of performing the sandblasting and painting at Redstone.

Labor Hours per $\mathrm{MH}=(4$ days $* 8$ Hours/Day $* 2$ person $) / 3 \mathrm{MH}=21.3$ Hours

Hourly Labor Rate $=\$ 35 /$ Hour in $1996 \times 1.48$ escalation factor to $2005=\$ 51.8 /$ Hour

Labor Cost $=21.3$ Hours $x \$ 51.8 /$ Hour $=\$ 1,103$ per MH

Initial Investment Cost:

Initial Investment Cost $=$ Labor Cost + Material Cost

Initial Investment Cost $=\$ 1,103+\$ 107.8=\$ 1,210.8$

The PERTAN Group 


\section{Preventive Maintenance (PM)}

Even though widely accepted preventive maintenance procedures ${ }^{4}$ recommend repairing the deteriorated insulation around the carrier pipes in the manholes, lack of manpower at the installations render the practice a low priority status. As a consequence, in order to make this analysis reflect the every day practice at the installation, the PM cost of repairing insulation under the Status Quo and Primer-Insulation alternatives is zero.

There isn't any preventive maintenance requirement for the combination of primer and ceramic paint. Moreover, the expected life of the paint combination is expected to be 30 plus years. Therefore, the estimated cost of preventive maintenance for the P-ExCP-I and P-AcCP-1 alternatives is also zero.

Corrective Maintenance

This cost element captures the cost of activities involving breakdown maintenance, including materials and investigative time to determine the cause of a failure or incident.

\section{Status Quo Alternative}

Under the status quo alternative, the corrective maintenance activities required to repair failed pipes inside and out of the manhole:

- Remove Insulation

- Replace carrier pipes inside MH

- Replace valves inside MH

- Apply new insulation and protective jacket to pipes inside MH

- Replace buried pipe outside MH

The cost of applying new insulation won't be estimated because it washes out with the initial investment cost of installing new insulation for both the P-ExCP-I and P-AcCP-I alternatives.

Under the Status Quo alternative, the life expectancy of the carrier pipe inside the manhole is considered to be only 15 years. At the beginning of year 15 , the carrier pipes will present considerable pitting and have to be replaced. The cost of replacing the pipes inside the manhole is estimated using NMD report as follows:

From 1996 report the cost for replacing 10 feet section pipe is=2 Hours @ $\$ 35 /$ Hour $+\$ 178$ material $=\$ 247 / 10$ Feet. Escalating those prices to 2006 and considering that there are 30 feet pipe inside:

Preliminary estimate to replace pipe in $\mathrm{MH}=\$ 247 * 1.48 * 3=\$ 1,096$

The above estimate doesn't take into account the fact that the average manhole has 2 Ts and flanges for 2 Valves that also need to be replaced due to the pitting. It is estimated that the flanges and the Ts add complexity to the replacement and hence increases the cost by $50 \%$

Cost to replace pipe inside $\mathrm{MH}=\$ 1,096 \times 1.5=\$ 1,645$

${ }^{4}$ Engineering Management Sy stem For Heat Distribution System; NMD and Associates; Alexandria, VA; August 1995 The PERTAN Group 
The cost to replace the 2 valves form NMD and associates report and escalated to 2005 is:

$$
\text { Cost to replace Valves }=2 \times \$ 435 \times 1.48=\$ 1,288
$$

The cost to replace the direct buried pipe outside MH is also estimated using NMD report. The 1996 cost to replace 4" buried per liner feet is $\$ 101$. That cost doesn't include the cost involved in cutting through and then replacing grade level structures like parking areas, sidewalks, curves, and pavement. Considering that there are 500 feet of supply and 500 feet of return pipe, the minimum cost to replace the buried pipe at 2006 price level is:

Cost to replace buried pipe $=2 \times 500 \times 1.48 \times \$ 101=\$ 149,480$

The total corrective maintenance to replace insulation, pipes, valves, and buried pipes is then:

Total Corrective Maintenance Cost $=\$ 1,645+\$ 1,288+\$ 149,480=\$ 152,413$

\section{Energy Conservation:}

Under the Status Quo alternative, the pipes inside the manholes have 1.5" of mineral fiber insulation wrapped around the pipe and protected with an aluminum jacket with a conductivity factor of 0.024 Btu $/ \mathrm{Hr}-\mathrm{Ft}-{ }^{\circ} \mathrm{F}$. Under the P-I alternative, the pipe also has at least 1 primer coat of paint which protects the pipes from corrosion. Appendix 1 contains detailed estimates of the cost of energy lost through the pipes in the manhole under each alternative.

Under the P-ExCP-I and P-AcCP-I alternatives, the pipe also has at least 45 mil of ceramic paint which has a thermal conductivity of $0.0563 \mathrm{Btu} / \mathrm{Hr}-\mathrm{Ft}-{ }^{\circ} \mathrm{F}$. Appendix 1 contains detailed estimates of the cost of energy lost through the pipes in the manhole under each alternative. Under the Status Quo alternative, the estimated cost of the annual energy lost in the average manhole is $\$ 372$. Under the P -I combination alternative, the estimated cost of the annual energy lost in the average manhole is also $\$ 372 /$ Year.

Under the P-ExCP-I combination alternatives, the estimated cost of the annual energy lost in the average manhole is $\$ 119 /$ Year. Under the P-AcCP-I combination alternative, due to the fact that the ceramic paint underperformed, the estimated cost of the annual energy lost in the average manhole is $\$ 372 /$ Year. The ceramic paint did not provide the expected energy savings after 2 months.

\section{Residual Value:}

The economic life left at the end of the period of analysis is similar under all alternatives. Hence, the residual value is a wash cost.

Table 2 below summarizes the estimated values for each cost component. 
Table 2: Summary of Cost Components

\begin{tabular}{|l|c|c|c|c|}
\hline Cost Elements & Status Quo & $\begin{array}{c}\text { Primer-Insulation } \\
\text { (P-I) }\end{array}$ & $\begin{array}{c}\text { Primer- } \\
\text { ExpectedCeramicPaint- } \\
\text { Insulation } \\
\text { (P-ExCP-I) }\end{array}$ & $\begin{array}{c}\text { Primer- } \\
\text { AcutalCeramicPaint- } \\
\text { Insulation } \\
\text { (P-AcCP-I) }\end{array}$ \\
\hline Initial Investment & $\$ 0$ & $\$ 563$ & $\$ 1,210$ & $\$ 1,210$ \\
\hline $\begin{array}{l}\text { Preventive } \\
\text { Maintenance }\end{array}$ & $\$ 0$ & $\$ 0$ & $\$ 0$ & $\$ 0$ \\
\hline $\begin{array}{l}\text { Corrective } \\
\text { Maintenance }\end{array}$ & $\$ 152,413$ at year 15 & $\$ 0$ & $\$ 0$ & $\$ 0$ \\
\hline Energy Consumption & $\$ 372 /$ Year & $\$ 372 /$ Year & $\$ 119 /$ Year & $\$ 372 /$ Year \\
\hline Residual Value & Wash & Wash & Wash & Wash \\
\hline
\end{tabular}




\section{COMPARING COST AND BENEFITS}

\section{Introduction}

The next two steps in the EA process are (1) the comparison of alternatives and (2) the performance of sensitivity analysis. Alternatives are compared and ranked using three methods: Net Present Value (NPV), Savings-to-Investment Ratio (SIR), and Discounted Payback Period (DPP). These comparisons were done using the ECONPACK 3.2.2 computer program.

The NPV method is the standard way to compare alternatives in the Army when all the alternatives meet the requirements. The NPV is calculated for each alternative by discounting the value of the costs minus the benefits for each of the twenty years of the analysis and summing them up for a total net (current) value in today's dollars.

SIR is used only to compare investment cost to savings to determine if the investment cost can be recovered through the savings. It is the ratio of savings resulting from using an alternative, instead of using the status quo, to the investment required for implementing the new alternative. When computing SIR, total annual maintenance and operation costs are not discounted, only the difference between annual costs for the two alternatives.

Payback period is the time required for the total accumulating savings of an alternative to offset investment costs. DPP is used in conjunction with SIR. When the SIR is greater than 1, DPP answers the question "How long does it take to recoup the investment cost?" Alternatives with earlier DPP are often preferred over those with longer DPP because the extra uncertainty of future returns.

\section{Comparing Alternatives}

The costs estimated in the prior section were used to compute the Life Cycle Cost of each alternative. Appendix 2 contains the ECONPACK output file with the results of the analysis. Following is a summary of the results.

\section{Life Cycle Cost of Status Quo}

The Life Cycle Cost (LCC) per manhole of the Status Quo alternative over the 20-year period has a

- Cumulative Net Present Value of $\$ 84,401$

Life Cycle Cost of Corrosion Protection Primer-Insulation (P -I) Combination The LCC per manhole of the Corrosion Protection Primer and Insulation alternative over the 20-year period has a

- Cumulative Net Present Value of $\$ 5,138$

- Present Value of Savings of $\$ 79,794$

- Present Value of the Initial Investment of $\$ 531$

- Savings to Investment Ratio of 150.3

- Discounted Payback Period of 15 Years 
Life Cycle Cost of Corrosion Protection Primer-ExpectedCeramicPaint-Insulation (P-ExCPI) Combination

The LCC per manhole of the Corrosion Protection Primer-Ceramic Based Paint and Insulation alternative over the 20-year period has a

- Cumulative Net Present Value of $\$ 2,615$

- Present Value of Savings of $\$ 82,927$

- Present Value of the Initial Investment of $\$ 1,141$

- Savings to Investment Ratio of 72.7

- Discounted Payback Period of 6.4 Years

Life Cycle Cost of Corrosion Protection Primer-ActualCeramicPaint-Insulation (P-AcCP-I) Combination

The LCC per manhole of the Corrosion Protection Primer-Ceramic Based Paint and Insulation alternative over the 20 -year period has a

- Cumulative Net Present Value of $\$ 6,098$

- Present Value of Savings of $\$ 79,444$

- Present Value of the Initial Investment of $\$ 1,141$

- Savings to Investment Ratio of 69.6

- Discounted Payback Period of 15 Years

Table 3 below summarizes the results:

\begin{tabular}{|l} 
Table 3: Alternative Comparisons of Life Cycle Costs \\
\begin{tabular}{|l|c|c|c|}
\hline & $\begin{array}{c}\text { Net Present Value } \\
(\mathrm{NPV})\end{array}$ & $\begin{array}{c}\text { Savings to } \\
\text { Investment Ratio } \\
\text { (SIR) }\end{array}$ & $\begin{array}{c}\text { Discount Payback } \\
\text { Period } \\
\text { (DPP) }\end{array}$ \\
\hline Status Quo & $\$ 84,401$ & $\mathrm{~N} / \mathrm{A}$ & N/A \\
\hline Primer-Insulation (P-I) & $\$ 5,138$ & 150.3 & 15 years \\
\hline $\begin{array}{l}\text { Primer-ExpectedCeramicPaint- } \\
\text { Insulation (P-ExCP-I) }\end{array}$ & $\$ 2,615$ & 72.7 & 6.4 years \\
\hline $\begin{array}{l}\text { Primer-AcutalCeramicPaint- } \\
\text { Insulation (P-AcCP-I) }\end{array}$ & $\$ 6,098$ & 69.6 & 15 years \\
\hline
\end{tabular}
\end{tabular}

\section{Sensitivity Analysis}

Alternative's rankings may change when some of the assumptions in the analysis change. To test the robustness of the above ranking a test of the sensitivity of the analysis to changes in the estimated savings was performed. The analysis showed that the ranking of the alternatives was sensitive to changes in the cost of the major repair of the Status Quo alternative. For the Status Quo alternative to become the least cost alternative, the cost of the major repair has to be reduced by $99.3 \%$. In other word, the cost of replacing 500 feet of supply and return buried pipe has to be less than $\$ 1,070$, well below ongoing rates. Figure 3 below, shows the NPV of each alternative against percentage changes in the cost of major repairs. 


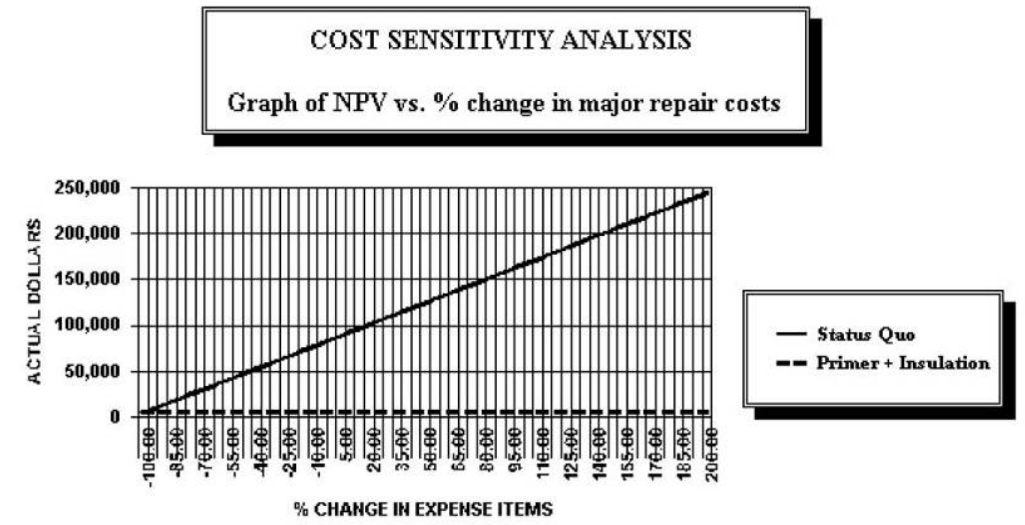

Figure 3: Pipe Replacement Cost Sensitivity Analysis 


\section{CONCLUSIONS}

An economic analysis of two alternative methods of maintaining and repairing the manholes of underground drainable dryable heat distribution systems was performed. The two alternative maintenance methodologies contemplate coating the carrier pipes inside the manholes with a coat of corrosion protection primer paint and new insulation. In addition, one of the methodologies contemplates adding two coats of ceramic based paint between the primer and the insulation.

Moreover, because of the unknown performance of the ceramic paint a priori, the Economic Analysis contemplated two scenarios for the performance of the ceramic paint namely: As Intended by Manufacturer, and As Tested by CERL in the field.

The economic analysis found that if the ceramic coating had performed as the manufacturer intended, this alternative would have produced a net savings of $\$ 82,927$ per manhole over a 20 -year life cycle, resulting in a Savings to Investment Ratio (SIR) of 72.7 and a Discounted Payback Period (DPP) of only 6.4 years. However, the field test of the ceramic paint reveled that the ceramic paint saved energy only for a few months, after which it became ineffective. In other words, the field test showed that the ceramic paint alternative only produced a net saving of $\$ 79,444$ per manhole over a 20 year life cycle, resulting in a SIR of 69.6 and a DPP of 15 years. In addition, the analysis showed that most of the savings came from the corrosion protection provided by the primer paint.

Given the inability of the ceramic paint to perform as intended by the manufacturer, the EA shows that the next best alternative is the combination of just primer paint and insulation. This alternative produces a net savings of $\$ 79,794$ per manhole over a 20-year life cycle, and results in a SIR of 150.3 although it takes 15 years to recover the investment - DPP of 15 years. 


\section{APPENDIX 1: DIFFERENNTIAL COST ANALYSIS OF ANNUAL ENERGY LOSSES THROUGH CARRIER PIPES AT MANHOLE}

Heat Transfer: The equations governing the amount of heat transferred through the walls of a pipe by conduction are derived from the Fourier's Law of Conduction ${ }^{5}$. For a rectangular wall, the equation

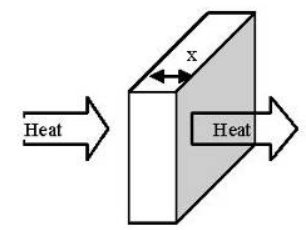

$$
\dot{Q}=k \times A \times\left(\frac{\nabla T}{\nabla x}\right)
$$

Equation 1

For a cylinder, the equation is:

$$
\dot{Q}=k A\left(\frac{\nabla T}{\nabla r}\right)
$$

Where:

$\dot{Q}=$ rate of heat transfer $(\mathrm{Btu} / \mathrm{hr})$

$\mathrm{A}=$ cross-sectional area of heat transfer $\left(\mathrm{ft}^{2}\right)$

$\Delta \mathrm{x}=$ thickness of slab $(\mathrm{ft})$

$\Delta \mathrm{r}=$ thickness of cylindrical wall ( $\mathrm{ft})$

$\Delta \mathrm{T}=$ temperature difference $\left({ }^{\circ} \mathrm{F}\right)$

$\mathrm{k}=$ thermal conductivity of slab, or of pipe wall $\left(\mathrm{Btu} / \mathrm{ft}-\mathrm{hr}-{ }^{\circ} \mathrm{F}\right)$

For a pipe with insulation wrapped around, the Fourier's Law has the form ${ }^{6}$ :

\footnotetext{
${ }^{5}$ DOE Fundamentals Handbook; Thermodynamics, Heat Transfer, and Fluid Flow, Volume 2 of 3; U.S. Department of Energy; Washington, D.C. 20585; June 1992; Page 6.

${ }^{6}$ DOE Fundamentals Handbook; Thermodynamics, Heat Transfer, and Fluid Flow, Volume 2 of 3; U.S. Department of Energy; Washington, D.C. 20585; June 1992; Page 17
}

$$
\text { The PERTAN Group }
$$




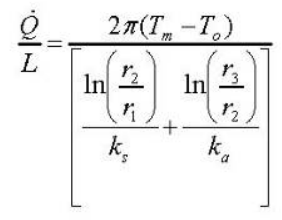

Equation 3

Where:

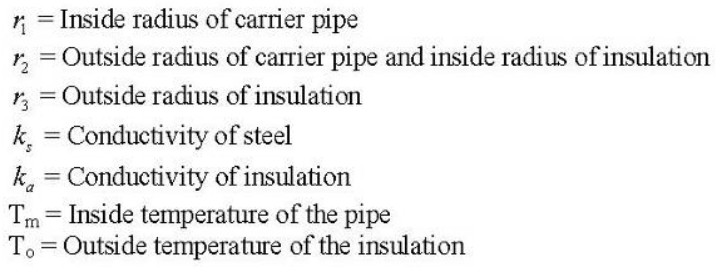

To estimate the annual cost of the energy lost through the pipe under both scenarios the following assumptions were made for the average manhole:

- Pipes inside the manhole are horizontal

- Nominal Diameter 4"

- 30 feet of steel pipe $5 / 32$ " thick

- Status Quo insulation thickness $=1.5$ "

- Ceramic Paint insulation thickness $\geq 0.045^{\text {" }}$

- The system operates 24 Hours/Day, 356 Days/Year.

- The temperature of the water inside the carrier pipe is $200^{\circ} \mathrm{F}$

- The boiler Efficiency Factor is 0.8

- The cost of fuel is $\$ 0.6 /$ Therm

Estimating method:

The temperatures were measured at two different manholes. One representative of alternative P-CP-I containing a line insulated with 1.5 " mineral insulation and with a minimum of 45 mils of ceramic paint. The other manhole, representing the status quo alternative, containing just the line with 1.5 " insulation. Both manholes were contiguous and hence having the same temperature inside the supply line. The temperatures were monitored between the pipe and the mineral insulation. The temperature in the pipe with the ceramic paint was on average $10^{\circ} \mathrm{F}$ lower than the temperature in the pipe without the ceramic paint. The average temperature in the status quo alternative during January 2007 was $380.2312^{\circ} \mathrm{F}$, and the temperature in the P-CP-I alternative was 371.4056 . During the same period, the average temperature inside the pits was $159.75^{\circ} \mathrm{F}$. 
Since the temperatures were measured between the insulation and the pipe, equation (3) is then used with $r_{1}=r_{2}$ and turns into equation (4):

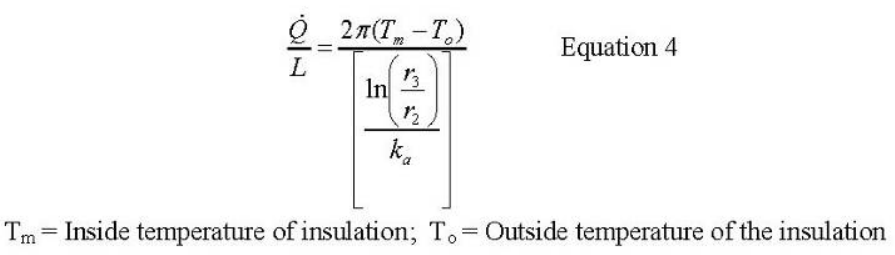

For the status quo alternative, the values for Equation 4 are:

$$
\begin{aligned}
& r_{2}=2.156^{\prime \prime} ; r_{3}=3.656^{\prime \prime} ; k_{\alpha}=0.024 \mathrm{Btu} /\left(\mathrm{Hr}-\mathrm{Ft}-{ }^{\circ} \mathrm{F}\right) ; \\
& \mathrm{T}_{\mathrm{m}}=380.23^{\circ} \mathrm{F} ; \mathrm{T}_{\circ}=159.75^{\circ} \mathrm{F} ;
\end{aligned}
$$

For the above values, the energy loss in the carrier pipe inside the average manhole per foot of pipe is $63 \mathrm{Btu} / \mathrm{Hr}-\mathrm{Ft}$ and the annual cost of that energy for the average manhole is $\$ 124.09$.

For the ceramic paint alternative, the values for equation 4 are:

$$
\begin{aligned}
& r_{2}=2.156^{\prime \prime} ; r_{3}=3.656^{\prime \prime} ; \\
& k_{\alpha}=0.024 \mathrm{Btu} /\left(\mathrm{Hr}-\mathrm{Ft}-{ }^{\circ} \mathrm{F}\right) ; \mathrm{T}_{\mathrm{m}}=371.4^{\circ} \mathrm{F} ; \mathrm{T}_{\mathrm{o}}=159.75^{\circ} \mathrm{F}
\end{aligned}
$$

\begin{tabular}{|c|c|c|c|c|c|}
\hline Variables & Units & Status Quo & $\begin{array}{c}\text { Primer- } \\
\text { Insulation } \\
\underline{(\mathbf{P}-\mathbf{I})}\end{array}$ & $\begin{array}{c}\text { Primer- } \\
\text { ExpectedCeramicPaint- } \\
\text { Insulation } \\
\text { (P-ExCP-I) } \\
\end{array}$ & $\begin{array}{c}\text { Primer- } \\
\text { ActualCeramicPaint- } \\
\text { Insulation } \\
\text { (P-AcCP-I) } \\
\end{array}$ \\
\hline $\mathrm{Tm}$ & ${ }^{\circ} \mathrm{F}$ & 380.23 & 380.23 & 371.4 & 380.23 \\
\hline To & ${ }^{\circ} \mathrm{F}$ & 159.75 & 159.75 & 159.75 & 159.75 \\
\hline$r_{2}$ & Inches & 2.156 & 2.156 & 2.156 & 2.156 \\
\hline$r_{3}$ & Inches & 3.656 & 3.656 & 3.656 & 3.656 \\
\hline $\mathrm{k}_{\mathrm{a}}$ & $\mathrm{Btu} /\left(\mathrm{Hr}-\mathrm{Ft}-{ }^{\circ} \mathrm{F}\right)$ & 0.024 & 0.024 & 0.024 & 0.024 \\
\hline $\mathrm{Q} / \mathrm{L}$ & $\mathrm{Btu} / \mathrm{Hr}-\mathrm{Ft}$ & 62.9553761 & 62.9553761 & 60.43408 & 62.9553761 \\
\hline L & $\mathrm{Ft}$ & 30 & 30 & 30 & 30 \\
\hline Q & $\mathrm{Btu} / \mathrm{Hr}$ & 1888.66128 & 1888.66128 & 1813.022 & 1888.66128 \\
\hline $\mathrm{QD}_{\mathrm{D}}$ & Btu/Day & 45,328 & 45,328 & 43,513 & 45,328 \\
\hline Boiler Efficiency & $\mathrm{EF}$ & 0.8 & 0.8 & 0.8 & 0.8 \\
\hline Energy Unit Cost & \$/Term & 0.6 & 0.6 & 0.6 & 0.6 \\
\hline Daily Cost & $\$ /$ Day & $\$ 0.34$ & $\$ 0.34$ & $\$ 0.33$ & $\$ 0.34$ \\
\hline Annual Cost & $\$ /$ Year & $\$ 124.09$ & $\$ 124.09$ & $\$ 119.12$ & $\$ 124.09$ \\
\hline
\end{tabular}

For the above values, the energy loss in the carrier pipe inside the average manhole per foot of pipe is $60 \mathrm{Btu} / \mathrm{Hr}-\mathrm{Ft}$ and the annual cost of that energy for the average manhole is $\$ 119.12$. Table 3 below contains a summary of the calculations. 
The \$124.09/Year Annual Cost of Energy Lost in the Status Quo was estimated assuming a dry insulation. If the insulation is wet, the losses can increase by a factor of $5^{7}$. Assuming that the insulation is wet $50 \%$ of the time, the annual cost is then: Annual Cost of Energy Lost in the Status Quo $=\$ 124 \times 5 \times 50 \%=\$ 310 /$ Year

${ }^{7}$ Engineer Management System for Heat Distribution Systems: Project level; NMD and Associates; Alexandria, VA; February 1996

The PERTAN Group 


\title{
APPENDIX 2: ECONPACK OUTPUT FILE
}

\author{
DATE GENERATED: 01 May 2008 \\ TIME GENERATED: 11:39:27 \\ VERSION: ECONPACK 3.2 .2
}

Heat Distribution Economic Analysis ECONOMIC ANALYSIS

EXECUTIVE SUMMARY REPORT

PROJECT TITLE: Redstone Arsenal

TYPE OF ANALYSIS: Return on Investment

DISCOUNT RATE: 4\%

PERIOD OF ANALYSIS: 20 Years

START YEAR: 2007

BASE YEAR: 2006

DOLLAR ANALYSIS: Constant Dollars

PROJECT OBJECTIVE:

Provide quantitative documentation of economic Return on Investment (ROI)

performance of the heat distribution system coating system under consideration at Redstone Arsenal, AL.

ALTERNATIVES CONSIDERED FOR THIS ANALYSIS:

Status Quo (Current Operations) -

ECONOMIC INDICATORS:

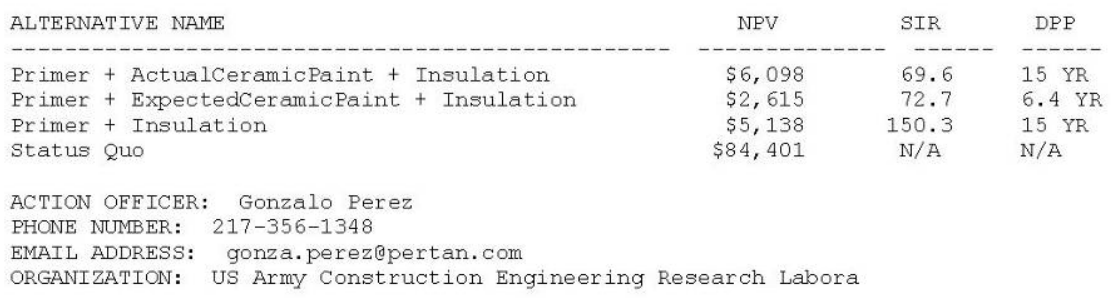

The PERTAN Group 
LIFE CYCLE COST REPORT

Primer + ActualCeramicPaint + Insulation

\begin{tabular}{|c|c|c|c|c|c|}
\hline \multirow[b]{2}{*}{ YEAR } & $\begin{array}{l}\text { Initial } \\
\text { Investment }\end{array}$ & \multirow[t]{2}{*}{ utilities } & \multirow[t]{2}{*}{$\begin{array}{l}\text { Corrective } \\
\text { Maintenance }\end{array}$} & \multirow{2}{*}{$\begin{array}{l}\text { TOTAL } \\
\text { ANNUAL } \\
\text { OUTLAYS }\end{array}$} & \multirow{2}{*}{$\begin{array}{l}\text { MIDDLE } \\
\text { OF YEAR } \\
\text { DISCOUNT } \\
\text { FACTORS }\end{array}$} \\
\hline & (1) & & & & \\
\hline 2007 & $\$ 1,210$ & $\$ 372$ & so & $\$ 1,582$ & 0.943 \\
\hline 2008 & $\$ 0$ & $\$ 372$ & \$0 & $\$ 372$ & 0.907 \\
\hline 2009 & $\$ 0$ & $\$ 372$ & $\$ 0$ & $\$ 372$ & 0.872 \\
\hline 2010 & \$0 & $\$ 372$ & \$0 & $\$ 372$ & 0.838 \\
\hline 2011 & \$0 & $\$ 372$ & $\$ 0$ & $\$ 372$ & 0.806 \\
\hline 2012 & $\$ 0$ & $\$ 372$ & $\$ 0$ & $\$ 372$ & 0.775 \\
\hline 2013 & $\$ 0$ & $\$ 372$ & $\$ 0$ & $\$ 372$ & 0.745 \\
\hline 2014 & $\$ 0$ & $\$ 372$ & $\$ 0$ & $\$ 372$ & 0.717 \\
\hline 2015 & $\$ 0$ & $\$ 372$ & $\$ 0$ & $\$ 372$ & 0.689 \\
\hline 2016 & $\$ 0$ & $\$ 372$ & $\$ 0$ & $\$ 372$ & 0.662 \\
\hline 2017 & \$0 & $\$ 372$ & $\$ 0$ & $\$ 372$ & 0.637 \\
\hline 2018 & \$0 & $\$ 372$ & \$o & $\$ 372$ & 0.612 \\
\hline 2019 & \$0 & $\$ 372$ & $\$ 0$ & $\$ 372$ & 0.589 \\
\hline 2020 & \$0 & $\$ 372$ & $\$ 0$ & $\$ 372$ & 0.566 \\
\hline 2021 & \$0 & $\$ 372$ & $\$ 0$ & $\$ 372$ & 0.544 \\
\hline 2022 & $\$ 0$ & $\$ 372$ & $\$ 0$ & $\$ 372$ & 0.524 \\
\hline 2023 & $\$ 0$ & $\$ 372$ & $\$ 0$ & $\$ 372$ & 0.503 \\
\hline 2024 & \$o & $\$ 372$ & $\$ 0$ & $\$ 372$ & 0.484 \\
\hline 2025 & $\$ 0$ & $\$ 372$ & $\$ 0$ & $\$ 372$ & 0.465 \\
\hline 2026 & $\$ 0$ & $\$ 372$ & $\$ 0$ & $\$ 372$ & 0.448 \\
\hline $8 N P V$ & $\begin{array}{r}18.71 \\
\$ 1,141\end{array}$ & $\begin{array}{l}81.29 \\
\$ 4,957\end{array}$ & $\begin{array}{c}0.00 \\
\$ 0\end{array}$ & & \\
\hline DISCOUNTING & & & & & \\
\hline CONVENT ION & $M-O-Y$ & $M-O-Y$ & $M-O-Y$ & & \\
\hline INF LATI I ON & & & & & \\
\hline SCHEDULE & No & No & No & & \\
\hline & Inflation & Inflation & Inflation & & \\
\hline CATEGORY/ & & & & & \\
\hline RES SCHD & $\begin{array}{l}\text { Non-Recurring } \\
\text { Costs }\end{array}$ & $\begin{array}{l}\text { Recurring } \\
\text { Costs }\end{array}$ & $\begin{array}{l}\text { Recurring } \\
\text { Costs }\end{array}$ & & \\
\hline
\end{tabular}

The PERTAN Group 
LIFE CYCLE COST REPORT

Primer + ActualCeramicPaint + Insulation

\begin{tabular}{crr}
\multicolumn{4}{c}{ CUMULATIVE } \\
YEAR & $\begin{array}{r}\text { PRESENT } \\
\text { VALUE }\end{array}$ & \multicolumn{2}{c}{ NET PRESENT } \\
& & \\
\hline--- & VALUE \\
2007 & $\$ 1,492$ & $\$ 1,492$ \\
2008 & $\$ 337$ & $\$ 1,829$ \\
2009 & $\$ 324$ & $\$ 2,153$ \\
2010 & $\$ 312$ & $\$ 2,465$ \\
2011 & $\$ 300$ & $\$ 2,765$ \\
2012 & $\$ 288$ & $\$ 3,053$ \\
2013 & $\$ 277$ & $\$ 3,330$ \\
2014 & $\$ 267$ & $\$ 3,597$ \\
2015 & $\$ 256$ & $\$ 3,853$ \\
2016 & $\$ 246$ & $\$ 4,100$ \\
2017 & $\$ 237$ & $\$ 4,336$ \\
2018 & $\$ 228$ & $\$ 4,564$ \\
2019 & $\$ 219$ & $\$ 4,783$ \\
2020 & $\$ 211$ & $\$ 4,994$ \\
2021 & $\$ 203$ & $\$ 5,197$ \\
2022 & $\$ 195$ & $\$ 5,391$ \\
2023 & $\$ 187$ & $\$ 5,579$ \\
2024 & $\$ 180$ & $\$ 5,759$ \\
2025 & $\$ 173$ & $\$ 6,932$ \\
2026 & $\$ 166$ &
\end{tabular}

CATEGORY/

RES SCHD

$4 \%$ DISCOUNT RATE, 20 YEARS 
RETURN ON INVESTMENT ECONOMIC ANALYSIS REPORT

\begin{tabular}{|c|c|c|c|c|c|}
\hline & Operating Co: & ts & & Present & Value of \\
\hline Project & Status Quo & Proposed & Differential & Value & Differential \\
\hline Year (s) & Alternative & Alternative & Costs & Factor & Costs \\
\hline 2007 & $\$ 0$ & $\$ 372$ & $-\$ 372$ & 0.943 & $-\$ 351$ \\
\hline 2008 & $\$ 372$ & $\$ 372$ & $\$ 0$ & 0.907 & \$0 \\
\hline 2009 & $\$ 372$ & $\$ 372$ & $\$ 0$ & 0.872 & $\$ 0$ \\
\hline 2010 & $\$ 372$ & $\$ 372$ & $\$ 0$ & 0.838 & \$o \\
\hline 2011 & $\$ 372$ & $\$ 372$ & $\$ 0$ & 0.806 & \$O \\
\hline 2012 & $\$ 372$ & $\$ 372$ & $\$ 0$ & 0.775 & $\$ 0$ \\
\hline 2013 & $\$ 372$ & $\$ 372$ & $\$ 0$ & 0.745 & \$o \\
\hline 2014 & $\$ 372$ & $\$ 372$ & $\$ 0$ & 0.717 & $\$ 0$ \\
\hline 2015 & $\$ 372$ & $\$ 372$ & $\$ 0$ & 0.689 & \$0 \\
\hline 2016 & $\$ 372$ & $\$ 372$ & $\$ 0$ & 0.662 & \$o \\
\hline 2017 & $\$ 372$ & $\$ 372$ & $\$ 0$ & 0.637 & \$0 \\
\hline 2018 & $\$ 372$ & $\$ 372$ & $\$ 0$ & 0.612 & \$o \\
\hline 2019 & $\$ 372$ & $\$ 372$ & $\$ 0$ & 0.589 & \$o \\
\hline 2020 & $\$ 372$ & $\$ 372$ & $\$ 0$ & 0.566 & $\$ 0$ \\
\hline 2021 & $\$ 372$ & $\$ 372$ & $\$ 0$ & 0.544 & $\$ 0$ \\
\hline 2022 & $\$ 152,785$ & $\$ 372$ & $\$ 152,413$ & 0.524 & $\$ 79,794$ \\
\hline 2023 & $\$ 372$ & $\$ 372$ & $\$ 0$ & 0.503 & $\$ 0$ \\
\hline 2024 & $\$ 372$ & $\$ 372$ & $\$ 0$ & 0.484 & \$o \\
\hline 2025 & $\$ 372$ & $\$ 372$ & $\$ 0$ & 0.465 & $\$ 0$ \\
\hline 2026 & $\$ 372$ & $\$ 372$ & $\$ 0$ & 0.448 & $\$ 0$ \\
\hline Totals & $\$ 159,481$ & $\$ 7,440$ & $\$ 152,041$ & & $\$ 79,444$ \\
\hline
\end{tabular}

The PERTAN Group 
RETURN ON INVESTMENT ECONOMIC ANALYSIS REPORT

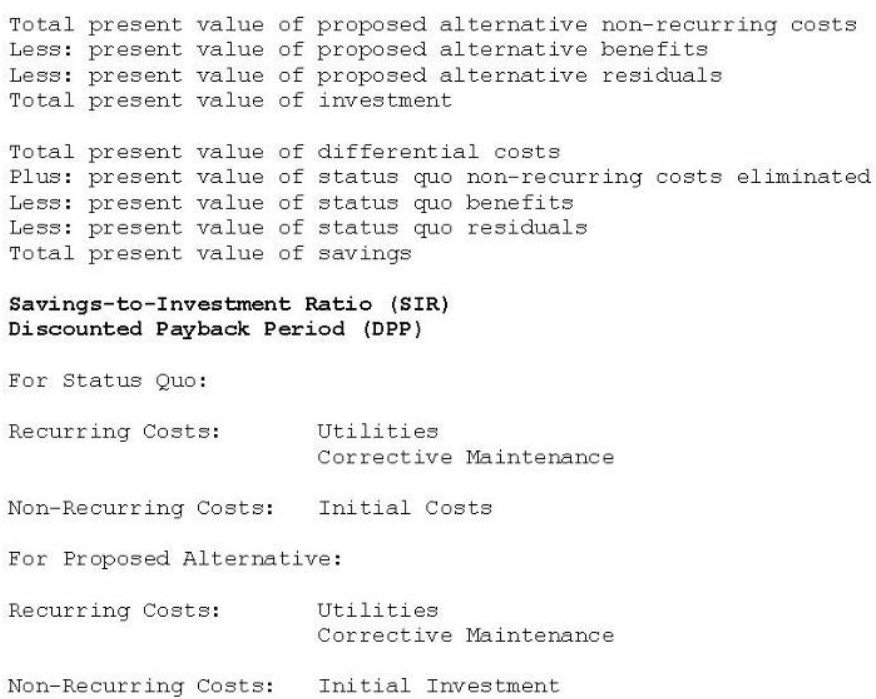


LIFE CYCLE COST REPORT

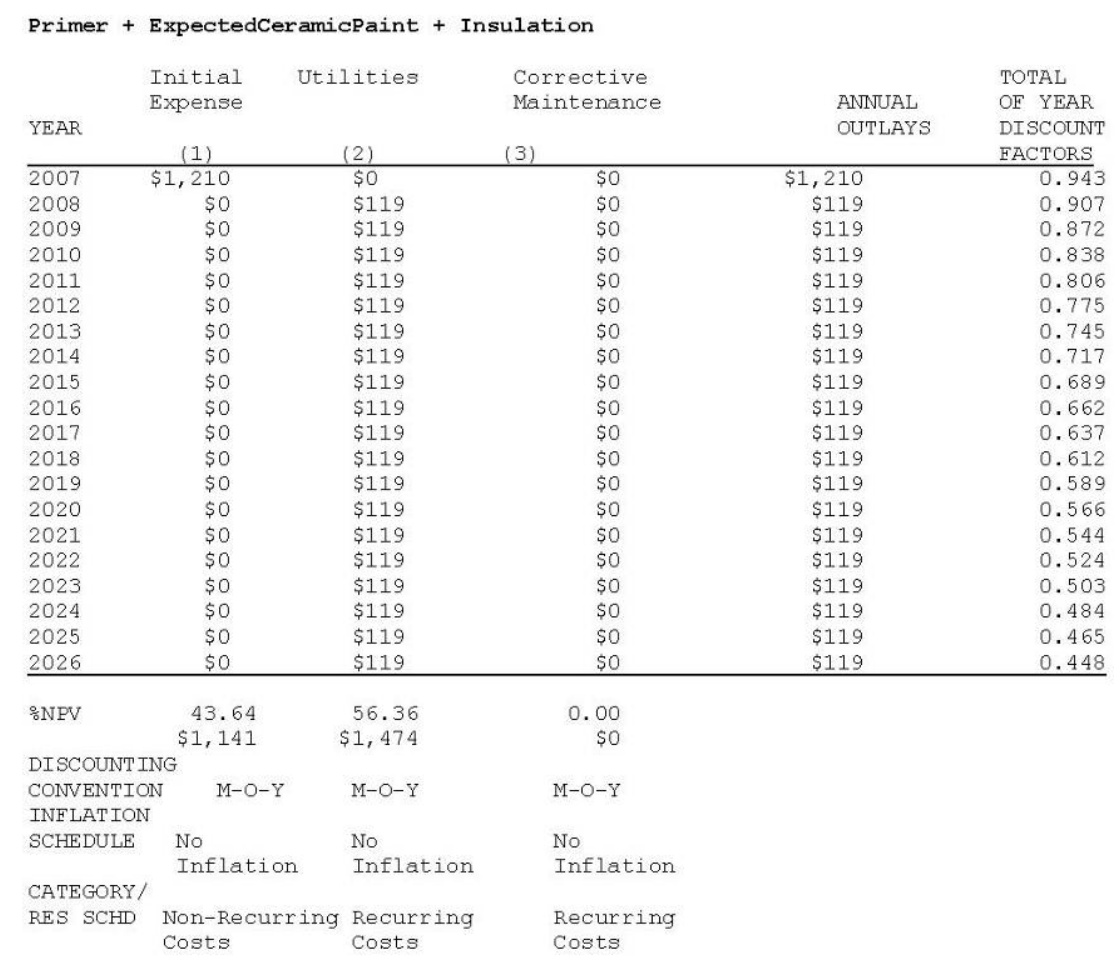


LIFE CYCLE COST REPORT

Primer + ExpectedCeramicPaint + Insulation

\begin{tabular}{crr}
\multicolumn{4}{c}{ CUMULATIVE } \\
YEAR & $\begin{array}{r}\text { PRESENT } \\
\text { VALUE }\end{array}$ & \multicolumn{2}{c}{ NET PRESENT } \\
& & \\
---- & VALUE \\
2007 & $\$ 1,141$ & $\$ 1,141$ \\
2008 & $\$ 108$ & $\$ 1,249$ \\
2009 & $\$ 104$ & $\$ 1,352$ \\
2010 & $\$ 100$ & $\$ 1,452$ \\
2011 & $\$ 96$ & $\$ 1,548$ \\
2012 & $\$ 92$ & $\$ 1,640$ \\
2013 & $\$ 89$ & $\$ 1,729$ \\
2014 & $\$ 85$ & $\$ 1,814$ \\
2015 & $\$ 82$ & $\$ 1,896$ \\
2016 & $\$ 79$ & $\$ 1,975$ \\
2017 & $\$ 76$ & $\$ 2,051$ \\
2018 & $\$ 73$ & $\$ 2,124$ \\
2019 & $\$ 70$ & $\$ 2,261$ \\
2020 & $\$ 67$ & $\$ 2,326$ \\
2021 & $\$ 65$ & $\$ 2,388$ \\
2022 & $\$ 62$ & $\$ 2,448$ \\
2023 & $\$ 60$ & $\$ 2,506$ \\
2024 & $\$ 58$ & $\$ 2,615$ \\
2025 & $\$ 55$ &
\end{tabular}

CATEGORY/

RES SCHD

4\% DISCOUNT RATE, 20 YEARS

The PERTAN Group 
RETURN ON INVESTMENT ECONOMIC ANALYSIS REPORT

Status Quo Alternative: Status Quo

Proposed Alternative : Primer + ExpectedCeramicPaint + Insulation

\begin{tabular}{|c|c|c|c|c|c|}
\hline & $\begin{array}{l}\text { Recurring An } \\
\text { Operating Co }\end{array}$ & & & Present & $\begin{array}{c}\text { Present } \\
\text { Value of }\end{array}$ \\
\hline Project & Status Quo & Proposed & Differential & Value & Differential \\
\hline Year (s) & Alternative & Alternative & Costs & Eactor & Costs \\
\hline 2007 & $\$ 0$ & $\$ 0$ & $\$ 0$ & 0.943 & $\$ 0$ \\
\hline 2008 & $\$ 372$ & $\$ 119$ & $\$ 253$ & 0.907 & $\$ 229$ \\
\hline 2009 & $\$ 372$ & $\$ 119$ & $\$ 253$ & 0.872 & $\$ 221$ \\
\hline 2010 & $\$ 372$ & $\$ 119$ & $\$ 253$ & 0.838 & $\$ 212$ \\
\hline 2011 & $\$ 372$ & $\$ 119$ & $\$ 253$ & 0.806 & $\$ 204$ \\
\hline 2012 & $\$ 372$ & $\$ 119$ & $\$ 253$ & 0.775 & $\$ 196$ \\
\hline 2013 & $\$ 372$ & $\$ 119$ & $\$ 253$ & 0.745 & $\$ 189$ \\
\hline 2014 & $\$ 372$ & $\$ 119$ & $\$ 253$ & 0.717 & $\$ 181$ \\
\hline 2015 & $\$ 372$ & $\$ 119$ & $\$ 253$ & 0.689 & $\$ 174$ \\
\hline 2016 & $\$ 372$ & $\$ 119$ & $\$ 253$ & 0.662 & $\$ 168$ \\
\hline 2017 & $\$ 372$ & $\$ 119$ & $\$ 253$ & 0.637 & $\$ 161$ \\
\hline 2018 & $\$ 372$ & $\$ 119$ & $\$ 253$ & 0.612 & $\$ 155$ \\
\hline 2019 & $\$ 372$ & $\$ 119$ & $\$ 253$ & 0.589 & $\$ 149$ \\
\hline 2020 & $\$ 372$ & $\$ 119$ & $\$ 253$ & 0.566 & $\$ 143$ \\
\hline 2021 & $\$ 372$ & $\$ 119$ & $\$ 253$ & 0.544 & $\$ 138$ \\
\hline 2022 & $\$ 152,785$ & $\$ 119$ & $\$ 152,666$ & 0.524 & $\$ 79,927$ \\
\hline 2023 & $\$ 372$ & $\$ 119$ & $\$ 253$ & 0.503 & $\$ 127$ \\
\hline 2024 & $\$ 372$ & $\$ 119$ & $\$ 253$ & 0.484 & $\$ 122$ \\
\hline 2025 & $\$ 372$ & $\$ 119$ & $\$ 253$ & 0.465 & $\$ 118$ \\
\hline 2026 & $\$ 372$ & $\$ 119$ & $\$ 253$ & 0.448 & $\$ 113$ \\
\hline cotals & $\$ 159,481$ & $\$ 2,261$ & $\$ 157,220$ & & $\$ 82,927$ \\
\hline
\end{tabular}

The PERTAN Group 
RETURN ON INVESTMENT ECONOMIC ANALYSIS REPORT

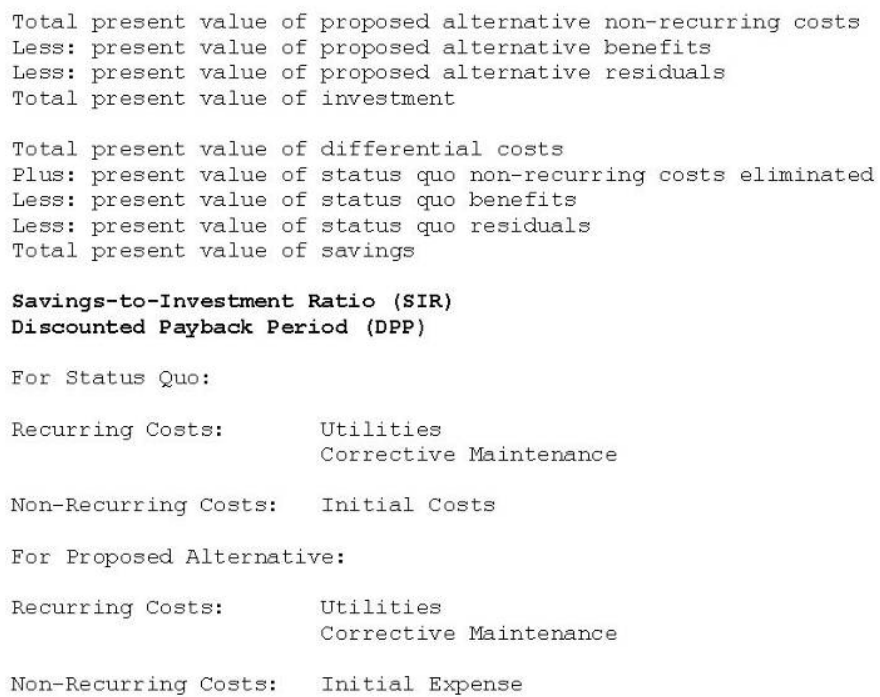




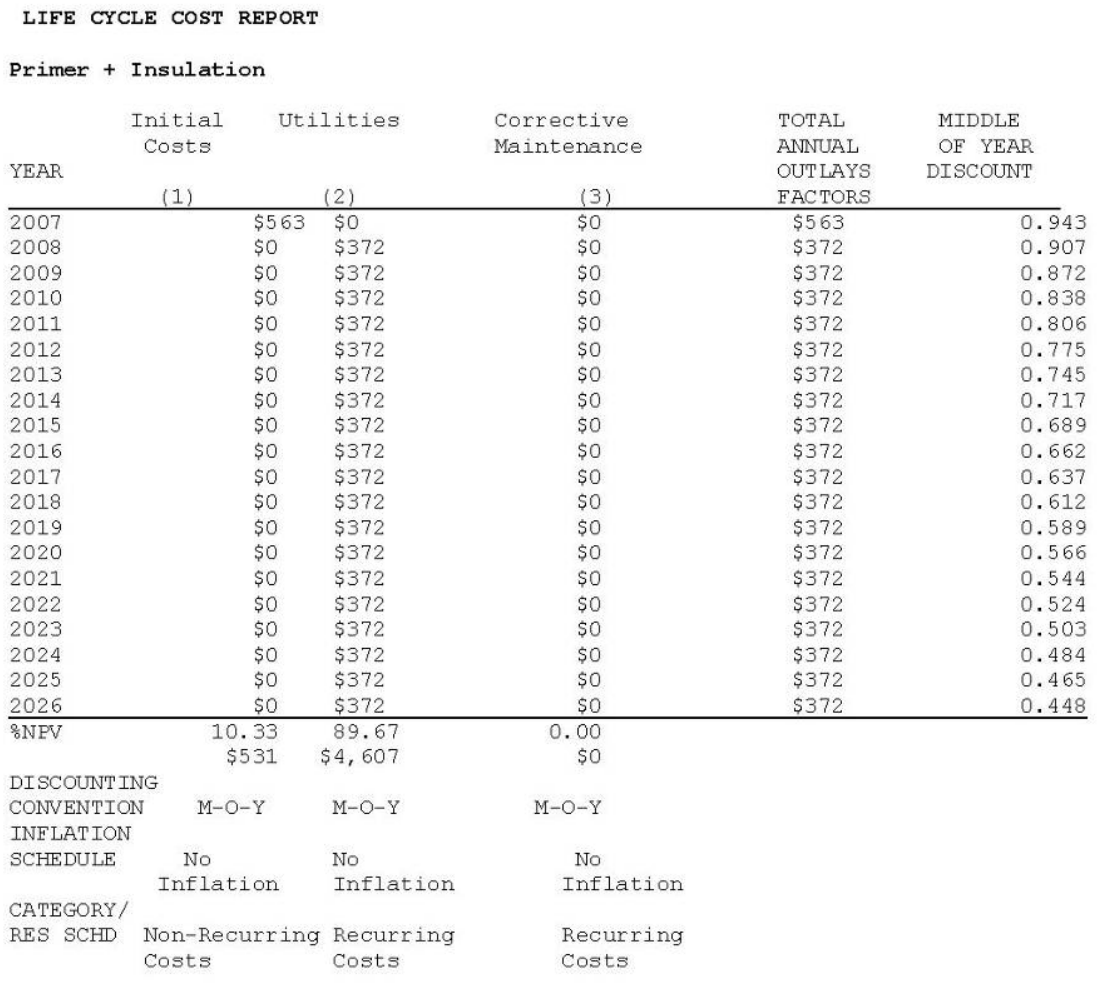


LIFE CYCLE COST REPORT (Cont.)

Primer + Insulation

\begin{tabular}{lrr}
\multicolumn{3}{c}{ CUMULATIVE } \\
YEAR & $\begin{array}{c}\text { PRESENT } \\
\text { VALUE }\end{array}$ & \\
& & \\
--- & VALUE \\
2007 & $\$ 531$ & $\$ 531$ \\
2008 & $\$ 337$ & $\$ 868$ \\
2009 & $\$ 324$ & $\$ 1,192$ \\
2010 & $\$ 312$ & $\$ 1,504$ \\
2011 & $\$ 300$ & $\$ 1,804$ \\
2012 & $\$ 288$ & $\$ 2,092$ \\
2013 & $\$ 277$ & $\$ 2,369$ \\
2014 & $\$ 267$ & $\$ 2,636$ \\
2015 & $\$ 256$ & $\$ 2,892$ \\
2016 & $\$ 246$ & $\$ 3,139$ \\
2017 & $\$ 237$ & $\$ 3,604$ \\
2018 & $\$ 228$ & $\$ 3,823$ \\
2019 & $\$ 219$ & $\$ 4,033$ \\
2020 & $\$ 211$ & $\$ 4,236$ \\
2021 & $\$ 203$ & $\$ 4,431$ \\
2022 & $\$ 195$ & $\$ 4,618$ \\
2023 & $\$ 187$ & $\$ 4,971$ \\
2024 & $\$ 180$ & $\$ 5,138$ \\
2025 & $\$ 173$ &
\end{tabular}

CATEGORY/

RES SCHD

4\% DISCOUNT RATE, 20 YEARS 
RETURN ON INVESTMENT ECONOMIC ANALYSIS REPORT

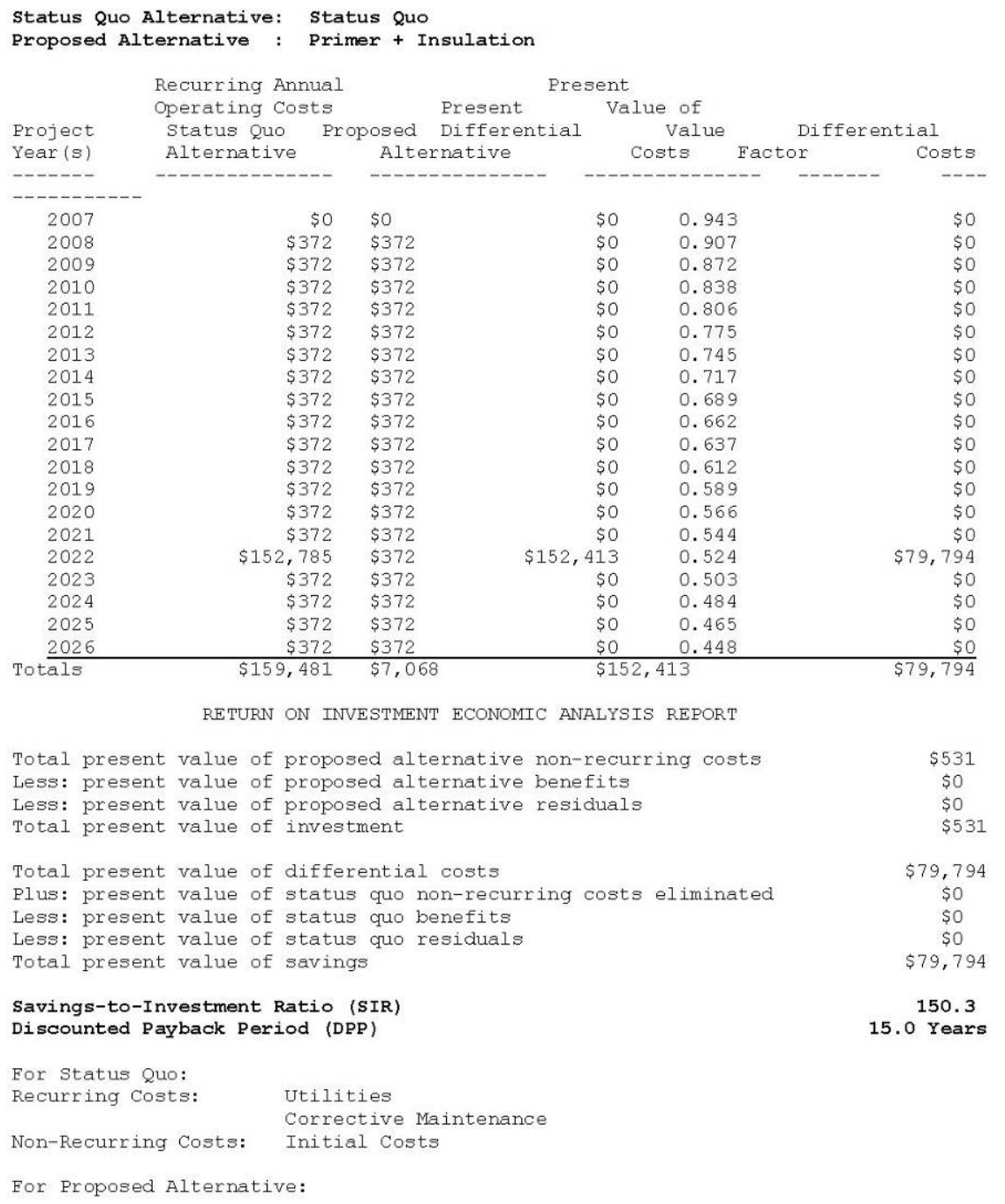

The PERTAN Group 


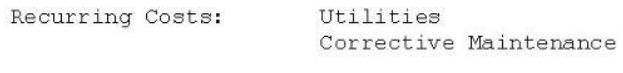

Non-Recurring Costs: Initial Costs

LIFE CYCLE COST REPORT

Status Quo

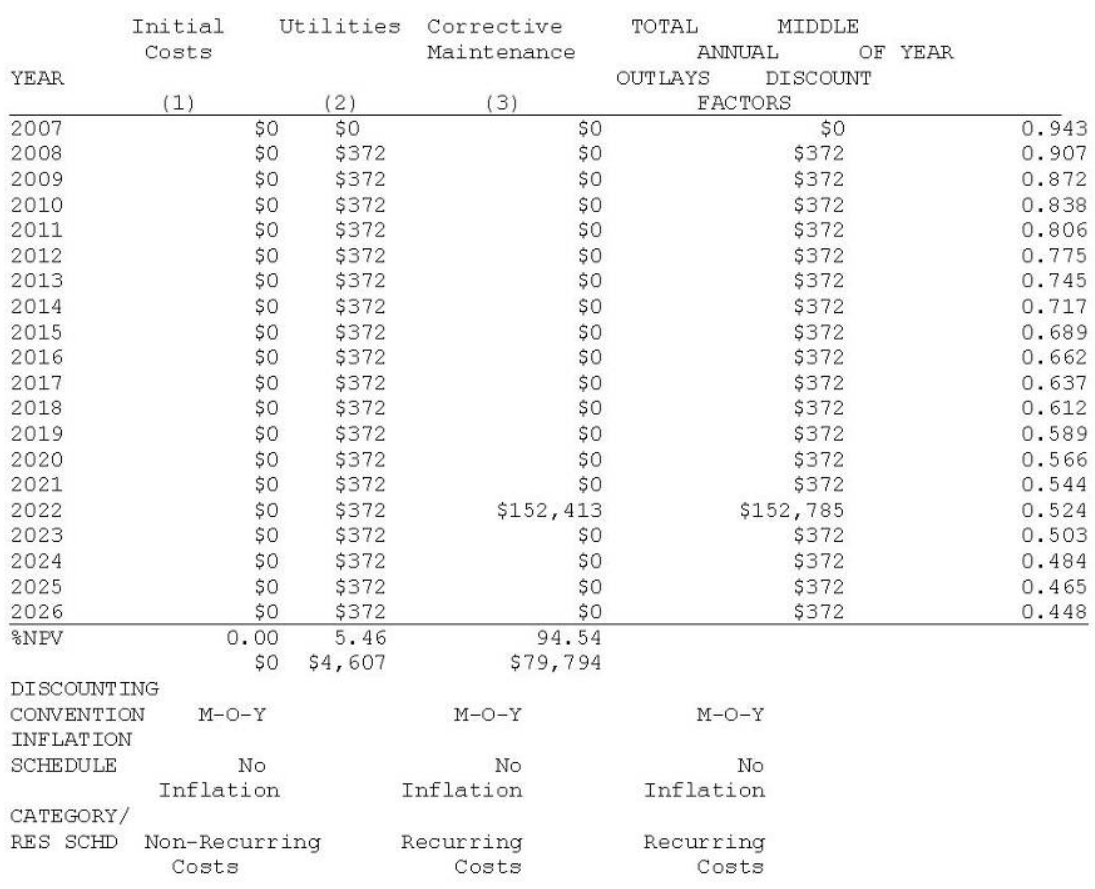

The PERTAN Group 
LIFE CYCLE COST REPORT

Status Quo

\begin{tabular}{lrr}
\multicolumn{3}{c}{ CUMULATIVE } \\
YEAR & $\begin{array}{r}\text { PRESENT } \\
\text { VALUE }\end{array}$ & \\
& \multicolumn{2}{c}{ NET PRESENT } \\
VALUE & \\
\hline 2007 & $\$ 0$ & $\$ 0$ \\
2008 & $\$ 337$ & $\$ 337$ \\
2009 & $\$ 324$ & $\$ 662$ \\
2010 & $\$ 312$ & $\$ 973$ \\
2011 & $\$ 300$ & $\$ 1,273$ \\
2012 & $\$ 288$ & $\$ 1,561$ \\
2013 & $\$ 277$ & $\$ 1,839$ \\
2014 & $\$ 267$ & $\$ 2,105$ \\
2015 & $\$ 256$ & $\$ 2,361$ \\
2016 & $\$ 246$ & $\$ 2,608$ \\
2017 & $\$ 237$ & $\$ 2,845$ \\
2018 & $\$ 228$ & $\$ 3,073$ \\
2019 & $\$ 219$ & $\$ 3,292$ \\
2020 & $\$ 211$ & $\$ 3,502$ \\
2021 & $\$ 203$ & $\$ 3,705$ \\
2022 & $\$ 79$, & $\$ 83,694$ \\
2023 & $\$ 187$ & $\$ 83,881$ \\
2024 & $\$ 180$ & $\$ 84,061$ \\
2025 & $\$ 173$ & $\$ 84,235$ \\
2026 & $\$ 166$ & $\$ 84,401$ \\
& &
\end{tabular}

CATEGORY/

RES SCHD

4\% DISCOUNT RATE, 20 YEARS 
TITLE: DRSA1

No changes in alternative ranking occurred

Table of Net Present Values for each Discount Rate

\begin{tabular}{|c|c|c|c|}
\hline \multicolumn{4}{|c|}{ Discount Rate $=01.00 \%$} \\
\hline Primer & + ExpectedCeram & - & $\$ 3,212$ \\
\hline Primer & + Insulation & - & $\$ 6,868$ \\
\hline Status & Quo & - & $\$ 135,649$ \\
\hline \multicolumn{4}{|c|}{ Discount Rate $=01.32 \%$} \\
\hline Primer & + ExpectedCeram & - & $\$ 3,136$ \\
\hline Primer & + Insulation & - & $\$ 6,646$ \\
\hline Status & Quo & - & $\$ 128,853$ \\
\hline \multicolumn{4}{|c|}{ Discount Rate $=01.64 \%$} \\
\hline Primer & + ExpectedCeram & - & $\$ 3,064$ \\
\hline Primer & + Insulation & - & $\$ 6,435$ \\
\hline Status & Quo & - & $\$ 122,420$ \\
\hline \multicolumn{4}{|c|}{ Discount Rate $=01.96 \%$} \\
\hline Primer & + ExpectedCeram & - & $\$ 2,994$ \\
\hline Primer & + Insulation & - & $\$ 6,233$ \\
\hline Status & Quo & - & $\$ 116,330$ \\
\hline \multicolumn{4}{|c|}{ Discount Rate $=02.28 \%$} \\
\hline Primer & + ExpectedCeram & - & $\$ 2,928$ \\
\hline Primer & + Insulation & - & $\$ 6,040$ \\
\hline Status & Quo & - & $\$ 110,565$ \\
\hline \multicolumn{4}{|c|}{ Discount Rate $=02.60 \%$} \\
\hline Primer & + ExpectedCeram & - & $\$ 2,864$ \\
\hline Primer & + Insulation & - & $\$ 5,855$ \\
\hline Status & Quo & - & $\$ 105,104$ \\
\hline \multicolumn{4}{|c|}{ Discount Rate $=02.92 \frac{\circ}{\circ}$} \\
\hline Primer & + ExpectedCeram & - & $\$ 2,803$ \\
\hline Primer & + Insulation & - & $\$ 5,679$ \\
\hline Status & Quo & - & $\$ 99,933$ \\
\hline \multicolumn{4}{|c|}{ Discount Rate $=03.24 \%$} \\
\hline Primer & + ExpectedCeram & - & $\$ 2,744$ \\
\hline Primer & + Insulation & - & $\$ 5,510$ \\
\hline Status & Quo & - & $\$ 95,033$ \\
\hline \multicolumn{4}{|c|}{ Discount Rate $=03.56 \%$} \\
\hline Primer & + ExpectedCeram & - & $\$ 2,688$ \\
\hline Primer & + Insulation & - & $\$ 5,348$ \\
\hline Status & Quo & - & $\$ 90,391$ \\
\hline \multicolumn{4}{|c|}{ Discount Rate $=03.88 \%$} \\
\hline Primer & + ExpectedCeram & - & $\$ 2,634$ \\
\hline Primer & + Insulation & - & $\$ 5,194$ \\
\hline Status & Quo & - & $\$ 85,991$ \\
\hline
\end{tabular}

Discount Rate $=01.16 \%$ Primer + ExpectedCeram Primer + Insulation Status Quo

$\$ 3,173$

$\$ 6,756$

$\$ 132,204$

Discount Rate $=01.48 \%$ Primer + ExpectedCeram Primer + Insulation Primer + Insulation
Status Quo

$\$ 3,099$

$\$ 6,539$ $\$ 125,592$

Discount Rate $=01.80 \%$ Primer + ExpectedCeram Primer + Insulation Status Quo

$\$ 3,028$

$\$ 6,333$ $\$ 119,334$

Discount Rate $=02.12 \%$ Primer + ExpectedCeram Primer + Insulation Status Quo

$\$ 2,961$

, 135

Discount Rate $=02.44 \%$ Primer + ExpectedCeram Primer + Insulation Status Quo

$\$ 5,797$

Discount Rate $=02.76 \%$ Primer + ExpectedCeram Status Quo

$\$ 5,766$ $\$ 102,483$

Discount Rate $=03.08 \%$ Primer + ExpectedCeram - $\$ 2,773$ Primer + Insulation - $\quad \$ 5,594$ Status Quo

$\$ 97,450$

Discount Rate $=03.40 \%$ Primer + ExpectedCeram Primer + Insulation _ _ $\$ 5,428$ Status Quo

$\$ 92,681$

Discount Rate $=03.72^{\circ}$ Primer + ExpectedCeram - $\$ 2,661$ $\begin{array}{ll}\text { Primer + Expectedceram - } & \$ 2,661 \\ \text { Primer + Insulation - } & \$ 5,270\end{array}$ $\begin{array}{llr}\text { Primer + Insulation } & - & \$ 5,270 \\ \text { Status Quo } & - & \$ 88,161\end{array}$

Discount Rate $=04.00 \%$ Primer + ExpectedCeram - $\$ 2,615$ Primer + Insulation - _ \$5, 138 $\begin{array}{llr}\text { Primer + Insulation } & - & \$ 5,138 \\ \text { Status Quo } & - & \$ 84,401\end{array}$ 
TITLE: DRSA1

No changes in alternative ranking occurred

Table of Net Present Values for each Discount Rate

\begin{tabular}{|c|c|c|c|}
\hline \multicolumn{4}{|c|}{ Discount Rate $=04.04 \%$} \\
\hline Primer & + ExpectedCeram & - & $\$ 2,608$ \\
\hline Primer & + Insulation & - & $\$ 5,119$ \\
\hline Status & Quo & - & $\$ 83,878$ \\
\hline \multicolumn{4}{|c|}{ Discount Rate $=04.36 \%$} \\
\hline Primer & + ExpectedCeram & - & $\$ 2,557$ \\
\hline Primer & + Insulation & - & $\$ 4,974$ \\
\hline Status & Quo & - & $\$ 79,818$ \\
\hline \multicolumn{4}{|c|}{ Discount Rate $=04.68 \%$} \\
\hline Primer & + ExpectedCeram & - & $\$ 2,508$ \\
\hline Primer & + Insulation & - & $\$ 4,835$ \\
\hline Status & Quo & - & $\$ 75,968$ \\
\hline \multicolumn{4}{|c|}{ Discount Rate $=05.00 \%$} \\
\hline Primer & + ExpectedCeram & - & $\$ 2,461$ \\
\hline Primer & + Insulation & - & $\$ 4,702$ \\
\hline Status & Quo & - & $\$ 72,318$ \\
\hline \multicolumn{4}{|c|}{ Discount Rate $=05.32 \%$} \\
\hline Primer & + ExpectedCeram & - & $\$ 2,416$ \\
\hline Primer & + Insulation & - & $\$ 4,574$ \\
\hline Status & Quo & - & $\$ 68,856$ \\
\hline \multicolumn{4}{|c|}{ Discount Rate $=05.64 \%$} \\
\hline Primer & + ExpectedCeram & - & $\$ 2,372$ \\
\hline Primer & + Insulation & - & $\$ 4,451$ \\
\hline Status & Quo & - & $\$ 65,572$ \\
\hline \multicolumn{4}{|c|}{ Discount Rate $=05.96 \%$} \\
\hline Primer & + ExpectedCeram & - & $\$ 2,331$ \\
\hline Primer & + Insulation & - & $\$ 4,334$ \\
\hline Status & Quo & - & $\$ 62,456$ \\
\hline \multicolumn{4}{|c|}{ Discount Rate $=06.28 \%$} \\
\hline Primer & + ExpectedCeram & - & $\$ 2,290$ \\
\hline Primer & + Insulation & - & $\$ 4,221$ \\
\hline Status & Quo & - & $\$ 59,499$ \\
\hline \multicolumn{4}{|c|}{ Discount Rate $=06.60 \%$} \\
\hline Primer & + ExpectedCeram & - & $\$ 2,251$ \\
\hline Primer & + Insulation & - & $\$ 4,112$ \\
\hline Status & Quo & - & $\$ 56,693$ \\
\hline \multicolumn{4}{|c|}{ Discount Rate $=06.92 \%$} \\
\hline Prin & + ExpectedCeram & - & $\$ 2,214$ \\
\hline Primer & + Insulation & - & $\$ 4,008$ \\
\hline Status & Quo & - & $\$ 54,029$ \\
\hline
\end{tabular}

Discount Rate $=04.20 \%$ Primer + ExpectedCeram Primer + Insulation - $\quad \$ 5,046$ Status Quo

Discount Rate $=04.52 \%$ Primer + ExpectedCeram - \$2,532 Primer + Insulation - $\$ 4,904$ $\begin{array}{llr}\text { Primer + Insulation } & - & \$ 4,904 \\ \text { Status Quo } & - & \$ 77,867\end{array}$

Discount Rate $=04.84 \%$ Primer + ExpectedCeram - $\$ 2,485$ Primer + Insulation - $\quad \$ 4,768$ Status Quo

Discount Rate $=05.16 \%$ Primer + ExpectedCeram - $\$ 2,438$ Primer + Insulation - $\quad \$ 4,637$ Status Quo _ $\quad \$ 70,564$

Discount Rate $=05.48 \%$ Primer + ExpectedCeram - \$2,394 Primer + Insulation - $\quad \$ 4,512$ Status Quo

Discount Rate $=05.80 \%$ Primer + ExpectedCeram Status Quo

Discount Rate $=06.12 \%$ Primer + ExpectedCeram - \$2,310 Primer + Insulation - $\quad \$ 4,277$ Status Quo _ _ $\quad \$ 60,958$

Discount Rate $=06.44 \%$ $\begin{array}{ll}\text { Primer + ExpectedCeram - } & \$ 2,270 \\ \text { Primer + Insulation - } & \$ 4,166\end{array}$ Status Quo $\$ 58,077$

Discount Rate $=06.76^{\circ}$ Primer + ExpectedCeram - $\$ 2,232$ $\begin{array}{lr}\text { Primer + } & \$ 2,232 \\ \text { Primer + Insulation - } & \$ 4,060\end{array}$ $\begin{array}{llr}\text { Primer + Insulation } & - & \$ 4,060 \\ \text { Status Quo } & - & \$ 55,343\end{array}$

Discount Rate $=07.08 \%$ Primer + ExpectedCeram - \$2,195 Primer + Insulation - $\quad \$ 3,957$ $\begin{array}{llr}\text { Primer + Insulation } & - & \$ 3,957 \\ \text { Status Quo } & - & \$ 52,748\end{array}$ 
TITLE: DRSA1

No changes in alternative ranking occurred

Table of Net Present Values for each Discount Rate

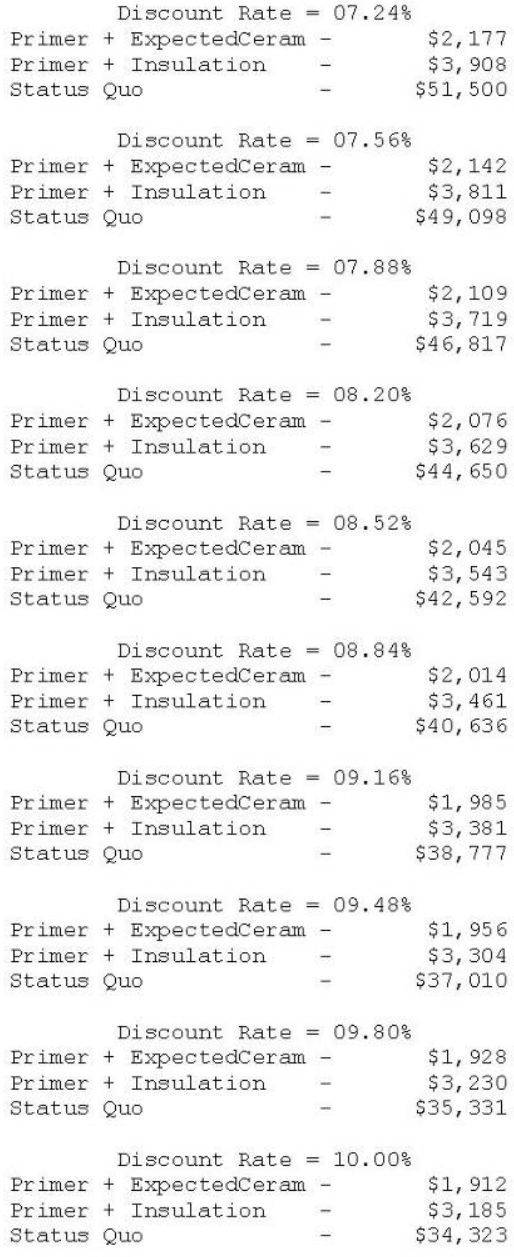




\section{Appendix E: Recommended Implementation Guidance}

Suggested implementation language for the subject coating system materials into DoD corrosion prevention and control practice is provided below.

\section{Unified Facilities Criteria (UFC) 3-430-01FA, Heating and Cooling Distribution}

Under Chapter 3. GENERAL DISTRIBUTION SYSTEM DESIGN

Under Section 3-6 VALVE MANHOLES

Under a) Manhole internals

(1-6) to stay as is

add: (7) Valve/ piping coatings

Metal piping and appurtenances in heat distribution system manholes will be coated prior to being insulated. Coating of valve packings and other equipment whose function would be impaired is to be avoided. At minimum, the coating will consist of a spray primer suitable for the expected system operating temperatures. Surface preparation will consist of a near-white blast with first coating to occur within 24 hours. For lowtemperature heat distribution systems $\left(200^{\circ} \mathrm{F}\right.$ and below, defined by AR 420-49, Utility Systems, 28 April 1997, Section 6 - 9) the additional protective coating of an insulating ceramic coating will be used.

\section{Unified Facilities Guide Specification (UFGS) 3360 01, Valves, Piping, and Equipment in Valve Manholes (July 2006)}

1. Renumber sections $2.12,2.13,2.14,2.15$ to $2.13,2.14,21.5,2.16$

2. Insert a new section 2.12 as follows:

\subsection{PIPING/VALVE COATING}

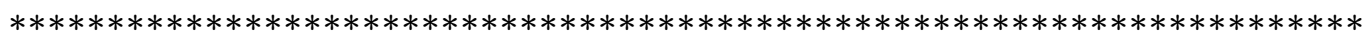
NOTE: This section applies only to heat distribution piping in valve manholes. 
Over the operational life of a heat distribution system, valve manholes often experience ambient conditions that are both wet and hot. These are ideal conditions to promote corrosive degradation that can lead to premature failure. All metal piping and appurtenances in heat distribution system valve manholes will be spray-coated with a metal primer suitable for the expected system operating conditions. Coating of valve packing and other equipment whose function would be impaired is to be avoided. Surface preparation will be in accordance with standard metal coating practices. For low temperature heat distribution systems ( $200^{\circ} \mathrm{F}$ and below) the additional protective top coat of an insulating ceramic coating will be used. 


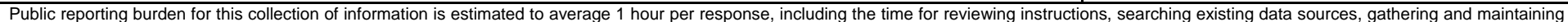

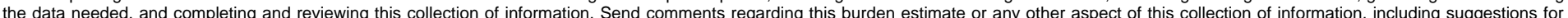

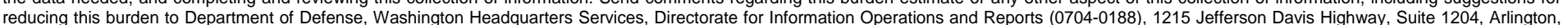

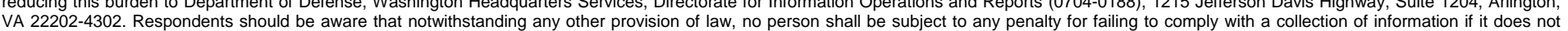
VA 22202-4302. Respondents should be aware that notwithstanding any other provision of law, no person shall be subj
display a currently valid OMB control number. PLEASE DO NOT RETURN YOUR FORM TO THE ABOVE ADDRESS.
1. REPORT DATE (DD-MM-YYYY) 2. REPORT TYPE August 2009 Final

4. TITLE AND SUBTITLE

Innovative Coating System for Corrosion Prevention and Temperature Reduction in Heat Distribution Manholes

3. DATES COVERED (From - To)

5a. CONTRACT NUMBER

5b. GRANT NUMBER

5c. PROGRAM ELEMENT NUMBER

Corrosion Prevention and Control

6. AUTHOR(S)

Alfred D. Beitelman, Thomas A. Carlson, Barclay G. Jones, Charles P. Marsh, David Kessler, Jennifer J. Ong, and Ling Zou

5d. PROJECT NUMBER

CPC FAR-11

5e. TASK NUMBER

MIPR6FCERB1020, MIPR6H6AG3CPC1

5f. WORK UNIT NUMBER

8. PERFORMING ORGANIZATION REPORT NUMBER

ERDC/CERL TR-09-24

U.S. Army Engineer Research and Development Center

Construction Engineering Research Laboratory

P.O. Box 9005

Champaign, IL 61826-9005

9. SPONSORING I MONITORING AGENCY NAME(S) AND ADDRESS(ES)

U.S. Army Installation Management Command

Engineering Office, Directorate of Public Works (IMPW-E)

2511 Jefferson Davis Hwy.

Arlington, VA 22202

10. SPONSOR/MONITOR'S ACRONYM(S)

IMCOM

11. SPONSOR/MONITOR'S REPORT NUMBER(S)

\section{DISTRIBUTION / AVAILABILITY STATEMENT}

Approved for public release; distribution is unlimited.

\section{SUPPLEMENTARY NOTES}

Additional Task Number is MIPR6HMBHDE097

\section{ABSTRACT}

Heat distribution system (HDS) pipes and appurtenances are subject to significantly reduced service life when they are located inside manholes with severely corrosive environments. This report documents the demonstration of an innovative coating system for HDS components intended to protect pipes directly, by preventing the corrosion of steel, and indirectly, by reducing heat-related corrosive conditions within manholes. The demonstration was performed at Redstone Arsenal, AL.

Field performance of the coating system components was mixed. The primer was straightforward to apply and showed no signs of degradation during the performance period. The topcoat essentially failed shortly after application by turning to powder. The topcoat failure mechanism appears to have been destruction of its acrylic binder by excessive heat, and the result was replicated in the laboratory through an extension of the initial oven tests. At this time it appears that topcoat material did not perform in accordance with the manufacturer's published product data. Because the primer material remains intact and is expected to offer corrosion protection in line with the product data, it represents a significant technology application for corrosion prevention and control. The report includes a return-on-investment calculation based on extension of HDS component service life. Lessons learned are documented.

\section{SUBJECT TERMS}

Redstone Arsenal, AL; corrosion prevention; pipes; heat distribution systems (HDS); manholes; high-temperature primers; ceramic coatings

\section{SECURITY CLASSIFICATION OF:}

\section{a. REPORT}

Unclassified

\section{b. ABSTRACT}

Unclassified c. THIS PAGE

Unclassified
17. LIMITATION OF ABSTRACT
18. NUMBER OF PAGES

117 19a. NAME OF RESPONSIBLE PERSON

19b. TELEPHONE NUMBER (include area code) 